\title{
Quartz OSL dating of late quaternary Chinese and Serbian loess: A cross Eurasian comparison of dust mass accumulation rates
}

Peric, Zoran; Adolphi, Emma Lagerbäck; Stevens, Thomas; Ujvari, Gabor; Zeeden, Christian; Buylaert, Jan-Pieter; Markovic, Slobodan B.; Hambach, Ulrich; Fischer, Peter; Schmidt, Christoph Total number of authors:

22

Published in:

Quaternary International

Link to article, DOI:

10.1016/j.quaint.2018.01.010

Publication date:

2019

Document Version

Peer reviewed version

Link back to DTU Orbit

Citation (APA):

Peric, Z., Adolphi, E. L., Stevens, T., Ujvari, G., Zeeden, C., Buylaert, J-P., Markovic, S. B., Hambach, U., Fischer, P., Schmidt, C., Schulte, P., Huayu, L., Shuangwen, Y., Lehmkuhl, F., Obreht, I., Veres, D., Thiel, C., Frechen, M., Jain, M., ... Gavrilov, M. B. (2019). Quartz OSL dating of late quaternary Chinese and Serbian loess: A cross Eurasian comparison of dust mass accumulation rates. Quaternary International, 502(Part A), 30 44. https://doi.org/10.1016/j.quaint.2018.01.010

\section{General rights}

Copyright and moral rights for the publications made accessible in the public portal are retained by the authors and/or other copyright owners and it is a condition of accessing publications that users recognise and abide by the legal requirements associated with these rights.

- Users may download and print one copy of any publication from the public portal for the purpose of private study or research.

- You may not further distribute the material or use it for any profit-making activity or commercial gain

- You may freely distribute the URL identifying the publication in the public portal 


\section{Quartz OSL dating of late Quaternary Chinese and Serbian loess: a cross Eurasian comparison of dust mass accumulation rates}

Zoran Perić ${ }^{1,2 *}$, Emma Lagerbäck Adolphi ${ }^{3}$, Thomas Stevens ${ }^{3}$, Gábor Újvári' ${ }^{4,5}$, Christian Zeeden $^{6}$, Jan-Pieter Buylaert ${ }^{5,7}$, Slobodan B. Marković ${ }^{2}$, Ulrich Hambach ${ }^{8,2}$, Peter Fischer $^{9}$, Christoph Schmidt ${ }^{8}$, Philipp Schulte ${ }^{10}$, Lu Huayu' ${ }^{11}$, Yi Shuangwen ${ }^{11}$, Frank Lehmkuhl $^{10}$, Igor Obreht ${ }^{12}$, Daniel Veres ${ }^{13,14}$, Christine Thiel ${ }^{15}$, Manfred Frechen ${ }^{15}$, Mayank Jain ${ }^{5}$, Andreas Vött ${ }^{9}$, Ludwig Zöller ${ }^{8}$, Milivoj B. Gavrilov²

${ }^{1}$ Research Group for Terrestrial Paleoclimates, Max Planck Institute for Chemistry, Hahn-Meitner Weg 1, 55128 Mainz

${ }^{2}$ Chair of Physical Geography, Faculty of Science and Mathematics, University of Novi Sad, Trg Dositeja Obradovića 3, 21000 Novi Sad, Serbia

${ }^{3}$ Department of Earth Sciences, Uppsala University, Villavägen 16, Uppsala, SE-75236, Sweden

${ }^{4}$ Institute for Geological and Geochemical Research Research, Centre for Astronomy and Earth Sciences, Hungarian Academy of Sciences, 1112 Budapest, Budaörsi út 45. Hungary

${ }^{5}$ Centre for Nuclear Technologies, Technical University of Denmark, Risø Campus, Roskilde, DK-4000, Denmark

${ }^{6}$ IMCCE, Observatoire de Paris, PSL Research University, CNRS, Sorbonne Universités, UPMC Univ Paris 06, Univ Lille, 75014 Paris, France

${ }^{7}$ Nordic Laboratory for Luminescence Dating, Department of Geosciences, University of Aarhus, DTU Nutech, Risø Campus, Roskilde, DK-4000, Denmark

${ }^{8}$ BayCEER and Chair of Geomorphology, University of Bayreuth, 95440 Bayreuth, Germany

${ }^{9}$ Institute for Geography, University of Mainz, Johann-Joachim-Becher Weg 21, 55099 Mainz, Germany

${ }^{10}$ Department of Geography, RWTH Aachen University, Templergraben 55, 52056 Aachen, Germany

${ }^{11}$ School of Geographic and Oceanographic Sciences, Nanjing University, Nanjing 210093, China. 
${ }^{12}$ Organic Geochemistry Group. MARUM-Center for Marine Environmental Sciences and Department of Geosciences, University of Bremen, D-28359 Bremen, Germany ${ }^{13}$ Institue of Speleology, Romanian Academy, Clinicilor 5, 400006 Cluj-Napoca, Romania ${ }^{14}$ Interdisciplinary Research Institue on Bio-Nano-Science of Babe-Bolyai University, 400006 Cluj-Napoca, Romania

15 Leibniz Institute for Applied Geophysics (LIAG) Geochronology and Isotope Hydrology, 30655 Hannover, Germany

*Corresponding author: zoranperic.geo@gmail.com

ABSTRACT: Reconstructing dust Mass Accumulation Rate (MAR) from loess deposits is critical to understanding past atmospheric mineral dust activity and requires accurate independent age models from loess deposits across Europe and Asia. Previous correlations of loess in Europe and China have tended to focus on multi-millennial timescales, with no detailed examination of dust MAR at the two ends of the Eurasian loess belt on shorter, suborbital scales. Here we present a detailed quartz optically stimulated luminescence (OSL) chronology from the Serbian Titel Loess Plateau (Veliki Surduk loess core) and the Chinese Loess Plateau (Lingtai section). The luminescence ages pass internal tests and show consistent increases in age with depth, with no obvious major hiatuses. However, as reported before, it seems the quartz OSL technique is only capable of accurate age determination up to accrued doses of ca. $150 \mathrm{~Gy}(\mathrm{ca} .30-40 \mathrm{ka})$ due to approaching field saturation of the quartz OSL signal. Two age-depth models were used to reconstruct dust MARs, where one utilises OSL data solely and the other additionally makes assumptions about sedimentation rates. Although short-term fluctuations in MAR are model dependent, general MAR patterns between the two sites are very similar, with peak MAR occurring rather late in the last glacial (ca. 13-25 ka). This suggests that at least broad scale trends in dust activity within the last glacial period may be similar at a continental scale.

Keywords: OSL dating, MAR, Titel Loess Plateau, Chinese Loess Plateau, loess, dust

\section{Introduction}

Loess deposits are important continental archives of climatic change and past atmospheric dust activity. Apart from the Chinese Loess Plateau dust deposits, which are some of the most 
extensively studied climate archives on the planet (Liu, 1985; Ding et al., 2002; Porter, 2001), a large number of the longest and most detailed loess-palaeosol sequences are situated in the Vojvodina region of Serbia (Buggle et al., 2013). These sequences are also some of the oldest and most complete archives of environmental change on the European continent (Marković et al., 2012) and provide an opportunity to reconstruct past climate and dust dynamics across a wide area of Eurasia from the same type of archives and under a uniform stratigraphic and interpretive framework (Marković et al., 2015). However, the climatic control on the formation of loess-palaeosol sequences in these regions is somewhat different: on the Chinese Loess Plateau, loess-palaeosol formation is closely associated with variations of winter and summer East Asian monsoon climates during the Quaternary (An, 2000; Porter, 2001) while the formation of the loess deposits in the Vojvodina region is controlled by the interplay of continental and Atlantic climates (Obrecht et al., 2016), with two possible predominant dust transport directions: northerly and south-easterly (Marković et al., 2008).

Marković et al. (2011) correlated loess deposits in the Vojvodina region with those in China, and similarities in loess palaeoclimate records at opposite ends of the Eurasian loess belt have been proposed by Marković et al. (2015) based on inter-profile correlation, using pedostratigraphy and magnetic susceptibility (MS) in the middle Danube Basin and the Chinese Loess Plateau. This holds great promise as understanding of loess dust mass accumulation rates (MAR) across such a wide continental area could provide insight into changes in past atmospheric dust activity over a hemispheric scale (Lu and Sun, 2000; Kohfeld and Harrison, 2003; Albani et al., 2015), which is a critical but poorly understood component of the climate system. However, it is uncertain if the similarities observed by Marković et al. (2015) are valid on shorter, sub-orbital or sub-Milankovic timescales, and no study has tested whether there are indeed similarities in dust accumulation rates within glacial stages at the two ends of the Eurasian loess belt. In order to achieve this, detailed independent age models are needed to 
calculate dust accumulation rates, as non-independent age models are incapable of resolving changes in accumulation rate within single glacial periods (Stevens et al., 2008; Kang et al., 2015).

Independent high sampling resolution dating of loess sequences is still relatively rare, as reflected in the few loess sites included in the dust MAR compilation of Albani et al. (2015). On the Chinese Loess Plateau, although still relatively unusual, loess sites with independent chronologies sufficiently detailed to examine shifts in dust MAR are numerous enough to permit some analysis of wider Late Quaternary trends on the plateau (Kang et al., 2014; Stevens et al., 2016). In European loess generally, Frechen et al. (2003) summarises a large body of research that used IRSL techniques to undertake relatively high-resolution dating and dust MAR calculation, while Rousseau et al. (2002) provide detailed ${ }^{14} \mathrm{C}$, OSL, IRSL and TL ages for the Nussloch site in Germany. However, most of these studies utilise luminescence methods that in recent years have been questioned (Roberts, 2008). Recently one Hungarian Carpathian Basin site dated in unprecedented detail using AMS radiocarbon dating of charcoal and small gastropods (Újvári et al., 2017), while in the Lower Danube Basin (Romania) tephra chronology and correlative age modelling using palaeoclimatic proxy data has been applied on several loess sequences (Obrecht et al., 2017; Zeeden et al., in press). However, these studies are still rare and as yet have not been conducted in Vojvodina (Vojvodina Province, southeastern part of the Carpathian Basin). Limited initial TL dating of the loess-palaeosol sequences in Vojvodina was conducted (Singhvi et al., 1989), although in recent years the validity of this method has been questioned. Recently, initial attempts have been made to date loess sequences in the area using quartz based OSL and polymineral post-IR IRSL dating techniques (Fuchs et al., 2008; Stevens et al., 2011). However, these are not dated with sufficient precision for detailed MAR calculation and analysis of climate proxies on fully independent timescales. Thus, this paper attempts to address this by applying a highly detailed 
study of quartz OSL ages from the last glacial period at two sites: one on the Titel loess plateau in Europe and one at the Lingtai loess section on the Chinese Loess Plateau (Fig. 1). To the best of our knowledge, the data presented here represents the most detailed luminescence-based age model in European loess to date.

\section{Regional setting, litho- and pedostratigraphy}

The analysis we present in this study covers the last glacial cycle loess (L1) unit recovered from a unique loess core taken from the Titel loess plateau (Vojvodina Province, Serbia, southeastern part of the Carpathian Basin) and the L1 unit of the Lingtai section on the Chinese Loess Plateau. The Titel core goes as deep as the penultimate interglacial palaeosol (S2) unit, and the samples recovered from the Lingtai section cover roughly the last climatic cycle loess (L1-S1) units and the top part of the penultimate glacial loess (L2) unit. However, the quartz OSL dating was performed only on the last glacial L1 unit and therefore, the following stratigraphic descriptions will focus only on the L1 loess unit.

\section{The Titel loess plateau}

The Titel loess plateau in the Vojvodina region of Serbia (Fig. 1) is considered to contain one of the most detailed terrestrial palaeoclimatic records in Europe, with a thick and apparently continuous record of climate and atmospheric dust deposition from the last five glacialinterglacial cycles (Marković et al., 2015). Due to the scarcity of archives and previous studies, as well as the potential importance of the region as a boundary between continental and Mediterranean climate systems, palaeoenvironmental reconstruction for this region is a major goal (Obreht et al., 2016). Here we present a description of the Veliki Surduk section $\left(45^{\circ} 17-\right.$ $18^{\prime} \mathrm{N}$ and $20^{\circ} 12-15^{\prime} \mathrm{E}$ ), which lies ca. $100 \mathrm{~m}$ from the location of the Titel drill core and is 
situated at the southern edge of Mošorin village (Fig. 2) at an elevation of $116(\max ) \mathrm{m}$ at the top of the section (Fig. 2).

The modern soil (S0) and the most recent three glacial loess units L1, L2, and L3 and pedocomplexes S1, S2, and S3 are represented at exposures in the Veliki Surduk deep loess gully at the southern edge of the village. Previous stratigraphic studies of loess sections at various exposures in northern Serbia (Vojvodina Province, southeastern part of the Carpathian Basin) focused on pedo- and litho-logical and magnetic susceptibility data, along with variations in amino acid racemization geochronology, all combined with luminescence dating, as the primary basis for correlation (Marković et al., 2011). These results have been used for the establishment of a chronostratigraphy for the various loess-palaeosol units in the Vojvodina region (Marković et al., 2008, 2009). The nomenclature for this chronostratigraphy follows the Chinese loess stratigraphic system, with one exception - use of the prefix "V-" to refer to the standard Pleistocene loess-palaeosol stratigraphy in Vojvodina (Marković et al., 2008). Recently, a Danubian loess stratigraphic model (Marković et al., 2015) has been developed to correlate the loess-palaeosol units of the Danube Basin with the Chinese stratotype sections of Luochuan. Thus, in this study we use this scheme and Chinese "L and S" labels (e.g. Kukla, 1987; Kukla and An, 1989) without using any regional prefix.

According to the current chronostratigraphic model for Serbian loess (Marković et al., 2015), the penultimate interglacial pedocomplex S2 and glacial loess L2 formed during marine isotope stages (MIS) 7 and 6, respectively. The pedocomplex S1 correlates with MIS 5, which is overlain by the composite loess unit L1, corresponding to MIS 4 through 2 . The lower loess sub-horizon (L1LL2) accumulated above the S1 palaeosol. The Middle Pleniglacial pedocomplex is represented in the area by one palaeosol unit or even multiple weakly developed soils (therefore we use the term L1SSX; where ' $X$ ' represents a number of developed palaeosoils in L1). The youngest loess layer (L1LL1) accumulated during the Late Pleniglacial 
period, mostly associated with the late last glacial. Finally, the modern soil (S0) developed during the Holocene (Marković et al., 2015). Table 1 shows the position of the upper and lower boundaries and the thickness of stratigraphic units at the Veliki Surduk drilling site and the Lingtai section. The Holocene soil cover on the loess plateau surface, at the top of Titel loess plateau, is a typical Chernozem. At the top of the Veliki Surduk deep loess gully sequence, the soil profile is $50 \mathrm{~cm}$ thick, with a $\mathrm{Ck}$ horizon that contains many $\mathrm{CaCO}_{3}$ nodules $(0.5-2.0 \mathrm{~cm}$ in diameter) and numerous krotovinas and root channels filled with humic material. The transitional $\mathrm{AC}$ horizon is $25 \mathrm{~cm}$ thick, porous, and has a silt loam texture and a granular structure. The silt loam Ah horizon is $20 \mathrm{~cm}$ thick and has granular structure, along with some carbonate pseudomycelia. The presence of a $\mathrm{P}$ (plough) horizon in the uppermost part of the section indicates a strong human influence on this soil due to long term intensive agriculture production.

At the Veliki Surduk deep loess gully sequence the last glacial loess unit (L1) is generally around $10 \mathrm{~m}$ to $11 \mathrm{~m}$ thick. The lower loess unit (L1LL2) is a light yellow to grey, coarse and porous loess layer; the superimposed weakly developed pedocomplex L1SSX is intensively bioturbated and contains three weakly developed humic horizons. The uppermost loess layer (L1LL1) is porous and especially in its uppermost part heavily bioturbated. Many spherical, soft, carbonate nodules and humic infiltrations in old root channels are found at the contact with the Holocene soil (S0) above. The brownish pedocomplex (S1), which is 220 to $240 \mathrm{~cm}$ thick, is comprised of three pedomembers: a brown horizon at the base and two fossil Chernozem type horizons that form the middle and upper part of the pedocomplex. The uppermost humic horizon is relatively weakly developed and characterised by abundant krotovinas. The lowermost part of the pedocomplex and the transition to the underlying loess contain carbonate concretions. 
The Chinese Loess Plateau - Lingtai section

The Chinese Loess Plateau is considered to contain the most complete and detailed continental record of Quaternary palaeoclimatic changes (Liu, 1985; Liu and Ding, 1993) and is one of the most investigated climate archives on the planet. The Lingtai section is situated in the southern part of the plateau $\left(107^{\circ} 30^{\prime} 33^{\prime \prime} \mathrm{E}, 35^{\circ} 00^{\prime} 75^{\prime \prime} \mathrm{N}\right.$; Fig. 2), about $15 \mathrm{~km}$ to the south of the town of Lingtai, Gansu Province, at an elevation of ca. 1340 m above sea level (Ding and Yang, 2000), and is situated on typical loess plateau table land.

The section consists of a $175 \mathrm{~m}$ thick loess-palaeosol sequence underlain by $130 \mathrm{~m}$ of the Pliocene Red Clay formation. The long-term chronology of the Lingtai section is based on palaeomagnetic reversal stratigraphy, as are the chronologies of many of the records in the Loess Plateau, although several sections have been tuned to an astronomical timescale (Ding et al., 1994, 2002; Lu et al., 1999).

The Lingtai section is one of the longest and most complete sections on the Chinese Loess Plateau, with a total of 33 palaeosol horizons developed sequentially during the Pleistocene representing warm/humid intervals alternating with cold/arid periods during which loess was deposited but remained largely unaltered. The Holocene soil cover on the top of the Lingtai section is a $\sim 75 \mathrm{~cm}$ thick horizon, loose in structure with a brownish colour. Like the Titel plateau, it contains a $\mathrm{Ck}$ horizon $(25-\sim 90 \mathrm{~cm})$ with $\mathrm{CaCO}_{3}$ nodules. The $\mathrm{Ah}$ horizon is $\sim 25 \mathrm{~cm}$ thick and represents a typical agricultural terrace with strong, recent soil development and numerous root channels filled with humic material.

The last glacial loess unit (L1) is $5.55 \mathrm{~m}$ thick and intersected with fine and a few larger roots in the upper $\sim 200 \mathrm{~cm}$ of the horizon. The lower loess unit (L1LL2) has a dense structure with many fine, elongated $\mathrm{CaCO}_{3}$ precipitates. At $540 \mathrm{~cm}$ depth, there is a noticeable increase in sand and $\mathrm{CaCO}_{3}$. The overlying pedocomplex L1SS1 is $220 \mathrm{~cm}$ thick, brown in colour with 
a few secondary carbonates mainly in fine root channels. From a depth of $\sim 280 \mathrm{~cm}$ downwards the deposits show a higher density in the structure.

The palaeosol $\mathrm{S} 1$ from the last interglacial is $270 \mathrm{~cm}$ thick and has a blackish-brownish colour indicating a high organic matter content (Ding et al., 1999). The lower, transitional part to L2 is clay rich, yellowish brown in colour and shows an increase in sand content. The middle part of the pedocomplex $(740-820 \mathrm{~cm})$ is characterised by very dominant Mn precipitates (ca. $0.5 \mathrm{~cm}$ in diameter). The uppermost horizon is angular-blocky in structure, clay rich and characterised by abundant krotovinas. Many authors have correlated the Lingtai section with other sections on the plateau using grain size and magnetic susceptibility records (Kukla and An, 1989; Rutter et al., 1991) but to date no independent chronology exists at the site to our knowledge.

\section{Sampling}

In order to obtain detailed stratigraphic, climatic and chronological information from the Titel loess plateau, two cores were drilled in the northern area of the plateau, near the village of Mošorin $\left(45^{\circ} 17^{\prime} 46^{\prime \prime} \mathrm{N} 20^{\circ} 11^{\prime} 21^{\prime \prime} \mathrm{E}\right)$ at the site called Veliki Surduk. The coring site is located on the eastern side of the loess gully, while the intensely studied outcrop is exposed on the western side. The first core (TLP 1) was drilled to a depth of $22.93 \mathrm{~m}$ while the second one (TLP 1A) was drilled to a depth of $21.42 \mathrm{~m}$. The two cores were drilled side by side, just $1 \mathrm{~m}$ apart, covering about the same stratigraphic depths. In general, the second core was drilled in order to compensate for core loss at the top and base of the $1 \mathrm{~m}$ long core segments of the TLP 1 core, and to provide backup samples in case the material from the first drilling was proved to be insufficient or not suitable for analysis. TLP 1A has a core depth offset of $0.5 \mathrm{~m}$ from $1.5 \mathrm{~m}$ down compared to TLP 1 . The cores were then split lengthwise, one half for luminescence dating and the other one for sedimentology, geochemistry, palaeo- and mineral magnetism. 
Luminescence sampling for equivalent dose determination was undertaken in continuous sections of 13-15 cm length in both cores. Samples for dose rate assessment via laboratory gamma spectrometry were taken in $6 \mathrm{~cm}$ segments from each end of the section matching the luminescence samples. The sampling was undertaken in the laboratory of the Chair of Geomorphology (member of BayCEER), University of Bayreuth, Germany under subdued redorange light. In core TLP 199 samples were obtained for both equivalent dose and dose rate measurements, while from TLP 1A 89 samples were obtained.

The samples from the Lingtai section were obtained by hammering stainless steel cylinders into the loess profiles at $10 \mathrm{~cm}$ intervals. In total, the results from 43 samples are presented here from the uppermost $5.6 \mathrm{~m}$. The sample preparation was carried out in the Nordic Laboratory for Luminescence Dating (Aarhus University), Risø Campus, Denmark, under subdued orange light. The inner material of the cylinders was used for equivalent dose measurement and the outer, light-exposed material for dose rate measurements.

\section{Samples, instrumentation and facilities}

In this study, we present the results from a detailed OSL investigation of the $63-90 \mu \mathrm{m}$ quartz grains from the Titel core TLP 1 and 4-11 $\mu$ m quartz grains from the Lingtai section, covering the last glacial period. The fraction $63-90 \mu \mathrm{m}$ from the Titel core proved to be relatively easy to extract and provided sufficient material in most of the samples, while for Lingtai average grain-size is finer and 63-90 $\mu \mathrm{m}$ grains are far less abundant. The $63-90 \mu \mathrm{m}$ grains were obtained by wet sieving through 90 and $63 \mu \mathrm{m}$ sieves. For four Titel samples a smaller grain size fraction $(40-63 \mu \mathrm{m})$ was used as there was insufficient material in the $63-90 \mu \mathrm{m}$ fraction. Chemical preparation of the bulk samples included 10\% hydrochloric acid $(\mathrm{HCl})$ and $10 \%$ hydrogen peroxide $\left(\mathrm{H}_{2} \mathrm{O}_{2}\right)$ treatments in order to remove carbonates and organic matter, respectively. Samples that showed a stronger carbonate reaction were left in the $\mathrm{HCl}$ solution 
for $24 \mathrm{~h}$. The $63-90 \mu \mathrm{m}$ grain size separates were treated with $10 \%$ hydrofluoric acid (HF) for 40 min to remove the alpha irradiated surface layer and weathering products and coatings, followed by $10 \% \mathrm{HCl}$ for $40 \mathrm{~min}$ to remove fluorides. After each chemical treatment, samples were washed three times in deionised water. The obtained material was separated using sodium heteropolytungstate dissolved in water $\left(2.58 \mathrm{~g} \mathrm{~cm}^{-3}\right.$; LST 'Fastfloat') to provide quartz-rich and K-feldspar-rich fractions. The isolated quartz-rich fraction was treated with concentrated (49\%) HF for 20 min to remove any remaining feldspar contamination. The quartz grains were mounted as large $8 \mathrm{~mm}$ aliquots on stainless steel cups using silicone oil spray for as an adhesive.

For the extraction of the fine quartz grains from the Lingtai samples, a standard procedure was used (Lowick and Preusser, 2010). All grains were first treated with $32 \% \mathrm{HCl}$ to remove carbonates followed by a $30 \% \mathrm{H}_{2} \mathrm{O}_{2}$ treatment to remove organic matter, and finally with sodium oxalate $\left(\mathrm{Na}_{2} \mathrm{C}_{2} \mathrm{O}_{4}\right)$ to avoid aggregation. The $4-11 \mu \mathrm{m}$ polymineral fine grains were extracted by settling using Stokes' Law, and the quartz fraction was obtained by subsequently immersing these grains in $32 \%$ hydrofluorosilicic acid $\left(\left(\mathrm{H}_{3} \mathrm{O}\right)_{2} \mathrm{SiF}_{6}\right)$ for 3 to 5 days. Finally, in order to remove fluorides, the grains were rinsed with $32 \% \mathrm{HCl}$. The grains were settled on $9.8 \mathrm{~mm}$ aluminium discs with acetone using the pipette method.

All the luminescence and dose rate measurements were conducted at the Nordic Laboratory for Luminescence Dating (Aarhus University) and DTU Nutech (Technical University of Denmark, DTU Risø Campus in Denmark). Luminescence measurements for both the Titel and Lingtai samples were conducted on several Risø TL/OSL readers, equipped with calibrated ${ }^{90} \mathrm{Sr} /{ }^{90} \mathrm{Y}$ beta sources (Bøtter-Jensen et al., 2010). The dose rates of the readers ranged between $0.05100 \mathrm{~Gy} \mathrm{~s}^{-1}$ and $0.24852 \mathrm{~Gy} \mathrm{~s}^{-1}$ depending on reader beta source and measurement substrate. Quartz stimulation employed blue (470 nm; 80 $\mathrm{mW} \mathrm{cm}^{-2}$ ) LEDs with the OSL signal detected through a $7 \mathrm{~mm}$ Hoya U-340 glass filter. For the determination of the 
equivalent dose $\left(D_{e}\right)$ a standard single-aliquot regenerative (SAR) protocol was employed (Murray and Wintle, 2000, 2003) with a preheat temperature of $260^{\circ} \mathrm{C}$ for $10 \mathrm{~s}$ and a cut heat of $220^{\circ} \mathrm{C}$. Details of dose recovery tests are given below. The aliquots that failed the OSL IR depletion test (outside 10\% of unity) were rejected (Duller, 2003). The initial $0.8 \mathrm{~s}$ of the quartz OSL decay curves minus a background of the following $0.8 \mathrm{~s}$ was used for calculation of net signal (early background subtraction; based on Cunningham and Wallinga, 2010). Luminescence data analysis was conducted using the Risø Analyst software, version 4.31.9.

\section{Dose rate measurements}

The material for dose rate $(\square)$ calculation was ground to $<200 \mu \mathrm{m}$, ignited at $450{ }^{\circ} \mathrm{C}$ for $24 \mathrm{~h}$, and cast in wax to retain radon. The material from both Titel and Lingtai was sufficient to cast solid disc-shaped samples ( $\sim 30 \mathrm{~g}$ of dry sample). The discs were then stored for $>3$ weeks to allow ${ }^{222} \mathrm{Rn}$ to build up to equilibrium with ${ }^{226} \mathrm{Ra}$, before analysing for $>24 \mathrm{~h}$ using high resolution gamma spectrometry (Murray et al., 1987). The radionuclide concentrations were converted to dry dose rates using the conversion factors provided by Guérin et al. (2011). The activities of ${ }^{238} \mathrm{U}$ and ${ }^{226} \mathrm{Ra},{ }^{210} \mathrm{~Pb},{ }^{232} \mathrm{Th}$ and ${ }^{40} \mathrm{~K}$ for the Titel and Lingtai samples are presented in Tables 2 and 3, respectively.

The contribution of cosmic rays to the total dose rate was calculated according to Prescott and Hutton (1994). The water content of the Titel samples was estimated to be $15 \pm 5 \%$ based on field observations and previous research conducted in this area and was assumed to apply throughout the burial period (Schmidt et al., 2010; Antoine at al., 2009). An internal dose rate from $\mathrm{U}$ and $\mathrm{Th}$ of $0.02 \pm 0.01 \mathrm{~Gy} \mathrm{ka}^{-1}$ was assumed for coarse grains from Titel (based on Vandenberghe et al, 2008). The water content of the Lingtai samples was estimated to be $20 \pm 5 \%$ based on analysis of multiple samples taken at the site, and is comparable to typical values for other sites on the southern part of the Chinese Loess Plateau (Stevens et al., 2013). 
The total dose rates are given in Tables 2 and 3 for Titel and Lingtai, respectively. For $4-11 \mu \mathrm{m}$ aliquots an $\alpha$ efficiency value of $0.04 \pm 0.02$ was used (Rees-Jones, 1995).

\section{Luminescence characteristics}

Aliquots for the OSL measurements on the Titel plateau quartz were obtained from samples 168110 (9.5 cm depth) - 168160 (1115 cm depth), covering the L1 unit in the loess-palaeosol sequence. For the Lingtai quartz, aliquots were obtained from samples H18101 (20 cm depth) to $\mathrm{H} 18149$ (560 $\mathrm{cm}$ depth) also corresponding to the L1 unit in the loess-palaeosol sequence. The SAR-procedural test results for the Titel and Lingtai samples are presented in Tables S1 and S2 respectively.

Most of the measured aliquots showed an OSL IR depletion ratio close to unity with a $\sim 34-51$ Gy regenerative dose and with the $110^{\circ} \mathrm{C}$ TL peak being clearly defined, indicating the purity of the quartz extracts $(19 \%$ of the aliquots from Titel were rejected based on this criterion). The OSL signals from both sites are bright and generally dominated by the fast component. The natural and regenerated decay curves show a very close match to each other, as well as to the signal from fast component dominated Risø calibration quartz (Figures 4 (A) and $4(\mathrm{~B}))$.

For the determination of an appropriate preheat temperature, a preheat plateau test was performed on 24 aliquots of the sample 168122 from the Titel loess plateau ( $309 \mathrm{~cm} \mathrm{depth),}$ and on 24 aliquots of the sample H18116 (210 cm depth) from the Lingtai section. For the Titel samples, temperatures ranging from $160^{\circ} \mathrm{C}$ to $300^{\circ} \mathrm{C}$ were employed for $10 \mathrm{~s}$ during the first preheat in combination with a $160^{\circ} \mathrm{C}$ to $260^{\circ} \mathrm{C}$ test dose preheat (cutheat). For the Lingtai samples we employed temperatures ranging from $180^{\circ} \mathrm{C}$ to $300^{\circ} \mathrm{C}$ for $10 \mathrm{~s}$ during the first preheat in combination with $140^{\circ} \mathrm{C}$ to $260^{\circ} \mathrm{C}$ test dose preheat. For the Titel quartz, the $D_{e}$ value did not show any significant sensitivity to preheat temperature up to approximately 
$260^{\circ} \mathrm{C}$. The recycling ratios are close to unity and the recuperation is close to $1 \%$ over the 160 $300^{\circ} \mathrm{C}$ first preheat interval. For Lingtai quartz, the $D_{e}$ is independent of temperature for preheats $\geq 220^{\circ} \mathrm{C}$. Based on these results, a first preheat temperature of $260^{\circ} \mathrm{C}$ for $10 \mathrm{~s}$ and cut heat of $220^{\circ} \mathrm{C}$ was chosen for all following measurements The results of the preheat plateau tests for the Titel and Lingtai samples are summarised in Figure 5.

As $19 \%$ of aliquots from Titel quartz were rejected based on OSL IR depletion ratio we further compared $D_{e}$ values derived from pure blue-light stimulated luminescence with those obtained using a double-SAR protocol (Roberts and Wintle, 2001) for 6 Titel samples (6 aliquots per sample). The measurement sequence included preheating to a temperature of $260^{\circ} \mathrm{C}$ for $10 \mathrm{~s}$, followed by stimulation using IR LEDs at a temperature of $60^{\circ} \mathrm{C}$ for $100 \mathrm{~s}$ to monitor and deplete the IRSL signal from feldspars. The 'double-SAR' protocol used in this study yielded $D_{e}$ values that are indistinguishable from the $D_{e}$ values measured with pure bluelight stimulation. The $D_{e}$ value obtained using the 'double-SAR' protocol for sample 168116 was $42 \pm 4$ Gy while the standard SAR protocol for the same sample yielded a value of $40 \pm 4$ Gy. This indicated that the feldspar contribution to the (post-IR) OSL signal was negligible and a standard blue-light stimulated SAR procedure was appropriate to measure dose for the Titel samples.

To test the applicability of the luminescence measurement protocol, dose recovery tests (Murray and Wintle, 2003) were performed on 6 aliquots of each of the following Titel samples: 168111, 168113, 168114, 168115, 168116 ( 30 Gy given dose) and 168141, 168143, 168158, 168159 ( $\sim 60$ Gy given dose). An additional dose recovery test was performed on samples 168124 and 168139 where doses ranging between $\sim 20$ and 250 Gy were employed (24 aliquots per sample; 6 aliquots per dose). The results of these tests are summarised in Figure 6 and show that the measurement protocol is able to accurately (within $10 \%$ of unity) measure doses of up to $270 \mathrm{~Gy}$ administered before any thermal pretreatment of the sample. However, 
we note that this dose might be beyond the reliable range of measurement of natural dose in quartz OSL dating (Buylaert et al., 2007; Roberts, 2008; Chapot et al., 2012; Trandafir et al., 2015). For the Lingtai samples, the dose recovery tests were performed on 4 aliquots on alternate samples (H18121 - H18134 $(n=12) \sim 120$ Gy given dose; H18135 - H18140 (n=6) $\sim 100$ Gy given dose). The average of the measured to given dose ratio for all the Titel samples ( $n=11 ; 6$ aliquots per sample) is $1.05 \pm 0.04$ and for the Lingtai samples $(n=18 ; 4$ aliquots per sample) it is $0.99 \pm 0.03$, which confirms that the applied SAR protocol is suitable for age determination and a known laboratory dose can be recovered. The frequency distributions of the dose recovery ratio for the Titel and Lingtai samples are shown in Figure 7 (A) and 7 (B) respectively.

For each sample from the Titel plateau $(168110-168160 ; n=51)$ a minimum of five replicate $D_{e}$ measurements were conducted (except for sample 168111 and 168129 where no sufficient quartz grains could be extracted), while for the samples from the Lingtai section (H18101 - H18149; $n=43$ 2-4 replicate measurements were performed. Figure 4 (C) shows a typical dose response curve for sample 168113 from the Titel Loess Plateau. A representative dose response curve for sample H18121 from Lingtai is presented in Figure 4 (D).

The weighted mean $D_{e}$ values (1 sigma standard error) of the Titel quartz range from $1.4 \pm 0.2$ Gy for the uppermost sample to $167.8 \pm 9.4$ Gy for sample 168142 (715 cm depth) (Table 2). The $D_{e}$ values generally increase with depth, but at $\sim 548 \mathrm{~cm}$ depth (sample 168134) and below, they reach a stationary value of $\sim 120 \mathrm{~Gy}$. This flattening in $\mathrm{D}_{\mathrm{e}}$ in quartz from the Titel loess plateau likely represents a saturation (or steady state) of the luminescence doseresponse in the field (field saturation).

The $D_{e}$ values of the Lingtai quartz range from 5.7 \pm 0.2 Gy for the uppermost sample to $150 \pm 6$ Gy for the lowermost sample dated. Similar to Titel, the $D_{e}$ values demonstrate an 
increase with depth up to $\sim 150 \mathrm{~Gy}$, where it reaches field saturation. This value also coincides with the upper limit for quartz dating in Chinese loess as suggested by Chapot et al. (2012).

The samples suffering from field saturation (Titel samples: $168124-345 \mathrm{~cm}$ depth and below; Lingtai samples: H18140 - $450 \mathrm{~cm}$ depth and below) are excluded from age model calculation and further discussion.

\section{Luminescence ages}

The luminescence ages, dosimetric information and equivalent doses, for the Titel and Lingtai samples are presented in Tables 2 and 3 respectively. Supplementary Tables S1 and S2 show equivalent dose measurements ( $D_{e}$, recycling ratio and recuperation), results of dose recovery tests (Dr) and luminescence ages for the Titel loess core.

The ages of the Titel core show a consistent increase with depth ranging from $0.44 \mathrm{ka}$ for the uppermost sample (168110, $9.5 \mathrm{~cm}$ depth) to $35.8 \mathrm{ka}(168124,345 \mathrm{~cm}$ depth) where the reliable age limit for quartz OSL dating on the Titel loess plateau is probably reached (Figure 8). Even though the samples generally display a constant age increase with depth, a few noticeable irregularities are observed. The most obvious are the changes in ages between samples 168112 to 168114 (between 47.5 and $109 \mathrm{~cm}$ depth). The remaining record shows a steady age increase to sample 168124 , after which the ages begin to decrease and show larger scatter on an average.

The ages of the Lingtai samples generally increase with depth but in some cases display irregularities (Figure 9). Most notable is the $14 \mathrm{ka}$ difference between sample H18101 $(1.60 \pm 0.27 \mathrm{ka})$ and H18103 (15.6 $\pm 1.5 \mathrm{ka})$, over a $50 \mathrm{~cm}$ depth change. Sample H18104 has an anomalously high age ( $22 \mathrm{ka})$ compared to succeeding samples while sample H18133 has a considerable lower age than the rest of the data would suggest. The highest observed age was 52 ka on sample H18135 whilst the succeeding samples all show lower ages (H18136 - 


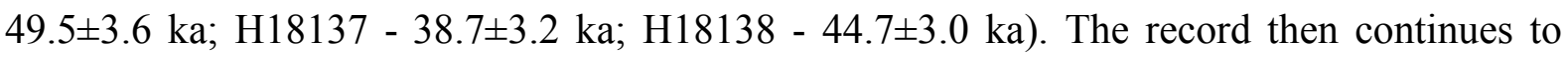
display consistent age increases with depth until sample H18141 (35.1 $\pm 4.5 \mathrm{ka}-460 \mathrm{~cm}$ depth).

\section{Age-depth models and dust Mass Accumulation Rate (MAR)}

The luminescence data provide the opportunity to develop continuous and fully independent age versus depth models for the two sites. Approaches as to how to derive continuous agedepth models from discrete luminescence age points vary in the literature (Kang et al., 2015; Stevens et al., 2016; Újvári et al., 2014; Zeeden et al., 2018) and as such here we have chosen to apply and briefly compare results from two approaches, which are based on contrasting assumptions. Firstly, we apply a Bayesian modeling approach using the Bacon code of Blaauw and Christen (2011), undertaken at $5 \mathrm{~cm}$ depth resolution. Bacon uses Bayesian statistics to reconstruct accumulation histories for deposits, through combining numerical age dates with prior information such as accumulation rate and its variability (memory). Accumulation rates are controlled using a gamma autoregressive semiparametric model with an arbitrary number of subdivisions along the sediment profile (Blaauw and Christen, 2011; here resolution is set to $5 \mathrm{~cm}$ ). Prior knowledge about accumulation rates can lead to reduced uncertainty and more realistic modeling (Blaauw and Christen, 2011). The priors for accumulation rate and memory (autocorrelation) are modeled by gamma and beta distributions, and the latter defines how much the accumulation rate at a particular depth in a core depends on the depth above it. The section thickness dictates to some degree the flexibility of the age-depth model, which is obtained by millions of Markov Chain Monte Carlo (MCMC) iterations (Blaauw and Christen, 2011). Secondly, an age-depth model of OSL dates was constructed using the model of Zeeden et al. (2018). This method constructs an age-depth model from luminescence ages without making any assumptions over sedimentation rate or process, but requires ages to be consistent with stratigraphy. It involves an inverse model and uses a conservative measure for the random 
part of overall uncertainty. Due to the Lingtai dataset size, the dataset was separated into several parts and was later recombined, with the third data point from top considered an outlier. Smoothing of results was undertaken using a Taner low pass filter as implemented in the 'astrochron' R package (Taner, 1992; Meyers, 2014; R Core Team, 2017). Cut-off frequencies of 0.2 and 0.1 kyr were used for Titel and Lingtai, respectively (see Supplementary Materials for the documented R code). Modeling results from both approaches are presented in Figure 10.

The lack of abrupt increases in OSL age with depth suggests that no major hiatuses are present in the studied sections. This allows continuous age-depth models to be developed from the OSL ages (Figure 10). While the general age-depth trends between the two models are similar, the model of Zeeden et al. (2018) is much more sensitive to changes in OSL age with depth, which results in a more variable age-depth function, especially at Titel. In contrast, the age depth function resulting from the Bacon model is nearly linear at both sites, indicating relatively constant sedimentation rates, at least within the error limits of the technique (Figure 10). The only exception is a change from relatively higher sedimentation rates to relatively lower ones at around $15 \mathrm{ka}$ at both sites. The results of the different age models are discussed below in light of age-depth model assumptions, the nature of loess deposition, and dust Mass Accumulation Rate (MAR) calculated from the age models.

In order that the results can be reliably compared between regions and other dust archives, as well as for use in estimating past atmospheric dust flux (Albani et al., 2015), we here calculated Mass Accumulation Rate (MAR) (Kohfeld and Harrison, 2003) at the two sites. $\operatorname{MAR}\left(\mathrm{g} \mathrm{m}^{-2} \mathrm{a}^{-1}\right)$ is calculated using the following equation:

$\mathrm{MAR}=\mathrm{SR} \times f_{\mathrm{eol}} \times \mathrm{BD}$,

where SR is sedimentation rate $\left(\mathrm{m} \mathrm{a}^{-1}\right), f_{\text {eol }}$ is the proportion of the sediment that is aeolian (assumed $=1$ ), and BD is bulk density of the loess $\left(\mathrm{g} \mathrm{cm}^{-3}\right)$. Estimated bulk density for loess 
values vary in the literature and in loess regions (Kohfeld and Harrison, 2003; Stevens et al., 2016; Újvári et al., 2010). Here we measured bulk density directly on all dated samples from Lingtai. While values range apparently randomly from ca. 1.3 to $1.7 \mathrm{~g} \mathrm{~cm}^{-3}$, the majority concentrate around a mean value of $1.5 \mathrm{~g} \mathrm{~cm}^{-3}$, which also matches almost exactly average Chinese Loess Plateau bulk density data in Kohfeld and Harrison (2003) and the average value of $1.52 \pm 0.02 \mathrm{~g} \mathrm{~cm}^{-3}$ measured on 33 samples from the S1 soil at Jingbian (Buylaert et al., 2015). Bulk density at Titel was not directly measured so we use estimates obtained from other middle Danube loess at the Dunaföldvár loess section in Hungary, which yielded average values of $1.5 \mathrm{~g} \mathrm{~cm}^{-3}$ (Újvári et al., 2010).

The calculated MAR trends with depth at both sites and from both models are shown in Figure 11. The model of Zeeden et al. (2018) shows much more variability in dust MAR for both sites, which is a consequence of the different assumptions made over loess accumulation rate and the weight given to individual age points in the two models. To what extent the process of true loess sedimentation is reflected in variability in closely-spaced luminescence ages is yet unclear, which makes determining the best choice of model difficult. Loess deposition over a variety of timescales may be considered a random and intermittent process (e.g., due to dust storms, phases of enhanced or reduced accumulation, erosional events, breaks in sedimentation, etc.). However, while some of these may be reflected in luminescence age with depth variability, given the typical uncertainty on luminescence ages of $5-10 \%$ it is not possible to constrain the nature of loess deposition on shorter than 1000 a timescales for samples older than $10 \mathrm{ka}$. In other words, there is currently no way of determining whether luminescence age variability within or close to error estimates on individual ages is real (i.e. low autocorrelation, implying highly temporally variable aeolian environment) or just the artefact of noise imposed by the inherent limitations of the OSL technique. Reassuringly, examination of the smoothed results from the Zeeden et al. (2018) model compared to the Bacon model results reveals 
general similarity in longer-term MAR trends for both sites, suggesting that irrespective of shorter-term fluctuations in MAR, the general trends at both sites are captured by both models (Fig. 11). However, the absolute MAR values yielded by the two models vary considerably, as discussed below.

In terms of the trends seen at the sites, we here focus on longer term trends due to uncertainty and discrepancies between modeled MARs on short-term (sub ka scale) timescales. Furthermore, while the MAR values presented here are given without error estimates, this is largely because there is no agreement about how to obtain realistic estimates of dust MAR uncertainty from loess. Apart from potential uncertainties in bulk density estimates and the impact of post-depositional modification, simple Gaussian error propagation from luminescence ages may not be valid as uncertainty may not be strictly Gaussian, or fully random. However, we anticipate that the error on MAR estimates will exceed the luminescence age uncertainty in percentage terms. As such, shorter-term variability in MAR, like the ca. 4-6 ka frequency oscillations seen especially at Lingtai (Fig. 11), cannot be considered as significant here. Generally, both absolute MAR values and trends in the data with age are remarkably similar between the sections (with the exception of the large ca. 15 ka MAR peak in the Zeeden et al. (2018) model output for Lingtai, which is driven by the model relying solely on the luminescence ages themselves, and not surrounding age depth information as with Bacon). Both show a peak in MAR around 25-13 ka, with values at both Titel and Lingtai peaking in the Bacon model around $200 \mathrm{~g} \mathrm{~m}^{-2} \mathrm{a}^{-1}$. In the model of Zeeden et al. (2018) peak values are much higher, especially at Titel where MAR peaks at around $650 \mathrm{~g} \mathrm{~m}^{-2} \mathrm{a}^{-1}$. However, given the discrepancies in absolute values between the models it is debatable how accurate these peak estimates are and it may be safer to simply state that MAR is generally in the range of $100-200 \mathrm{~g} \mathrm{~m}^{-2} \mathrm{a}^{-1}$ at both sites for the late last glacial. Prior to the last glacial MAR peak, MAR values at both sites are very similar, and both sites show lower MAR values after ca. 13 
ka (Fig. 11). These general MAR values are relatively low in comparison to average values for last glacial Central-Eastern European loess (Újvári et al., 2010), although European loess deposits show considerable variation in MAR and the peak MAR values here are more consistent with other studies. Indeed, a recent study that uses extremely detailed AMS ${ }^{14} \mathrm{C}$ dating of charcoal and small gastropods from the Dunaszekcső site in Hungary shows a major and variable dust peak between 24 and $27 \mathrm{ka}$, with peak MAR values of $2800 \mathrm{~g} \mathrm{~m}^{-2} \mathrm{a}^{-1}$ (Újvári et al., 2017). These extremely high values reflect the fact that this is a very short-term peak derived from a ${ }^{14} \mathrm{C}$ age model with much higher resolution than our OSL-based models, which will smooth out such peaks. However, the general MAR values at the sections are similar to last glacial Chinese Loess Plateau MARs (Stevens et al., 2016). The timing of peak MAR at the two sites under study matches broadly (but is slightly later than) the timing of peak MAR identified from analysis of multiple luminescence dated sites across the Chinese Loess Plateau (Fig. 11) in Kang et al. (2015). Stevens et al. (2016) also showed peak dust MAR at Xifeng occurring around 22-27 ka, earlier than in the records here, although due to soil formation driven disturbance the Xifeng record does not extend to the absolute peak MAR intervals presented here (see also Fig. 11). It is unclear whether these differences in peak MAR are an artefact of dating uncertainty, preservation, or whether these are real differences in dust accumulation between sites. The latter may also potentially be related to aspects such as proximity to local dust sources, and in the case of Titel, which is located close to the confluence of two major rivers, to local hydrodynamic conditions. In any case, there is now considerable evidence for a major peak in dust MAR across the Chinese Loess Plateau during the late last glacial period, and the similar age peak at Titel and recent evidence from Dunaszekcső in Hungary (Újvári et al., 2017) suggests that this may be also the case in Central-East and SouthEast European deposits. However, this must be tested extensively, as in contrast to China, very little sufficiently detailed MAR data exists for European deposits. Note that here we only 
consider evidence from age-models derived from ages obtained via fully independent, numerical geochronological techniques, which fully consider the resolution and uncertainty of their approaches, so as to avoid incorporating further assumptions over sediment depositional age. Furthermore, the heavy dependence of MAR on choice of age-depth model requires that a uniform and representative approach is now developed for dust accumulation in loess deposits, in order that this information can be incorporated into atmospheric dust deposition and loading models (Albani et al., 2015). To ensure use of dust MAR data in climate modelling (Albani et al., 2015) we provide grain-size distribution data for Lingtai in Table S3. Grain-size distribution data from Titel are not yet available but will be presented with MAR data when possible. We also include the results of our MAR versus age calculations at the two sites using the two models in Supplementary Table S4.

The remarkable similarity in MAR patterns between the two sites at east end west ends of the Eurasian loess belt suggests that at least broad scale trends in dust activity within the last glacial period may be similar at a continental scale. This is promising with regard to the use of loess deposits to gain a better geographical representation of past continental scale dust activity. The relative constancy in dust MAR at the sites also suggests rather constant levels of dustiness over much of the last glacial, and suggests no major hiatuses are discernible given the resolution of the OSL ages. As such, there seems to be considerable variation in the degree to which sites may show hiatuses in loess accumulation (Buylaert et al., 2008; Kang et al., 2015; Stevens et al., 2008, 2016). A major peak in dustiness during the late last glacial broadly corresponds to increases in dust activity shown in Northern Hemisphere ice cores and marine cores (Hovan et al., 1989; Rasmussen et al., 2014; Ruth et al., 2007). However, given the inconsistencies between loess accumulation timing between loess sections, further refining of the chronologies of dust deposition in general and more standardised approaches to age modelling and MAR 
calculation are required before leads or lags or differences in timing between different dust archives can be identified.

\section{Conclusions}

Detailed quartz OSL dating conducted on upper last glacial cycle loess at two sites at the extreme ends of the Eurasian loess belt shows that the technique is only capable of accurate age determination for $D_{e}$ values up to about $150 \mathrm{~Gy}$, with older samples providing minimum estimates due to the effects of signal saturation. However, high sampling resolution dating of the middle to late last glacial phase yields normally internally consistent ages that pass standard luminescence dating checks. Generally, the luminescence ages increase with depth and no obvious jumps in ages suggest major hiatuses are absent from these sites. The resultant age data were converted into age-depth models using two approaches, where one approach makes assumptions over sedimentation rates, and the other is based solely on the OSL data. Dust Mass Accumulation Rates (MAR) were calculated from these models and reveal strong model dependency on short term MAR fluctuations and absolute values. However, general MAR trends are consistent between models and show relatively constant and highly consistent dust MAR patterns over the last 35-45 ka at both the sites, with generally similar absolute MAR values at the sites. A peak in MAR values at both sites is shown around 13-25 ka, suggesting that similar patterns of last glacial dust activity may have occurred at either end of the Eurasian loess belt and that dust activity over this period may show a hemispheric trend.

\section{Acknowledgements:}

We thank Warren Thompson and Louise Helsted for help with OSL sample preparation and gamma spectrometry measurements, and to Shugang Kang for providing relative MAR changes from the CLP. We also thank Christian Laag for the assistance during sample 
preparation of the Titel loess core at the University of Bayreuth. Jan-Pieter Buylaert thanks the Danish Council for Independent Research | Natural Sciences (FNU) for financial support (Steno grant no. 11-104566). Christian Zeeden is financed through a PSL post-doctoral fellowship.

\section{References}

1. Albani, S., Mahowald, N. M., Winckler, G., Anderson, R. F., Bradtmiller, L. I., Delmonte, B., François, R., Goman, M., Heavens, N. G., Hesse, P. P., Hovan, S. A., Kang, S. G., Kohfeld, K. E., Lu, H., Maggi, V., Mason, J. A., Mayewski, P. A., McGee, D., Miao, X., Otto-Bliesner, B. L., Perry, A. T., Pourmand, A., Roberts, H. M., Rosenbloom, N., Stevens, T., and Sun, J., 2015. Twelve thousand years of dust: the Holocene global dust cycle constrained by natural archives. Climate of the Past 11, 869-903.

2. An, Z.S., 2000. The history and variability of the East Asian paleomonsoon climate. Quaternary Science Reviews 19, 171-187.

3. Antoine, P., Rousseau, D.D., Fuchs, M., Hatté C., Gautier, C., Marković, S.B., Jovanović, M., Gaudeenyi, T., Moine, O., Rossignol, J., 2009. High resolution record of the last climatic cycle in the Southern Carpathian basin (Surduk, Vojvodina, Serbia). Quaternary International 198, 19-36.

4. Blaauw, M., Christen, J.A., 2011. Flexible palaeoclimate age-depth models using an autoregressive gamma process. Bayesian Anal. 6 (3), 457-474.

5. Buggle, B., Hambach, U., Kehl, M., Marković, S.B., Zöller, L., Glaser, B., 2013. The progressive evolution of a continental climate in SE-Central European lowlands during the Middle Pleistocene recorded in loess paleosol sequences. Geology 41, 771-774. 
6. Buylaert, J. P., Vandenberghe, D., Murray, A. S., Huot, S., De Corte, F., Van den haute, P., 2007. Luminescence dating of old ( $>70 \mathrm{ka}$ ) Chinese loess: a comparison of single-aliquot OSL and IRSL techniques. Quaternary Geochronology 2, 9-14.

7. Buylaert J.P, Murray AS, Vandenberghe, D.,Vriend, M., De Corte, F., Van den haute, P., 2008. Optical dating of Chinese loess using sand-sized quartz: establishing a time frame for Late Pleistocene climate changes in the western part of the Chinese Loess Plateau. Quaternary Geochronology 3, 99-113.

8. Buylaert, J.P., Yeo, E-Y, Thiel, C., Yi, S., Stevens, T., Thompson, W., Frechen, M., Murray, A., Lu, H., 2015. A detailed post-IR IRSL chronology for the last interglacial soil at the Jingbian loess site (northern China). Quaternary Geochronology 30, 194-199.

9. Chapot, M.S., Roberts, H.M., Duller, GAT, Lai, Z.P., 2012. A comparison of natural- and laboratory-generated dose response curves for quartz optically stimulated luminescence signals from Chinese Loess. Radiation Measurements 47, 1045-1052.

10. Cunningham, A.C., Wallinga, J., 2010. Selection of integration time intervals for quartz OSL decay curves. Quaternary Geochronology 5, 657-666.

11. Ding, Z., Sun, J., Rutter, N.W., Rokosh, D., Liu, T., 1999. Changes in sand content of loess deposits along a north-south transect of the Chinese Loess Plateau and the implications for desert variations. Quaternary Research 52, 56-62.

12. Ding, Z.L., Ranov, V., Yang, S.L., Finaev, A., Han, J.M., Wang, G.A., 2002. The loess record in southern Tajikistan and correlation with Chinese loess. Earth and Planetary Science Letters 200, 387-400.

13. Duller, G.A.T., 2003. Distinguishing quartz and feldspar in single grain luminescence measurements. Radiation Measurements 37, 161-165.

14. Ding, Z., Yu, Z., Rutter, N.W. and Liu, T.S., 1994. Towards an orbital time-scale for Chinese loess deposits. Quaternary Science Reviews 13, 39-70. 
15. Ding, Z.L., Yang, S.L., 2000. C3/C4 vegetation evolution over the last 7.0 Myr in the Chinese Loess Plateau: evidence from pedogenic carbonate $\delta^{13} \mathrm{C}$. Palaeogeography, Palaeoclimatology, Palaeoecology 160, 291-299.

16. Hansen, V., Murray, A., Buylaert, J.-P., Yeo, E.-Y., Thomsen, K., 2015. A new irradiated quartz for beta source calibration. Radiation Measurements 81, 123-127.

17. Frechen, M., Oches, E.A., Kohfeld, K.E., 2003. Loess in Europe - mass accumulation rates during the Last Glacial Period. Quaternary Science Reviews 22, 1835-1857.

18. Fuchs, M., Rousseau, D., Antoine, P., Hatté, C., Gauthier, C., Marković, S., Zoeller, L., 2008. Chronology of the last climatic cycle (upper Pleistocene) of the Surduk loess sequence, Vojvodina, Serbia. Boreas 37, 66-73.

19. Guérin, G., Mercier, N., Adamiec, C., 2011. Dose-rate conversion factors: update. Ancient TL 29, 5-8.

20. Hovan, S.A., Rea, D.K., Pisias, N.G., Shackleton, N.J., 1989. A Direct Link Between The China Loess And Marine Delta-o-18 Records - Aeolian Flux To The North Pacific. Nature 340 (6231), 296-298.

21. Huntley, D.J., Baril, M.R., 1997. The K content of the K-feldspars being measured in optical dating or in thermoluminescence dating. Anc. TL 15, 11-13.

22. Kang, S., Roberts., H. M., Wang, X., An, Z., Wang, M., 2015. Mass accumulation rate changes in Chinese loess during MIS 2, and asynchrony with records from Greenland ice cores and North Pacific Ocean sediments during the Last Glacial Maximum. Aeolian Research 19B, 251-258.

23. Kohfeld, K. E., Harrison, S.P., 2003. Glacial-interglacial changes in dust deposition on the Chinese Loess Plateau. Quaternary Science Reviews 22, 1859-1878.

24. Kukla, G., 1987. Loess stratigraphy in Central China. Quaternary Science Reviews 6, 191219. 
25. Kukla, G., An, Z., 1989. Loess stratigraphy in Central China. Palaeogeography Palaeoclimatolology Palaeoecology 72, 203-225.

26. Liu, T.S., 1985. Loess and Environment. China Ocean Press: Beijing.

27. Liu, T.S., Ding, Z.L., 1993. Stepwise coupling of monsoon circulations to global ice volume variations during the late Cenozoic. Global and Planetary Change 7, 119-130.

28. Lowick, E.S., Preusser, F., 2011. Investigating age underestimation in the high dose region of optically stimulated luminescence using fine grain quartz. Quaternary Geochronology 6,334.

29. Lu, H.Y., Liu, X.D., Zhang, F., An, Z.S., Dodson, J., 1999. Astronomical calibration of loess paleosol deposits at Luochuan, central Chinese Loess Plateau. Palaeogeography Palaeoclimatolology Palaeoecology 154, 237-246.

30. Lu, H., Sun, D., 2000. Pathways of dust input to the Chinese Loess Plateau during the last glacial and interglacial periods. Catena 40, 251-261.

31. Marković, S.B., Bokhorst, M., Vandenberghe, J., Oches, E.A., Zöller, L., McCoy, W.D., Gaudenyi, T., Jovanović, M., Hambach, U., Machalett, B., 2008. Late Pleistocene loesspaleosol sequences in the Vojvodina region, North Serbia. Journal of Quaternary Science 23, $73-84$.

32. Marković, S. B. Hambach, U., Catto, N., Jovanović, M., Buggle, B., Machalett, B., Zöller, L., Glaser, B. Frechen, M., 2009. The middle and late Pleistocene loess-paleosol sequences at Batajanica, Vojvodina, Serbia. Quaternary International 198, 255-266.

33. Marković, S., Hambach, U., Stevens, T., Jovanović, M., O`Hara-Dhand, K., Basarin, B., Lu, H., Smalley, I., Buggle, B., Zech, M., Svirčev, Z., Sümegi, P., Milojković, N., Zöller, L., 2012. Loess in the Vojvodina region (Northern Serbia): an essential link between European and Asian Pleistocene environments. Netherlands Journal of Geosciences, Geol. Mijnbouw 91, $173-188$. 
34. Marković, S.B., Hambach, U., Stevens, T., Kukla, G., Hellere, F., McCoy, W.D., Oches, E.A., Buggle, B., Zöller, L., 2011. The last million years recorded at the Stari Slankamen (Northern Serbia) loess-palaeosol sequence: revised chronostratigraphy and long-term environmental trends. Quaternary Science Reviews, 30, 9-10, 1142-1154.

35. Marković, S.B., Stevens, T., Kukla, G. J., Hambach, U., Fitzsimmons, K. E., Gibbard, P., Buggle, B., Zech, M., Guo, Z. , Qingzhen, H., Haibin, W., Dhand, O. K., Smalley, I. J., Gábor, U., Sümegi, P., Timar-Gabor, A., Veres, D., Sirocko, F., Vasiljević, D. A., Jary, Z., Svensson, A., Jović, V., Lehmkuhl, F., Kovács, J., Svirčev, Z., 2015. Danube loess stratigraphy - Towards a pan-European loess stratigraphic model. Earth Science Reviews 148, 228-258.

36. Meyers, S.R., 2014. Astrochron: An R Package for Astrochronology, Version 0.7. https://cran.r-project.org/package=astrochron.

37. Muhs, D. R., 2007. Loess deposits, origins and properties. Encyclopedia of Quaternary Science, $1405-1418$.

38. Murray, A. S., Marten, R., Johnston, A. \& Martin, P., 1987. Analysis for naturally occurring radionuclides at environmental concentrations by gamma spectrometry. Journal of Radioanalytical and Nuclear Chemistry 115, 263-288.

39. Murray, A.S. and Wintle, A.G., 2000. Luminescence dating of quartz using an improved single-aliquot regenerative-dose protocol. Radiation Measurements 32, 57-73.

40. Murray, A. S. \& Wintle, A. G., 2003. The single aliquot regeneration dose protocol: potential for improvements in reliability. Radiation Measurements 37, 377-381.

41. Obreht, I., Zeeden, C., Hambach, U., Veres, D., Marković, S.B., Bösken, J., Svirčev, Z., Bačević, N., Gavrilov, M.B., Lehmkuhl, F., 2016. Tracing the influence of Mediterranean climate on Southeast Europe during the past 350,000 years. Scientific Reports 6, 36334.

42. Obreht, I., Hambach, U., Veres, D., Zeeden, C., Bösken, J., Stevens, T., Marković, S.B., Klasen, N., Brill, D., Burow, C., Lehmkuhl, F., 2017. Shift of large-scale atmospheric systems 
over Europe during late MIS 3 and implications for Modern Human dispersal. Scientific Reports 7, 58-48.

43. Porter, S.C., 2001. Chinese loess record of monsoon climate during the last glacialinterglacial cycle. Earth Science Reviews 54, 115-128.

44. Prescott, J.R. and Hutton, J.T., 1994: Cosmic ray contributions to dose rates for luminescence and ESR dating: large depths and long-term time variations. Radiation Measurements 23, 497-500.

45. Rasmussen, S.O., Bigler, M., Blockley, S.P., Blunier, T., Buchardt, S.L., Clausen, H.B., Cvijanovic, I., Dahl-Jensen, D., Johnsen, S. J., Fischer, H., Gkinis, V., Guillevic, M., Hoek, W.Z., Lowe, J. J., Pedro, J. B., Popp, T., Seierstad, I.K., Steffensen, J. P., Svensson, A. M., Vallelonga, P., Vinther, B.M., Walker, M.J.C., Wheatley, J.J., Winstrup, M., 2014. A stratigraphic framework for abrupt climatic changes during the Last Glacial period based on three synchronized Greenland ice-core records: refining and extending the INTIMATE event stratigraphy. Quaternary Science Reviews 106, 14-28.

46. Rees-Jones, J., 1995. Optical dating of young sediments using fine-grain quartz. Ancient TL 13, 9-14.

47. Roberts, H.M., 2007. Assessing the effectiveness of the double-SAR protocol in isolating a luminescence signal dominated by quartz. Radiation Measurements 42, 1627-1636.

48. Roberts, H.M., Wintle, A.G., 2001. Equivalent dose determinations for polymineralic finegrains using the SAR protocol: application to a Holocene sequence of the Chinese Loess Plateau. Quaternary Science Reviews (Quaternary Geochronology) 20, 859-863.

49. Roberts H.M., 2008. The development and application of luminescence dating to loess deposits: a perspective on the past, present and future. Boreas 37, 483-507.

50. Rousseau, D.D., Antoine, P., Hatté, C., Lang, A., Zöller, L., Fontugne, M., Othman, D.B., Luck, J.M., Moine, O., Labonne, M., Bentaleb, I., Jolly, D., 2002. Abrupt millennial climatic 
changes from Nussloch (Germany) Upper Weichselian eolian records during the Last Glaciation. Quaternary Science Reviews 21, 1577-1582.

51. Ruth, U., Bigler, M., Röthlisberger, R., Siggaard-Andersen, M.-L., Kipfstuhl, S., GotoAzuma, K., Hansson, M. E., Johnsen, S. J., Lu, H., Steffensen, J. P., 2007. Ice core evidence for a very tight link between North Atlantic and East Asian glacial climate. Geophysical Research Letters 34, L03706.

52. Rutter, N., Ding, Z. L., Evans, M. E., Liu, T., 1991. Baoji-type pedostratigraphic section, Loess Plateau, north-central China. Quaternary Science Reviews 10, 1-22.

53. R Core Team, 2017. R: A Language and Environment for Statistical Computing.

54. Schmidt, E.D., Machalett, B., Marković, S.B., Tsukamoto, S., Frechen, M., 2010. Luminescence chronology of the upper part of the Stari Slankamen loess sequence (Vojvodina, Serbia). Quaternary Geochronology 5, 137-142.

55. Singhvi, A.K., Bronger, A., Sauer, W., Pant, R.K., 1989. Thermoluminescence dating of loess - paleosol sequences in the Carpathian basin (East-Central Europe): A suggestion for a revised chronology. Chemical Geology 73, 307-317.

56. Stevens, T., Marković, S.B., Zech, M., Hambach, U., Sümegi, P., 2011. Dust deposition and climate in the Carpathian Basin over an independently dated last glacial-interglacial cycle. Quaternary Science Reviews 30, 662-681.

57. Stevens, T., Adamiec, G., Bird, A.F., Lu, H., 2013. An abrupt shift in dust source on the Chinese Loess Plateau revealed through high sampling resolution OSL dating. Quaternary Science Reviews 82, 121-132.

58. Stevens, T., Buylaert, J.P., Lu, H., Thiel, C., Murray, A., Frechen, M., Yi, S., Zeng, L., 2016. Mass accumulation rate and monsoon records from Xifeng, Chinese Loess Plateau, based on a luminescence age model. Journal of Quaternary Science 31, 391-405. 
59. Taner, M.T., 1992, in: Attributes revisited (Technical Report, Rock Solid Images, Inc), url: http://www.rocksolidimages.com/attributes-revisited/\#_Toc328470897.

60. Trandafir, O., Timar-Gabor, A., Schmidt, C., Veres, D., Anghelinu, M., Hambach, U., Simon, S., 2015. OSL dating of fine and coarse quartz from a Palaeolithic sequence on the Bistrita Valley (Northeastern Romania). Quaternary Geochronology 30, 487-492.

61. Újvári, G., Molnar, M., Novothny, A., Pall-Gergely, B., Kovacs, J., Varhegyi, A., 2014. AMS 14C and OSL/IRSL dating of the Dunaszekcso loess sequence (Hunagry): chronology for 20 to $150 \mathrm{ka}$ and implications for establishing reliable age-depth models for the last $40 \mathrm{ka}$. Quaternary Science Reviews 106, 140-154.

62. Újvári, G., Kovács, J., Varga, G., Raucsik, B., Marković, S.B., 2010. Dust flux estimates for the Last Glacial Period in East Central Europe based on terrestrial records of loess deposits: a review. Quaternary Science Reviews 29, 3157-3166.

63. Újvári, G., Stevens, T., Molnar, M., Demény, A., Lambert, F., Varga, G., Jull, A.J.T., PállGergely, B., Buylaert, J.P., Kovács, J., 2017. Coupled European and Greenland last glacial dust activity driven by North Atlantic climate. Proceedings of the National Academy of Sciences 114, E10622-E10631.

64. Vandenberghe, D., De Corte, F., Buylaert, J.-P., Kučera, J., Van den haute, P. 2008. On the internal radioactivity in quartz. Radiation Measurements, 43, 771-775.

65. Zeeden, C., Hambach, U., Veres, D., Fitzsimmons, K., Obreht, I., Bösken, J., Lehmkuhl, F., in press. Millennial scale climate oscillations recorded in the Lower Danube loess over the last glacial period. Palaeogeography, Palaeoclimatology, Palaeoecology. doi.org/10.1016/j.palaeo.2016.12.029. 
66. Zeeden, C., Dietze, M., Kreutzer, S., 2018. Discriminating luminescence age uncertainty composition for a robust Bayesian modelling. Quaternary Geochronology 43, 30-39. doi.org/10.1016/j.quageo.2017.10.001.

\section{Figure Captions}

Figure 1. Eurasian loess distribution (yellow). The locations of the two studied sites are marked with red crosses. Revised from Muhs et al. (2007).

Figure 2. Location of the study site and distribution of loess in Serbia. The drilling site is located 100 m from Veliki Surduk gully site, marked with a red cross (see text for details). Revised from Marković et al. (2008).

Figure 3. Location of the main loess sites in China (black circles). The Lingtai section is marked with the red star. Revised from Buylaert et al. (2015).

Figure 4. (A) Representative natural blue-light stimulated luminescence decay curve for sample 168124 from the Titel loess core (depth $3455 \mathrm{~cm}$ ). The inset shows the same data together with a decay curve of Risø calibration quartz (Hansen et al., 2015; dashed line), both curves are normalised to their initial intensity and are nearly identical. (B) representative natural bluelight stimulated luminescence decay curve for sample H18127 from the Lingtai loess section (depth $320 \mathrm{~cm}$ ). The inset shows the same data together with a decay curve of Risø calibration quartz (dashed line), both curves are normalised to their initial intensity. (C) representative SAR dose response curve for sample 168113 (depth $66.5 \mathrm{~cm}$ ). The recycled point is represented with an open triangle and the zero dose point with an open circle. (D) representative SAR dose response curve for sample H18121 (depth $260 \mathrm{~cm}$ ). The recycled point is represented with an open triangle and the zero dose point with an open circle. 
Figure 5. Equivalent dose as a function of first preheat temperature for sample 168122. (A) Three aliquots were used per preheat temperature and the error bars represent 1 standard error. The dashed line is drawn at the average $D_{e}$ of the aliquots measured with preheat temperatures between 160 and $280^{\circ} \mathrm{C}$. (B) Recycling ratios and recuperation as a function of preheat temperature for the same aliquots as in (A). A dashed line is drawn at an ideal recycling ratio of 1.0. Equivalent dose as a function of preheat temperature for sample H18116. (C) Three aliquots were used per preheat temperature and the error bars represent 1 standard error. The dashed line is drawn at the mean $D_{e}$ of the aliquots measured with preheat temperatures between 220 and $300^{\circ} \mathrm{C}$. (D) Recycling ratios and recuperation as a function of preheat temperature for the same aliquots as in (C). A dashed line is drawn at an ideal recycling ratio of 1.0 .

Figure 6. Results of dose recovery test on sample 168139. Six aliquots were measured per dose point. Error bars represent one standard error.

Figure 7. Histogram of the dose recovery ratio for samples from the Titel loess plateau (A) and the Lingtai loess section (B). $n$ represents the number of aliquots.

Figure 8. OSL ages from the Titel loess core plotted against the magnetic susceptibility record measured on the same core (TLP-1). Magnetic susceptibility was measured in $2 \mathrm{~cm}$ intervals just after the cores were split using an MS3 Magnetic Susceptibility Meter (MS2E Core Logging Sensor) from Bartington Instruments. The dashed lines represent the boundaries of the investigated stratigraphic units. The red solid line represents the proposed reliable age limit for quartz dating at the site.

Figure 9. OSL ages from the Lingtai loess section plotted against the low frequency magnetic susceptibility record (sampling in $5 \mathrm{~cm}$ intervals) from the same site. The dashed lines represent 
the boundaries of the investigated stratigraphic units. The red solid line represents the proposed reliable age limit for quartz dating at this site.

Figure 10. Age modelling results and OSL ages from A), C) Titel and B), D) Lingtai. A) and B) show results of Bayesian modelling using the Bacon model of Blaauw and Christen (2011). The results are based on over 15 and 19 million Monte Carlo iterations and yield mean 95\% confidence age ranges of 2257 and 2199 a for Titel and Lingtai, respectively. Top panel: Time series of the log-posterior for the sub-sampled MCMC (left), prior (green) and posterior (gray) for accumulation rates with priors acc.shape $=1.5$ and acc. mean $=100$ (center) and prior and posterior for the memory (right), mem.strength $=4$ and mem.mean $=0.7$. C) and D) show results of an age-depth modelling method proposed for specifically treating luminescence data (Zeeden et al., 2018). The original data and uncertainty are plotted as diamonds with error bars, with age estimates shown as a dark line,1-sigma uncertainty as dark grey shade, and 2-sigma uncertainty as lighter grey shade. Mean age and uncertainty were linearly interpolated between the age depth points used in the modelling.

Figure 11. Dust Mass Accumulation Rate (MAR) as a function of age at the sites. A) MAR values for Titel obtained via the Bacon model (blue line) and by the smoothed (orange) and unsmoothed (grey) model of Zeeden et al. (2018). Note the results from the Zeeden et al. (2018) model are plotted on a separate y-axis (right hand side) for clarity; B) Same as in A) but for Lingtai MAR results; C) MAR values from the Bacon model from Titel (red line) and Lingtai (black line) plotted against MAR values from Xifeng (grey line) obtained by Stevens et al. (2016) using linear regression and relative MAR changes from the Chinese Loess Plateau (yellow line) indicated by the relative frequency of quartz OSL age from 15 sites, as summarized in Kang et al. (2015); D) same as C) but MAR results from the smoothed model of Zeeden et al. (2018). 


\section{Table Captions}

Table 1. Position of unit boundaries and thickness of stratigraphic units at the Veliki Surduk coring site and the Lingtai section.

Table 2. Summary of depth information, sample codes, dry beta and gamma dose rates, radionuclide activities, total dose rates, weighted mean $D e$ values and luminescence ages for the Titel samples. The grain size range of extracted quartz was $63-90 \mu \mathrm{m}$ for all samples except for samples $168110,168117,168121$ and $168122(40-63 \mu \mathrm{m}) . n$ represents the number of aliquots. Error terms are given as 1 standard error.

Table 3. Summary of depth information, sample codes, dry alpha, beta and gamma dose rates, radionuclide concentrations, total dose rates, weighted mean $D_{e}$ values and luminescence ages for the Lingtai section. Grain size range of quartz extract was $4-11 \mu \mathrm{m}$ for all samples. $n$ represents the number of aliquots. Error terms are given as 1 standard error. 


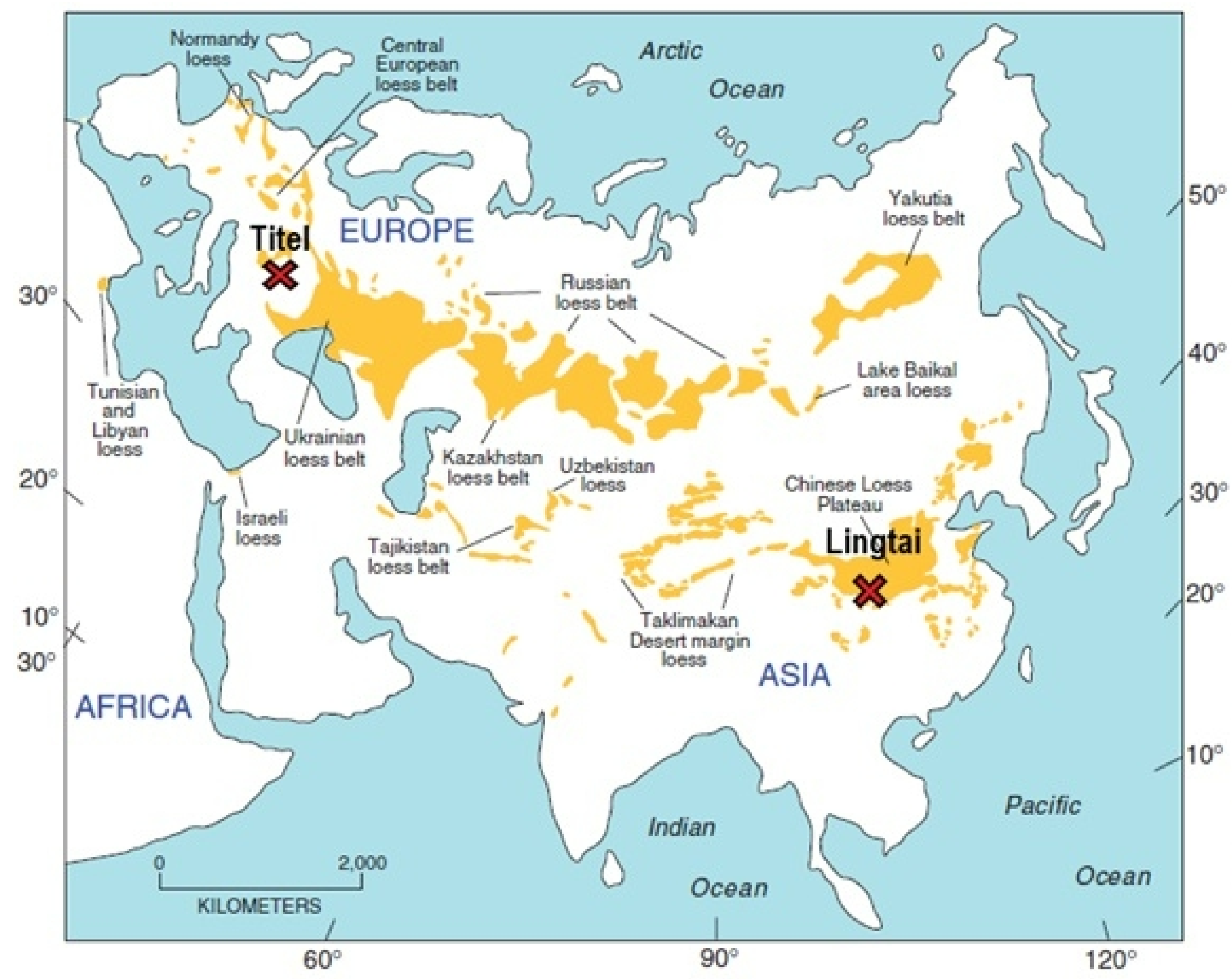




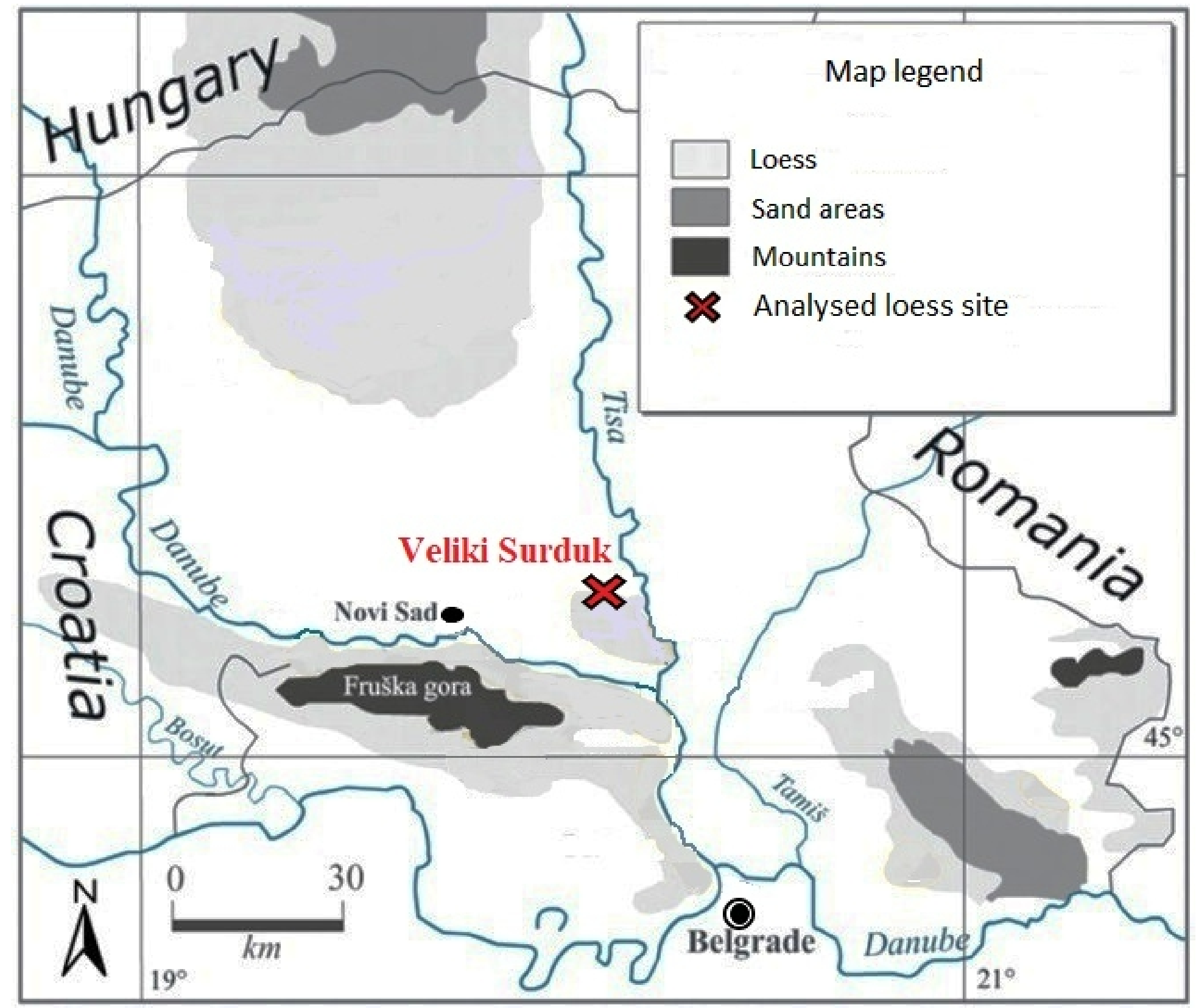




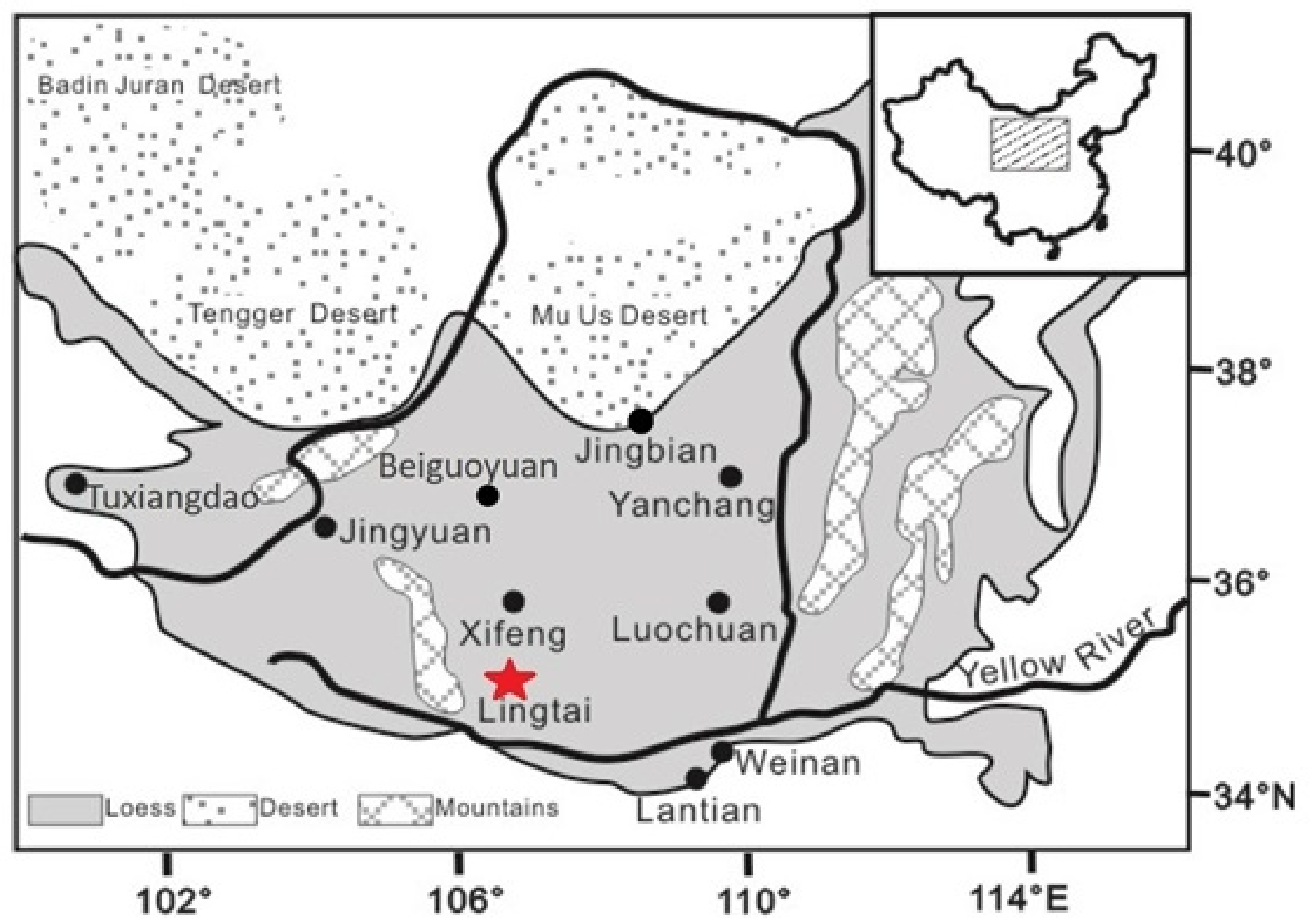


(A)

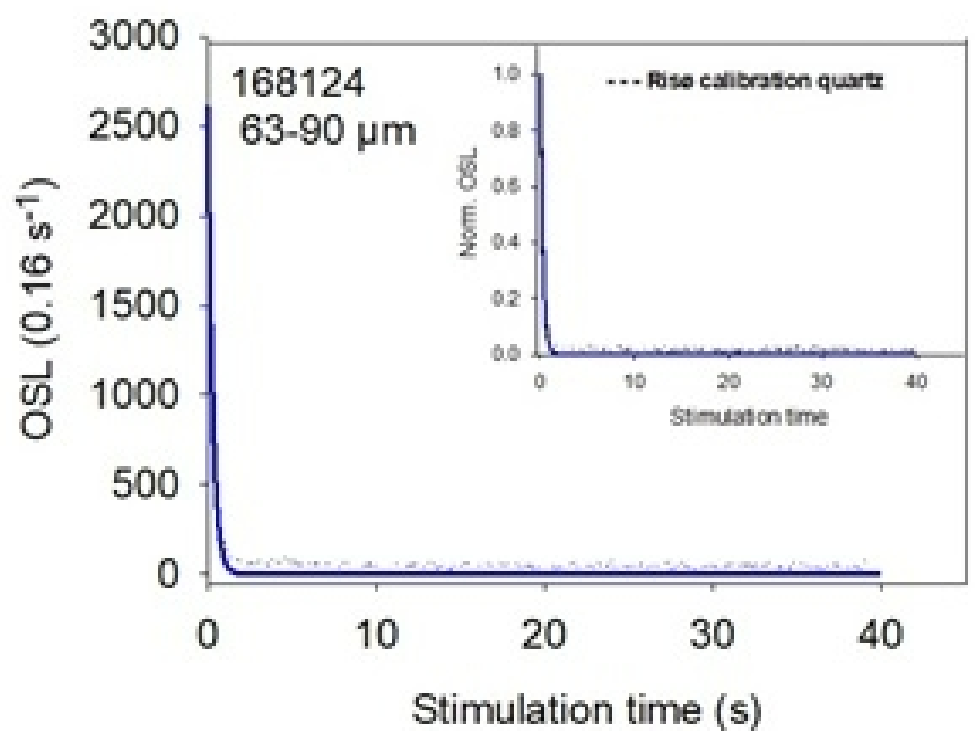

(C)

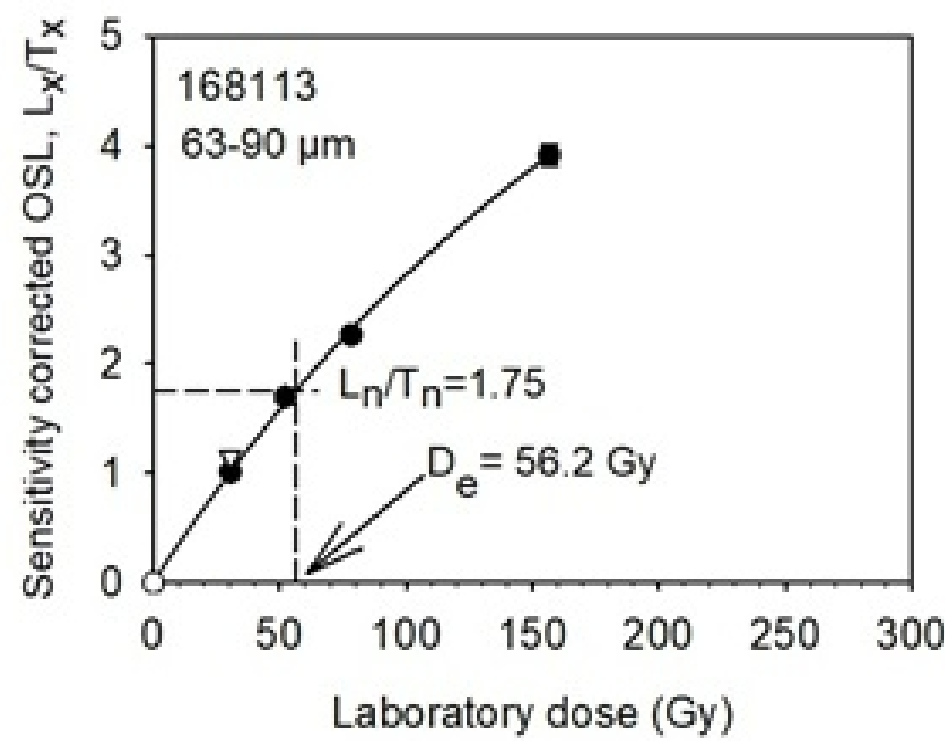

(B)

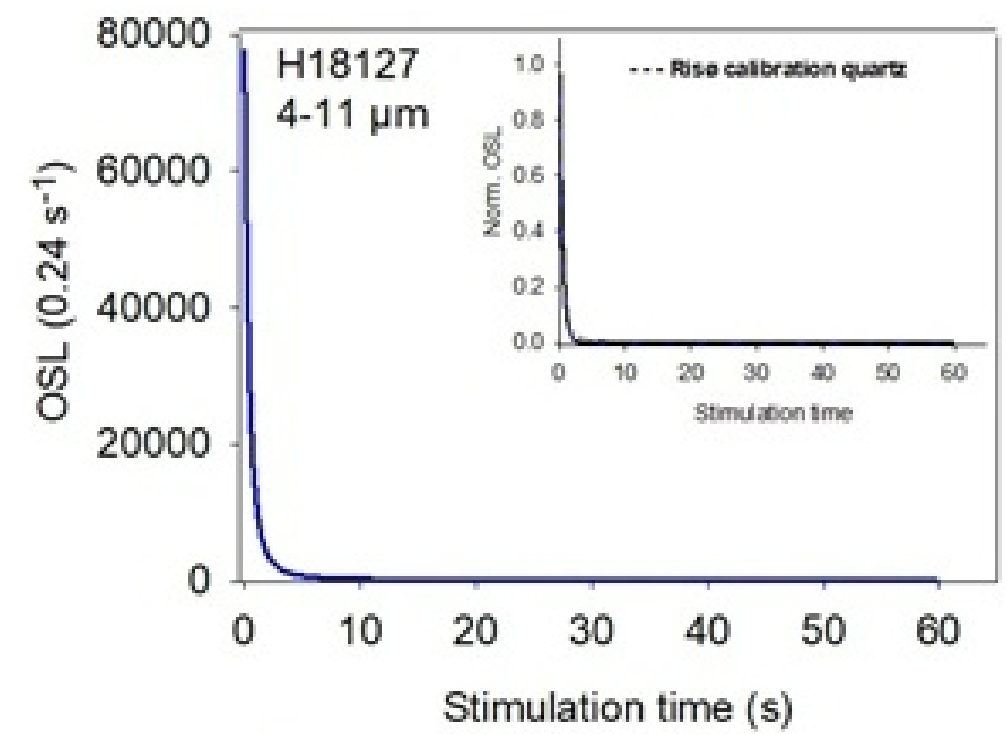

(D)

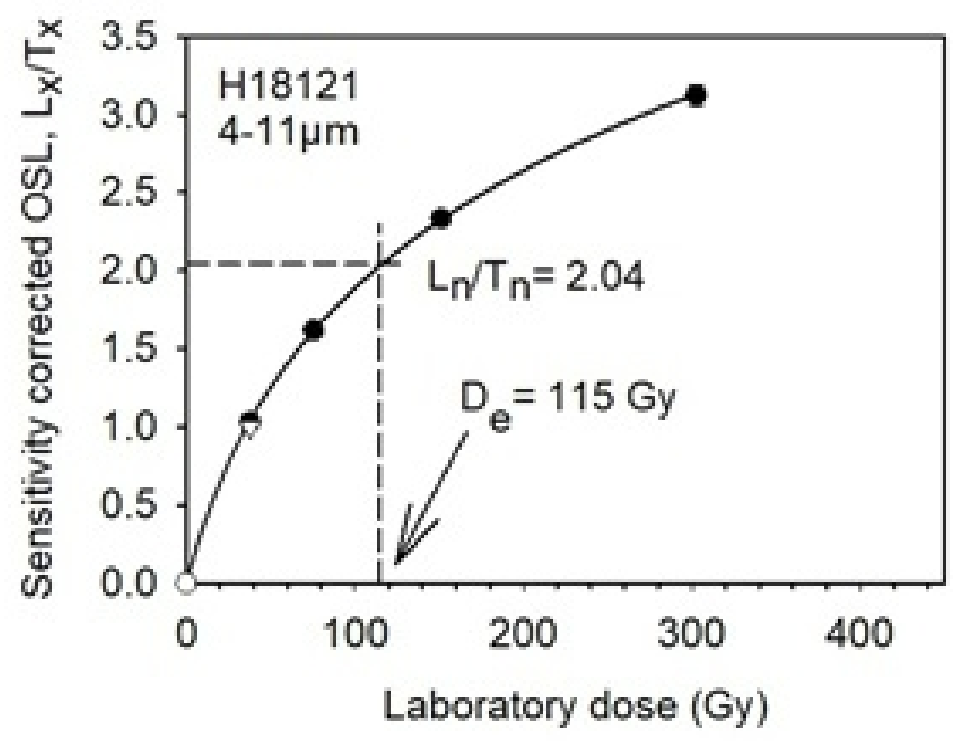



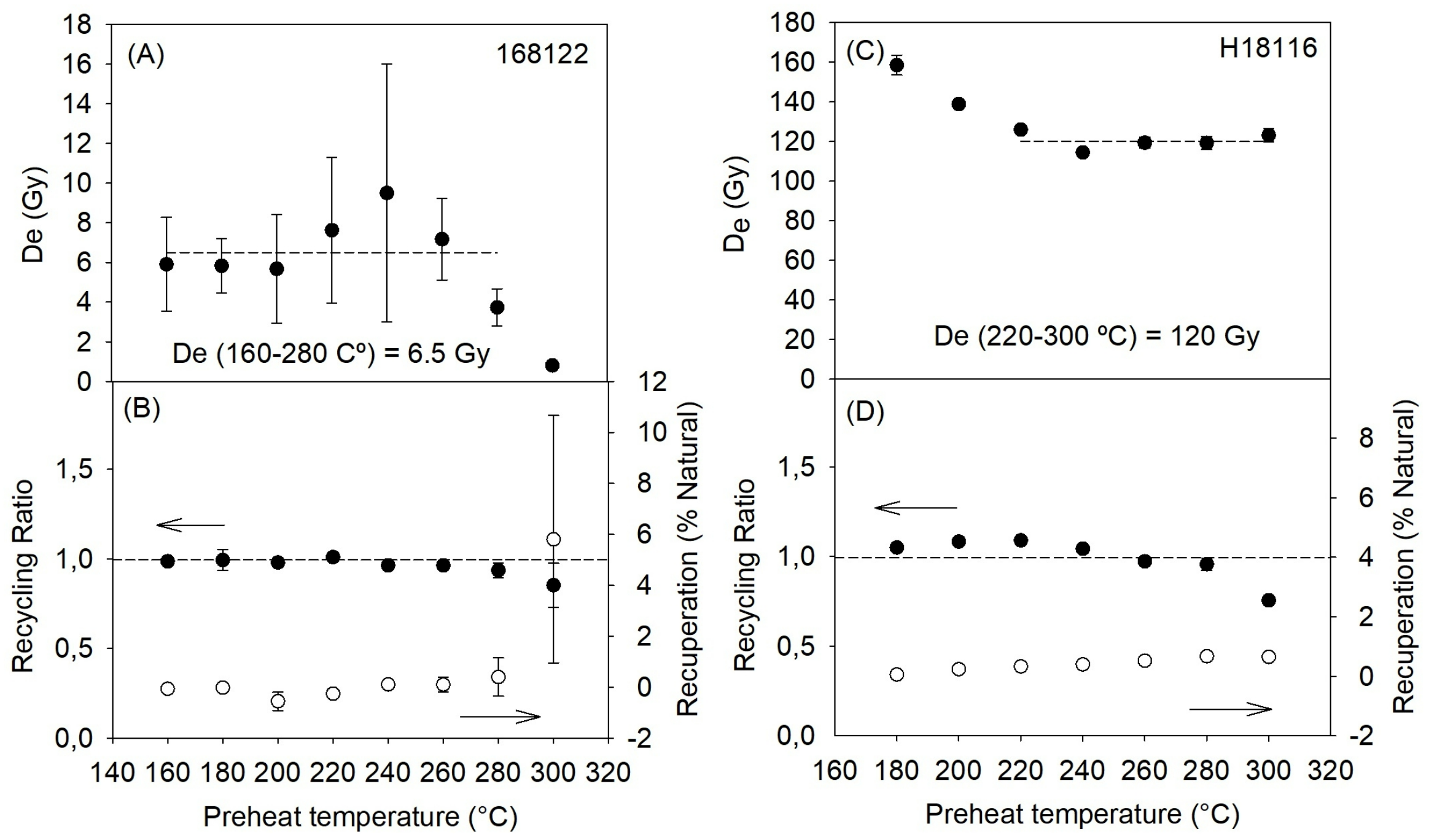


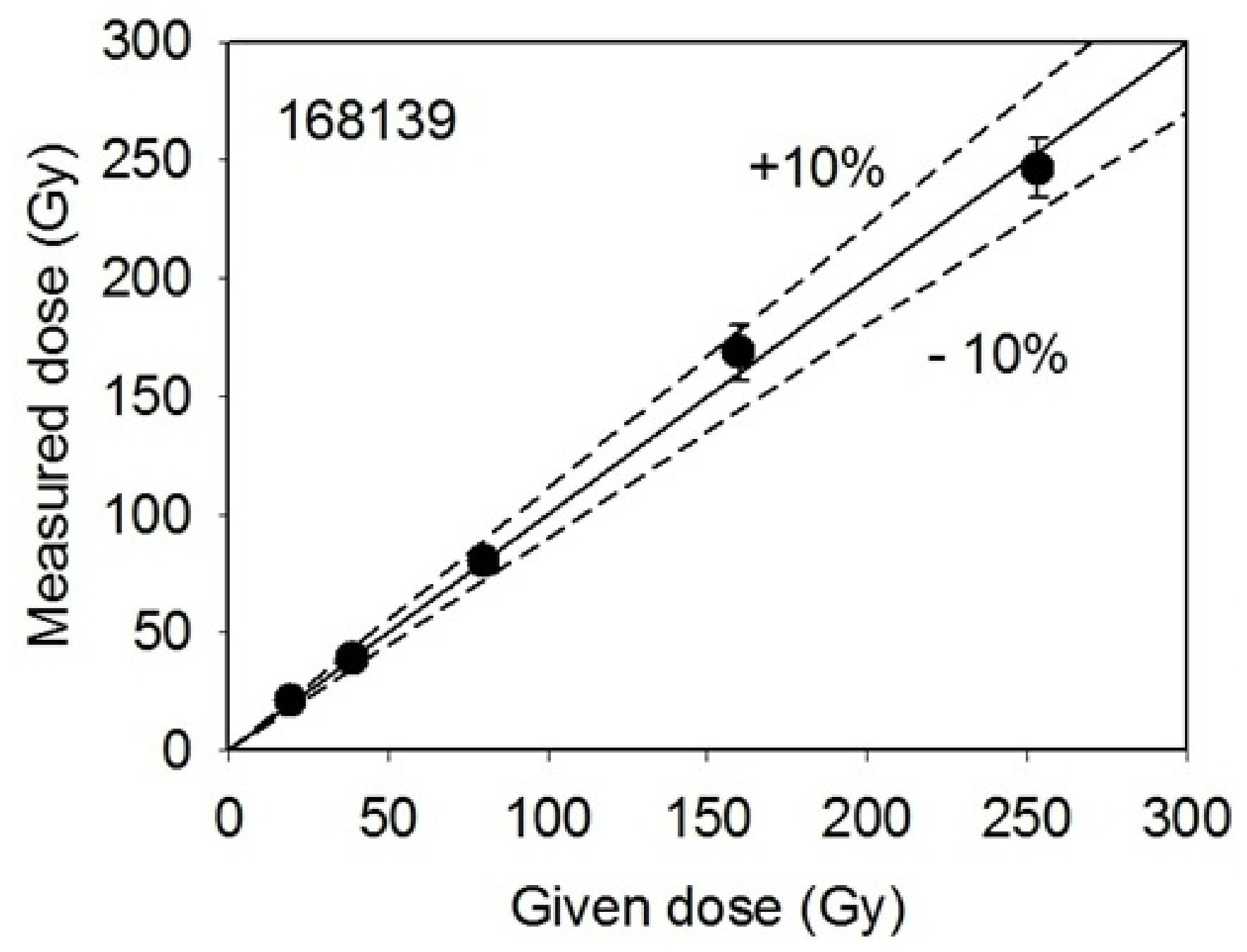



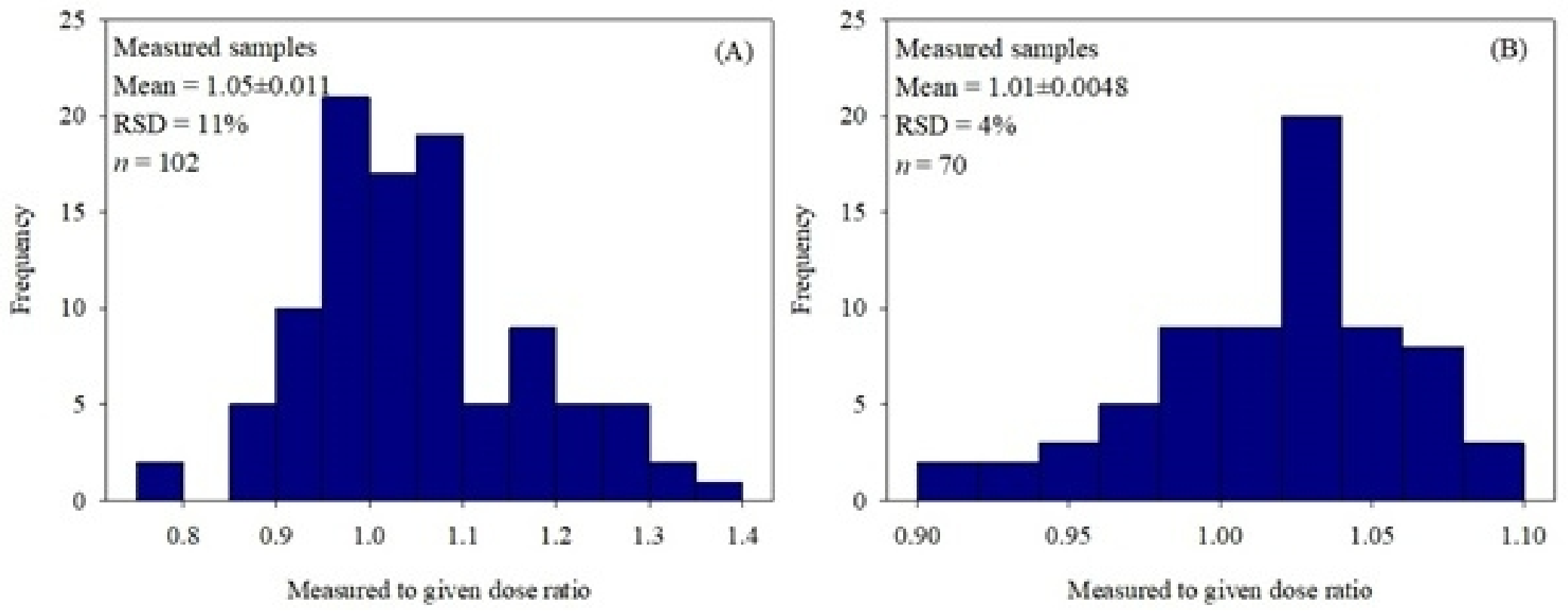


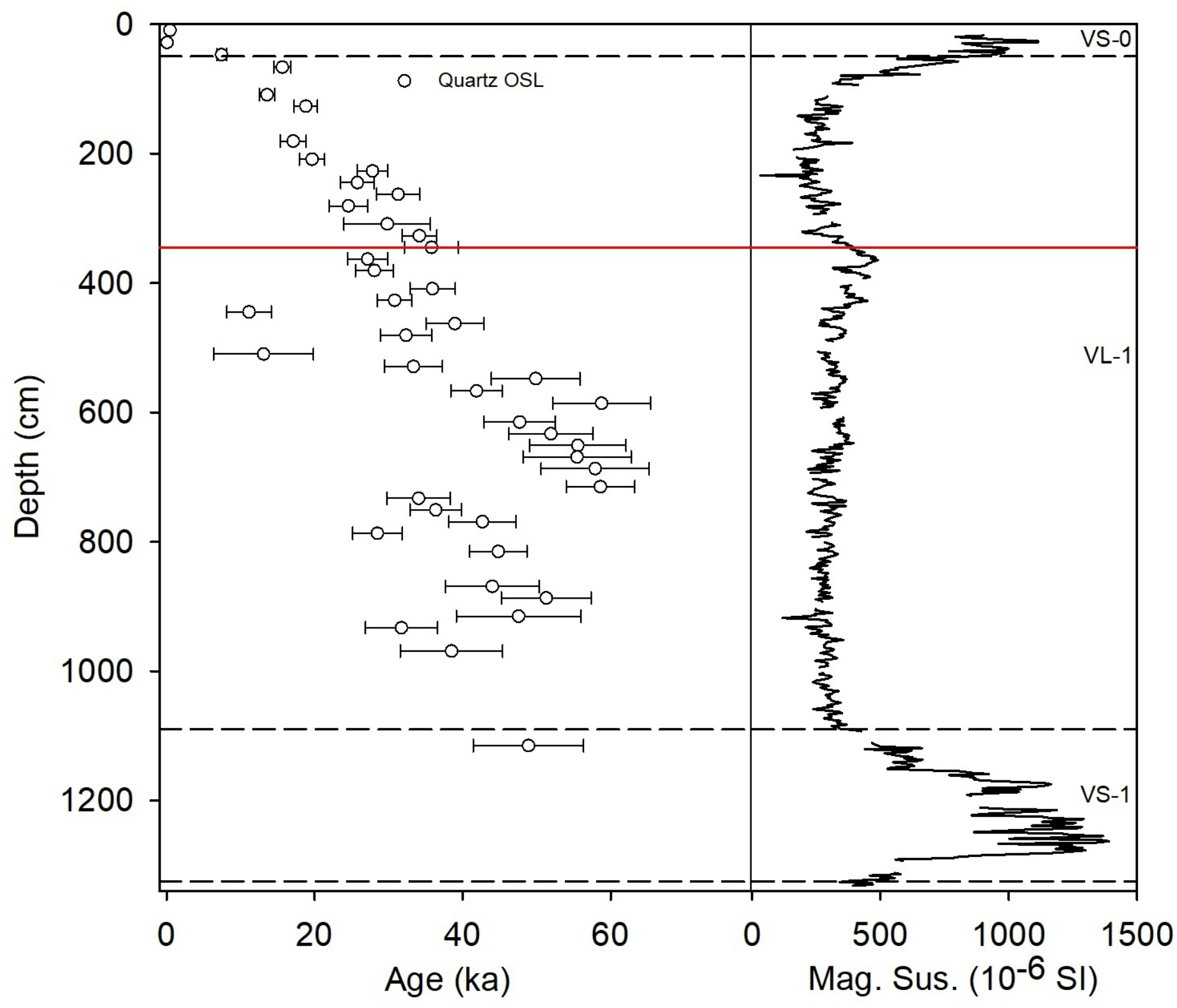




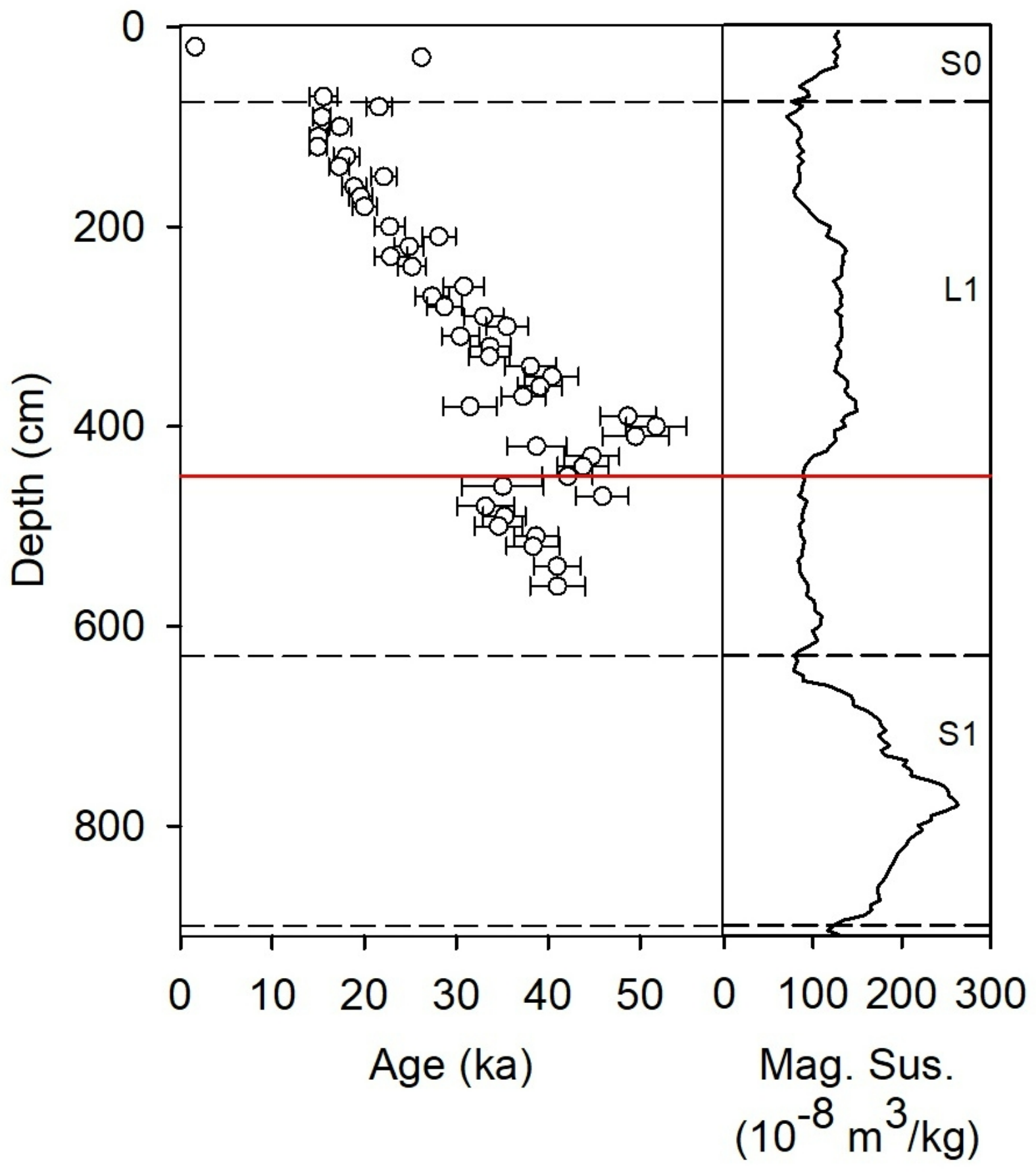



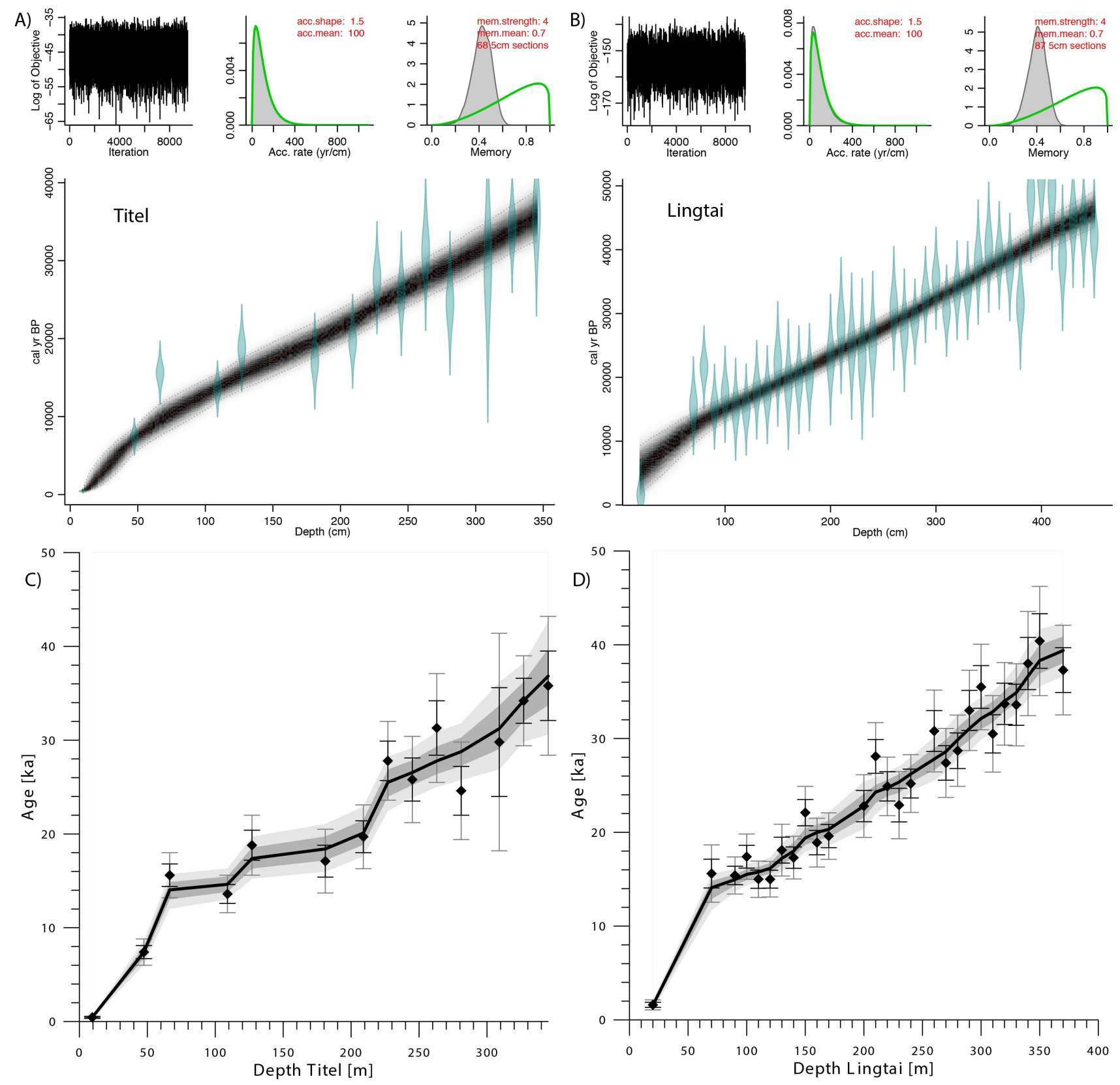

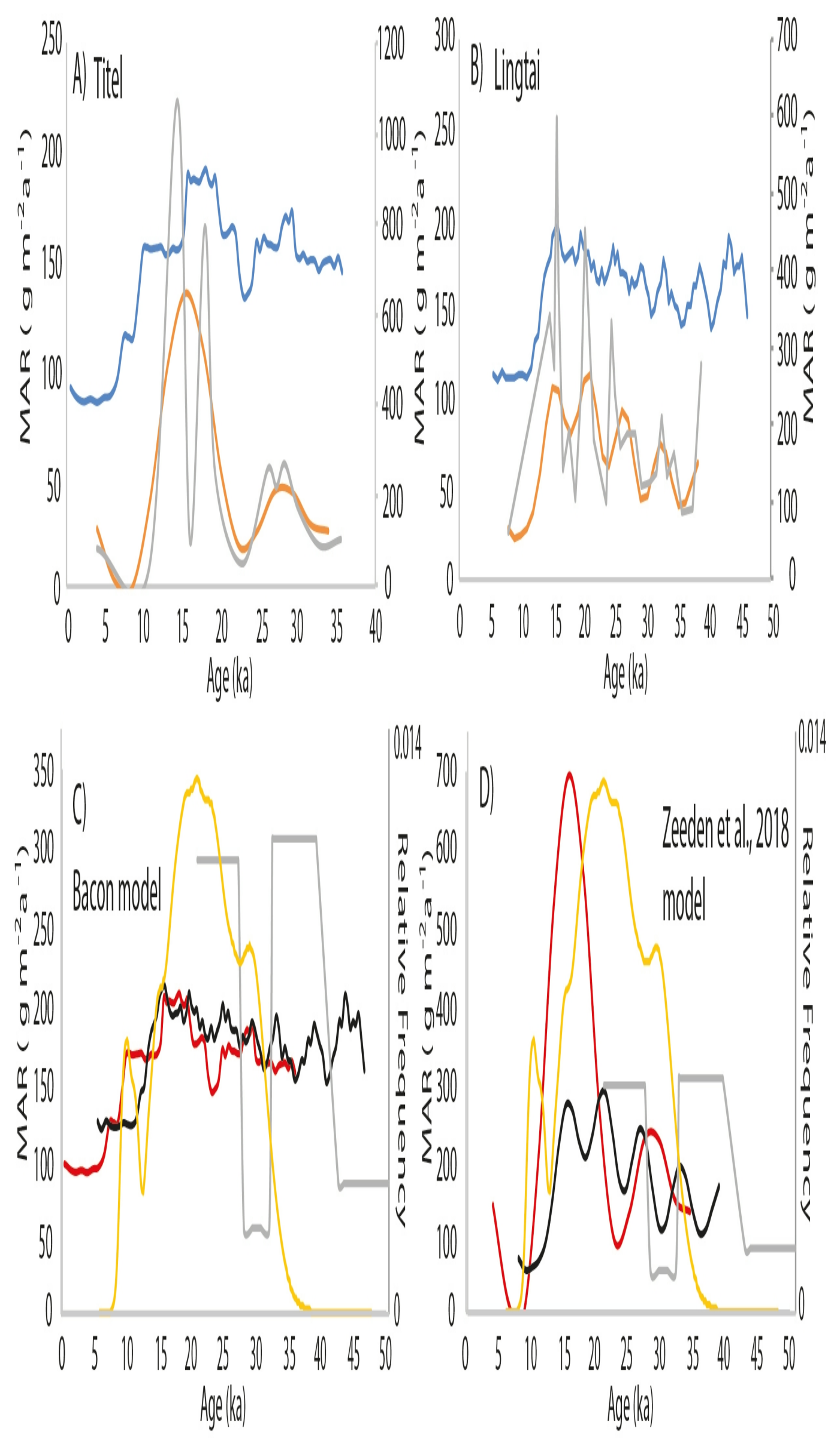


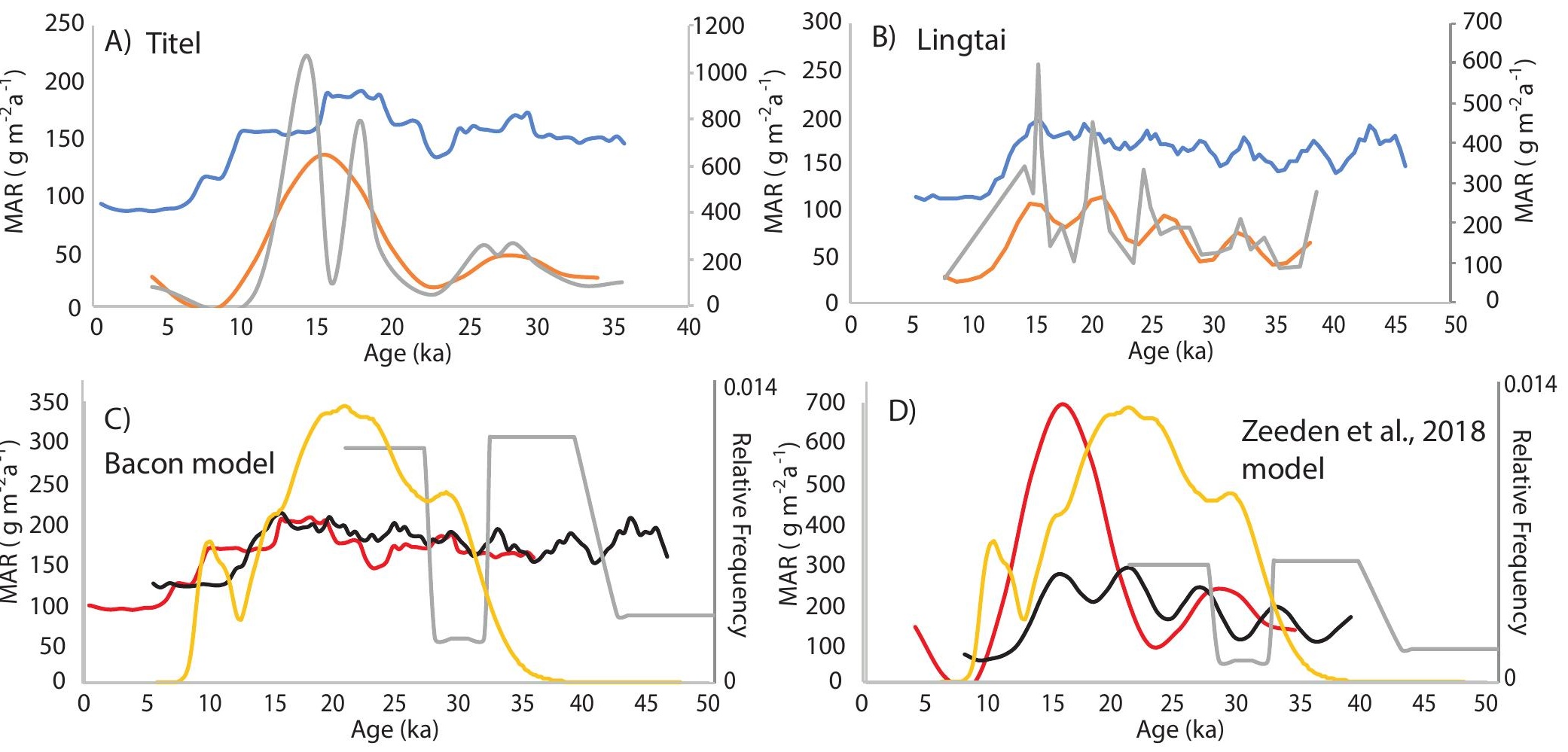


Table 1. Position of unit boundaries and thickness of stratigraphic units at the Veliki Surduk coring site and the Lingtai section.

\begin{tabular}{|c|c|c|c|c|c|}
\hline \multicolumn{2}{|l|}{ Stratigraphic unit } & \multicolumn{2}{l|}{ Upper/lower boundary (m) } & \multicolumn{2}{l|}{ Thickness (m) } \\
\hline Titel & Lingtai & Titel & Lingtai & Titel & Lingtai \\
\hline S0 & S0 & $0.00 / 0.60$ & $0.00 / 0.75$ & 0.60 & 0.75 \\
\hline L1 & L1 & $0.60 / 10.90$ & $0.75 / 6.30$ & 10.30 & 5.55 \\
\hline L1LL1 & L1LL1 & $0.60 / 3.15$ & $0.75 / 2.20$ & 2.55 & 1.45 \\
\hline L1SSX & L1SS1 & $3.15 / 7.60$ & $2.20 / 4.20$ & 4.45 & 2.00 \\
\hline L1LL2 & L1LL2 & $7.60 / 10.90$ & $4.20 / 6.30$ & 3.30 & 2.10 \\
\hline S1 & S1 & $10.90 / 13.25$ & $6.30 / 9.00$ & 2.35 & 2.70 \\
\hline
\end{tabular}


Table 2. Summary of depth information, sample codes, dry beta and gamma dose rates, radionuclide activities, total dose rates, weighted mean De values and luminescence ages for the Titel samples. The grain size range of extracted quartz was $63-90 \mu \mathrm{m}$ for all samples except for samples $168110,168117,168121$ and 168122 (40-63 $\mu \mathrm{m}) . n$ represents the number of aliquots. Error terms are given as 1 standard error.

\begin{tabular}{|c|c|c|c|c|c|c|c|c|c|c|c|c|}
\hline $\begin{array}{c}\text { Depth } \\
\text { (cm) }\end{array}$ & $\begin{array}{c}\text { Sample } \\
\text { code }\end{array}$ & $\begin{array}{c}\text { Beta } \square \\
\left(\text { Gy ka }^{-1}\right)\end{array}$ & $\begin{array}{c}\text { Gamma } \square \\
\left(\mathbf{G y ~ k a}^{-1}\right)\end{array}$ & $\begin{array}{c}{ }^{238} \mathrm{U} \\
\left(\mathrm{Bq} \mathrm{kg}^{-1}\right)\end{array}$ & $\begin{array}{c}{ }^{226} \mathrm{Ra} \\
\left(\mathrm{Bq} \mathrm{kg} \mathrm{kg}^{-1}\right)\end{array}$ & $\begin{array}{c}{ }^{210} \mathrm{~Pb} \\
\left(\mathrm{~Bq} \mathrm{~kg} \mathrm{~kg}^{-1}\right)\end{array}$ & $\begin{array}{c}{ }^{232} \mathrm{Th} \\
\left.(\mathrm{Bq} \mathrm{kg})^{-1}\right)\end{array}$ & $\begin{array}{c}{ }^{40} \mathrm{~K} \\
\left(\mathrm{~Bq} \mathrm{~kg}^{-1}\right)\end{array}$ & $\begin{array}{c}\text { Total } \square \\
\left(\text { Gy ka }^{-1}\right)\end{array}$ & $D_{e}(\mathrm{~Gy})$ & $n$ & Age (ka) \\
\hline 9.5 & 168110 & $2.01 \pm 0.03$ & $1.44 \pm 0.04$ & $34 \pm 4$ & $41.7 \pm 0.7$ & $59 \pm 5$ & $45 \pm 0.8$ & $501 \pm 10$ & $3.25 \pm 0.16$ & $1.4 \pm 0.2$ & 10 & $0.4 \pm 0.1$ \\
\hline 28.5 & 168111 & $1.71 \pm 0.02$ & $1.18 \pm 0.03$ & $26 \pm 3$ & $39.0 \pm 0.6$ & $42 \pm 3$ & $40 \pm 0.5$ & $442 \pm 8$ & $2.72 \pm 0.13$ & & & \\
\hline 47.5 & 168112 & $1.65 \pm 0.08$ & $1.15 \pm 0.04$ & $29 \pm 18$ & $41.6 \pm 1.3$ & & $44 \pm 1.4$ & $443 \pm 18$ & $2.63 \pm 0.15$ & $19.5 \pm 1.3$ & 26 & $7.4 \pm 0.7$ \\
\hline 66.5 & 168113 & $1.50 \pm 0.02$ & $1.03 \pm 0.02$ & $29 \pm 2$ & $34.6 \pm 0.4$ & $35 \pm 3$ & $37 \pm 0.4$ & $384 \pm 7$ & $2.38 \pm 0.11$ & $37.3 \pm 2.0$ & 26 & $15.6 \pm 1.2$ \\
\hline 109 & 168114 & $1.51 \pm 0.06$ & $1.06 \pm 0.03$ & $26 \pm 12$ & $37.6 \pm 1.0$ & & $41 \pm 0.9$ & $404 \pm 15$ & $2.71 \pm 0.14$ & $36.8 \pm 1.9$ & 26 & $13.6 \pm 1.0$ \\
\hline 127 & 168115 & $1.46 \pm 0.08$ & $1.05 \pm 0.04$ & $22 \pm 15$ & $37.5 \pm 1.2$ & & $41 \pm 1.0$ & $389 \pm 17$ & $2.34 \pm 0.13$ & $44.0 \pm 2.6$ & 24 & $18.8 \pm 1.6$ \\
\hline 181 & 168116 & $1.58 \pm 0.07$ & $1.05 \pm 0.03$ & $44 \pm 14$ & $37.5 \pm 1.0$ & & $39 \pm 1.1$ & $410 \pm 14$ & $2.43 \pm 0.13$ & $41.7 \pm 3.5$ & 24 & $17.1 \pm 1.7$ \\
\hline 209 & 168117 & $1.54 \pm 0.05$ & $1.07 \pm 0.03$ & $24 \pm 9$ & $37.3 \pm 0.8$ & & $41 \pm 0.8$ & $425 \pm 13$ & $2.43 \pm 0.13$ & $47.8 \pm 3.2$ & 24 & $19.7 \pm 1.7$ \\
\hline 227 & 168118 & $1.43 \pm 0.04$ & $1.00 \pm 0.03$ & $25 \pm 8$ & $34.1 \pm 0.6$ & & $39 \pm 0.6$ & $385 \pm 10$ & $2.25 \pm 0.11$ & $62.6 \pm 3.1$ & 17 & $27.8 \pm 2.1$ \\
\hline 245 & 168119 & $1.64 \pm 0.06$ & $1.13 \pm 0.03$ & $32 \pm 11$ & $38.4 \pm 0.9$ & & $44 \pm 0.8$ & $444 \pm 13$ & $2.54 \pm 0.13$ & $65.6 \pm 4.4$ & 24 & $25.8 \pm 2.3$ \\
\hline 263 & 168120 & $1.36 \pm 0.10$ & $0.98 \pm 0.03$ & $6 \pm 21$ & $32.4 \pm 1.6$ & & $38 \pm 1.4$ & $393 \pm 23$ & $2.17 \pm 0.14$ & $67.8 \pm 4.5$ & 24 & $31.3 \pm 2.9$ \\
\hline 281 & 168121 & $1.97 \pm 0.07$ & $1.32 \pm 0.04$ & $53 \pm 14$ & $46.5 \pm 1.0$ & & $50 \pm 1.1$ & $510 \pm 14$ & $3.00 \pm 0.16$ & $73.6 \pm 6.6$ & 18 & $24.6 \pm 2.6$ \\
\hline 309 & 168122 & $1.46 \pm 0.05$ & $0.98 \pm 0.03$ & $40 \pm 18$ & $34.7 \pm 1.4$ & & $37 \pm 1.2$ & $384 \pm 20$ & $2.26 \pm 0.12$ & $67.3 \pm 12.6$ & 6 & $29.8 \pm 5.8$ \\
\hline 327 & 168123 & $1.61 \pm 0.07$ & $1.11 \pm 0.04$ & $31 \pm 12$ & $37.9 \pm 1.0$ & & $43 \pm 1.0$ & $431 \pm 17$ & $2.48 \pm 0.13$ & $84.8 \pm 3.2$ & 39 & $34.2 \pm 2.4$ \\
\hline 345 & 168124 & $2.04 \pm 0.03$ & $1.43 \pm 0.03$ & $41 \pm 3$ & $46.8 \pm 0.7$ & $51 \pm 4$ & $49 \pm 0.6$ & $518 \pm 9$ & $3.12 \pm 0.16$ & $111.8 \pm 9.8$ & 26 & $35.8 \pm 3.7$ \\
\hline 363 & 168125 & $2.12 \pm 0.08$ & $1.43 \pm 0.04$ & $46 \pm 17$ & $47.0 \pm 1.3$ & & $55 \pm 1.3$ & $571 \pm 18$ & $3.19 \pm 0.17$ & $86.6 \pm 7.0$ & 21 & $27.2 \pm 2.7$ \\
\hline 381 & 168126 & $2.24 \pm 0.09$ & $1.50 \pm 0.05$ & $32 \pm 17$ & $48.9 \pm 1.3$ & & $56 \pm 1.2$ & $638 \pm 22$ & $3.35 \pm 0.18$ & $93.9 \pm 6.5$ & 24 & $28.1 \pm 2.5$ \\
\hline 409 & 168127 & $1.95 \pm 0.04$ & $1.32 \pm 0.04$ & $45 \pm 14$ & $46.1 \pm 1.1$ & & $51 \pm 1.1$ & $510 \pm 14$ & $2.94 \pm 0.15$ & $105.6 \pm 6.9$ & 20 & $35.9 \pm 3.1$ \\
\hline 427 & 168128 & $2.11 \pm 0.03$ & $1.46 \pm 0.03$ & $39 \pm 3$ & $46.0 \pm 0.7$ & $51 \pm 3$ & $50 \pm 0.5$ & $544 \pm 9$ & $3.20 \pm 0.16$ & $98.5 \pm 5.3$ & 30 & $30.8 \pm 2.3$ \\
\hline 445 & 168129 & $1.92 \pm 0.03$ & $1.37 \pm 0.35$ & $42 \pm 4$ & $41.3 \pm 0.6$ & $49 \pm 4$ & $48 \pm 0.6$ & $484 \pm 10$ & $2.95 \pm 0.33$ & & & \\
\hline 463 & 168130 & $1.70 \pm 0.07$ & $1.10 \pm 0.03$ & $37 \pm 14$ & $35.5 \pm 1.2$ & & $41 \pm 1.1$ & $471 \pm 20$ & $2.53 \pm 0.14$ & $98.7 \pm 8.0$ & 26 & $38.9 \pm 3.9$ \\
\hline 481 & 168131 & $1.64 \pm 0.10$ & $1.20 \pm 0.04$ & $10 \pm 20$ & $41.6 \pm 1.6$ & & $44 \pm 1.4$ & $504 \pm 24$ & $2.56 \pm 0.15$ & $82.8 \pm 7.1$ & 23 & $32.3 \pm 3.5$ \\
\hline 510 & 168132 & $1.53 \pm 0.03$ & $1.00 \pm 0.03$ & $4 \pm 8$ & $32.9 \pm 0.7$ & & $38 \pm 0.7$ & $420 \pm 11$ & $2.30 \pm 0.12$ & & & \\
\hline 529 & 168133 & $2.20 \pm 0.10$ & $1.45 \pm 0.05$ & $75 \pm 22$ & $51.7 \pm 1.6$ & & $56 \pm 1.7$ & $539 \pm 23$ & $3.25 \pm 0.19$ & $108.3 \pm 10.9$ & 30 & $33.4 \pm 3.9$ \\
\hline 548 & 168134 & $1.91 \pm 0.27$ & $1.34 \pm 0.03$ & $44 \pm 3$ & $42.3 \pm 0.5$ & $46 \pm 3$ & $47 \pm 0.5$ & $487 \pm 9$ & $2.91 \pm 0.27$ & $144.9 \pm 10.8$ & 27 & $49.9 \pm 6.0$ \\
\hline 567 & 168135 & $2.01 \pm 0.03$ & $1.41 \pm 0.04$ & $40 \pm 4$ & $46.6 \pm 0.9$ & $47 \pm 4$ & $51 \pm 0.7$ & $509 \pm 11$ & $3.05 \pm 0.16$ & $127.7 \pm 7.9$ & 26 & $41.9 \pm 3.5$ \\
\hline
\end{tabular}




\begin{tabular}{|c|c|c|c|c|c|c|c|c|c|c|c|c|}
\hline 586 & 168136 & $1.59 \pm 0.07$ & $1.14 \pm 0.04$ & $24 \pm 14$ & $37.9 \pm 1.1$ & & $46 \pm 1.1$ & $427 \pm 19$ & $2.46 \pm 0.14$ & $144.3 \pm 13.8$ & 21 & $58.8 \pm 6.6$ \\
\hline 615 & 168137 & $1.91 \pm 0.04$ & $1.30 \pm 0.04$ & $38 \pm 16$ & $44.3 \pm 1.2$ & & $50 \pm 1.3$ & $503 \pm 16$ & $2.86 \pm 0.15$ & $136.4 \pm 11.4$ & 21 & $47.7 \pm 4.8$ \\
\hline 633 & 168138 & $1.55 \pm 0.04$ & $1.10 \pm 0.03$ & $9 \pm 8$ & $35.9 \pm 0.6$ & & $43 \pm 0.6$ & $450 \pm 10$ & $2.39 \pm 0.12$ & $124.0 \pm 11.6$ & 20 & $51.9 \pm 5.7$ \\
\hline 651 & 168139 & $1.85 \pm 0.04$ & $1.25 \pm 0.04$ & $33 \pm 5$ & $40.7 \pm 1.0$ & $41 \pm 5$ & $44 \pm 0.7$ & $487 \pm 12$ & $2.77 \pm 0.14$ & $153.6 \pm 15.9$ & 14 & $55.6 \pm 6.5$ \\
\hline 669 & 168140 & $1.78 \pm 0.06$ & $1.24 \pm 0.04$ & $28 \pm 12$ & $43.8 \pm 0.9$ & & $48 \pm 0.9$ & $483 \pm 12$ & $2.70 \pm 0.14$ & $149.6 \pm 17.7$ & 9 & $55.5 \pm 7.3$ \\
\hline 687 & 168141 & $1.79 \pm 0.04$ & $1.26 \pm 0.05$ & $35 \pm 5$ & $40.3 \pm 1.1$ & $47 \pm 6$ & $42 \pm 0.8$ & $452 \pm 13$ & $2.72 \pm 0.14$ & $157.3 \pm 17.7$ & 9 & $57.9 \pm 7.3$ \\
\hline 715 & 168142 & $1.88 \pm 0.04$ & $1.34 \pm 0.04$ & $32 \pm 5$ & $40.8 \pm 1.0$ & $52 \pm 5$ & $44 \pm 0.8$ & $472 \pm 12$ & $2.86 \pm 0.15$ & $167.8 \pm 9.4$ & 9 & $58.6 \pm 4.6$ \\
\hline 733 & 168143 & $1.87 \pm 0.02$ & $1.29 \pm 0.03$ & $39 \pm 3$ & $42.2 \pm 0.6$ & $43 \pm 3$ & $45 \pm 0.5$ & $486 \pm 8$ & $2.81 \pm 0.14$ & $95.6 \pm 10.9$ & 11 & $34.0 \pm 4.3$ \\
\hline 751 & 168144 & $1.25 \pm 0.04$ & $1.77 \pm 0.04$ & $34 \pm 5$ & $39.5 \pm 1.0$ & $47 \pm 5$ & $43 \pm 0.7$ & $445 \pm 12$ & $2.69 \pm 0.14$ & $97.9 \pm 7.6$ & 21 & $36.4 \pm 3.5$ \\
\hline 769 & 168145 & $1.94 \pm 0.03$ & $1.38 \pm 0.03$ & $45 \pm 3$ & $43.0 \pm 0.7$ & $51 \pm 4$ & $47 \pm 0.6$ & $488 \pm 9$ & $2.94 \pm 0.15$ & $125.6 \pm 11.4$ & 15 & $42.7 \pm 4.5$ \\
\hline 787 & 168146 & $1.91 \pm 0.03$ & $1.35 \pm 0.03$ & $40 \pm 4$ & $41.7 \pm 0.6$ & $47 \pm 4$ & $48 \pm 0.6$ & $483 \pm 10$ & $2.89 \pm 0.15$ & $82.5 \pm 8.6$ & 15 & $28.5 \pm 3.3$ \\
\hline 815 & 168147 & $1.82 \pm 0.06$ & $1.24 \pm 0.04$ & $40 \pm 20$ & $43.6 \pm 1.6$ & & $48 \pm 1.4$ & $474 \pm 24$ & $2.71 \pm 0.15$ & $121.6 \pm 7.7$ & 17 & $44.8 \pm 3.9$ \\
\hline 869 & 168148 & $1.86 \pm 0.09$ & $1.38 \pm 0.04$ & $22 \pm 19$ & $40.8 \pm 1.5$ & & $48 \pm 1.4$ & $487 \pm 23$ & $2.87 \pm 0.17$ & $126.1 \pm 16.4$ & 16 & $44.0 \pm 6.3$ \\
\hline 887 & 168149 & $1.18 \pm 0.07$ & $1.32 \pm 0.04$ & $32 \pm 13$ & $39.3 \pm 1.0$ & & $46 \pm 0.9$ & $467 \pm 16$ & $2.24 \pm 0.13$ & $114.9 \pm 11.7$ & 18 & $51.3 \pm 6.1$ \\
\hline 915 & 168150 & $1.81 \pm 0.06$ & $1.27 \pm 0.36$ & $36 \pm 12$ & $39.2 \pm 1.0$ & & $47 \pm 1.0$ & $480 \pm 17$ & $2.72 \pm 0.34$ & $129.5 \pm 16.0$ & 13 & $47.6 \pm 8.4$ \\
\hline 933 & 168151 & $1.95 \pm 0.04$ & $1.32 \pm 0.04$ & $34 \pm 4$ & $43.2 \pm 0.9$ & $42 \pm 5$ & $47 \pm 0.7$ & $514 \pm 12$ & $2.88 \pm 0.15$ & $91.5 \pm 13.1$ & 17 & $31.7 \pm 4.9$ \\
\hline 951 & 168152 & $2.06 \pm 0.03$ & $1.40 \pm 0.03$ & $42 \pm 3$ & $44.9 \pm 0.6$ & $47 \pm 3$ & $49 \pm 0.5$ & $540 \pm 9$ & $3.05 \pm 0.15$ & $91.9 \pm 17.2$ & 12 & $30.1 \pm 5.9$ \\
\hline 969 & 168153 & $2.10 \pm 0.03$ & $1.46 \pm 0.03$ & $38 \pm 3$ & $44.4 \pm 0.5$ & $51 \pm 3$ & $50 \pm 0.5$ & $544 \pm 9$ & $3.13 \pm 0.16$ & $120.5 \pm 20.3$ & 13 & $38.5 \pm 6.8$ \\
\hline 987 & 168154 & $1.95 \pm 0.06$ & $1.28 \pm 0.38$ & $48 \pm 12$ & $43.2 \pm 0.9$ & & $48 \pm 0.9$ & $520 \pm 13$ & $2.85 \pm 0.36$ & $91.0 \pm 19.5$ & 10 & $32.0 \pm 8.0$ \\
\hline 1015 & 168155 & $2.01 \pm 0.03$ & $1.38 \pm 0.03$ & $39 \pm 3$ & $43.7 \pm 0.6$ & $47 \pm 3$ & $48 \pm 0.5$ & $521 \pm 9$ & $2.99 \pm 0.15$ & $95.3 \pm 25.2$ & 9 & $31.9 \pm 8.6$ \\
\hline 1033 & 168156 & $1.94 \pm 0.04$ & $1.34 \pm 0.04$ & $40 \pm 5$ & $44.1 \pm 0.8$ & $45 \pm 5$ & $47 \pm 0.7$ & $501 \pm 12$ & $2.89 \pm 0.15$ & $154.3 \pm 25.8$ & 11 & $53.4 \pm 9.4$ \\
\hline 1051 & 168157 & $1.97 \pm 0.43$ & $1.33 \pm 0.04$ & $45 \pm 5$ & $49.5 \pm 1.1$ & $50 \pm 5$ & $49 \pm 0.8$ & $520 \pm 13$ & $2.91 \pm 0.40$ & $131.5 \pm 13.6$ & 11 & $45.1 \pm 7.8$ \\
\hline 1069 & 168158 & $2.03 \pm 0.04$ & $1.38 \pm 0.04$ & $41 \pm 5$ & $48.3 \pm 1.0$ & $52 \pm 5$ & $52 \pm 0.8$ & $546 \pm 13$ & $3.00 \pm 0.16$ & $134.8 \pm 12.9$ & 11 & $44.9 \pm 5.0$ \\
\hline 1087 & 168159 & $1.97 \pm 0.04$ & $1.32 \pm 0.04$ & $43 \pm 5$ & $46.2 \pm 1.0$ & $40 \pm 5$ & $50 \pm 0.7$ & $529 \pm 13$ & $2.90 \pm 0.15$ & $159.0 \pm 13.1$ & 11 & $54.8 \pm 5.5$ \\
\hline 1115 & 168160 & $0.66 \pm 0.02$ & $0.44 \pm 0.01$ & $14 \pm 2$ & $14.6 \pm 0.5$ & $16 \pm 3$ & $17 \pm 0.4$ & $177 \pm 6$ & $1.02 \pm 0.05$ & $50.0 \pm 7.9$ & 6 & $48.9 \pm 10.0$ \\
\hline
\end{tabular}

Note: $D_{e}$ and dose rate results for samples $(168111,168129$ and 168132$)$ are not yet available. The missing ${ }^{210} \mathrm{~Pb}$ values are not available because not all gamma spectrometers can measure the $40 \mathrm{keV}$ peak of ${ }^{210} \mathrm{~Pb}$. 
Table 3. Summary of depth information, sample codes, dry alpha, beta and gamma dose rates, radionuclide concentrations, total dose rates, weighted mean $D_{e}$ values and luminescence ages for the Lingtai section. Grain size range of quartz extract was $4-11 \mu \mathrm{m}$ for all samples. $n$ represents the number of aliquots. Error terms are given as 1 standard error.

\begin{tabular}{|c|c|c|c|c|c|c|c|c|c|c|c|c|c|}
\hline $\begin{array}{l}\text { Depth } \\
\text { (cm) }\end{array}$ & $\begin{array}{l}\text { Sample } \\
\text { code }\end{array}$ & $\begin{array}{l}\text { Alpha } \square \\
\left(G_{y} \mathbf{k a}^{-1}\right)\end{array}$ & $\begin{array}{c}\text { Beta } \square \\
\left(\text { Gy ka }^{-1}\right)\end{array}$ & $\begin{array}{c}\text { Gamma } \\
\square \text { (Gy ka } \\
\text { 1) }\end{array}$ & $\begin{array}{c}{ }^{238} \mathrm{U} \\
\left(\mathbf{B q} \mathbf{k g}^{-1}\right)\end{array}$ & $\begin{array}{c}{ }^{226} \mathrm{Ra} \\
\left(\mathrm{Bq} \mathrm{kg}^{-1}\right)\end{array}$ & $\begin{array}{c}{ }^{210} \mathrm{~Pb} \\
\left(\mathrm{~Bq} \mathrm{~kg}^{-1}\right)\end{array}$ & $\begin{array}{c}{ }^{232} \mathrm{Th}^{-1} \\
\left(\mathrm{~Bq} \mathrm{~kg}{ }^{-1}\right)\end{array}$ & $\begin{array}{c}{ }^{40} \mathrm{~K} \\
\left(\mathrm{~Bq} \mathrm{~kg}^{-1}\right)\end{array}$ & $\begin{array}{c}\text { Total } \square \\
\left(\text { Gy ka }^{-1}\right)\end{array}$ & $D_{e}(\mathrm{~Gy})$ & $n$ & Age (ka) \\
\hline 20 & H18101 & $0.254 \pm 0.011$ & $2.39 \pm 0.05$ & $1.60 \pm 0.06$ & $43 \pm 6$ & $42.5 \pm 1.0$ & $47.9 \pm 7.0$ & $56 \pm 1.0$ & $660 \pm 17$ & $3.58 \pm 0.58$ & $6.1 \pm 0.2$ & 6 & $1.6 \pm 0.3$ \\
\hline 60 & H18102 & $0.217 \pm 0.011$ & $2.18 \pm 0.05$ & $1.40 \pm 0.06$ & $28 \pm 6$ & $41.2 \pm 1.3$ & $37.5 \pm 7.1$ & $49 \pm 1.0$ & $623 \pm 18$ & & & & \\
\hline 70 & H18103 & $0.230 \pm 0.010$ & $2.14 \pm 0.05$ & $1.43 \pm 0.05$ & $24 \pm 6$ & $40.1 \pm 1.2$ & $44.0 \pm 6.3$ & $50 \pm 0.9$ & $589 \pm 16$ & $3.53 \pm 0.20$ & $54.8 \pm 4$ & 6 & $15.6 \pm 1.5$ \\
\hline 80 & H18104 & $0.227 \pm 0.009$ & $2.27 \pm 0.05$ & $1.47 \pm 0.05$ & $32 \pm 6$ & $40.3 \pm 0.9$ & $38.1 \pm 6.2$ & $53 \pm 0.9$ & $649 \pm 16$ & $3.50 \pm 0.20$ & $75.6 \pm 1.8$ & 9 & $21.6 \pm 1.4$ \\
\hline 90 & H18105 & $0.217 \pm 0.009$ & $2.21 \pm 0.05$ & $1.41 \pm 0.05$ & $26 \pm 5$ & $41.1 \pm 1.1$ & $34.3 \pm 5.8$ & $51 \pm 0.9$ & $639 \pm 16$ & $3.49 \pm 0.20$ & $53.7 \pm 1.0$ & 6 & $15.4 \pm 1.0$ \\
\hline 100 & H18106 & $0.215 \pm 0.012$ & $2.29 \pm 0.06$ & $1.43 \pm 0.07$ & $40 \pm 7$ & $41.3 \pm 1.4$ & $32.5 \pm 7.8$ & $52 \pm 1.1$ & $674 \pm 19$ & $3.62 \pm 0.21$ & $62.9 \pm 2.0$ & 6 & $17.4 \pm 1.2$ \\
\hline 110 & H18107 & $0.257 \pm 0.010$ & $2.37 \pm 0.05$ & $1.61 \pm 0.06$ & $38 \pm 6$ & $41.5 \pm 1.0$ & $50.8 \pm 6.4$ & $56 \pm 1.0$ & $650 \pm 16$ & $3.68 \pm 0.21$ & $55.2 \pm 1.3$ & 4 & $15.0 \pm 1.0$ \\
\hline 120 & H18108 & $0.232 \pm 0.006$ & $2.27 \pm 0.03$ & $1.48 \pm 0.03$ & $29 \pm 3$ & $41.1 \pm 0.6$ & $40.5 \pm 3.6$ & $53 \pm 0.6$ & $640 \pm 10$ & $3.74 \pm 0.22$ & $55.9 \pm 0.5$ & 6 & $15.0 \pm 1.0$ \\
\hline 130 & H18109 & $0.252 \pm 0.012$ & $2.55 \pm 0.06$ & $1.65 \pm 0.07$ & $33 \pm 7$ & $42.5 \pm 1.2$ & $46.9 \pm 7.9$ & $57 \pm 1.1$ & $732 \pm 20$ & $3.82 \pm 0.23$ & $68.9 \pm 3.0$ & 6 & $18.1 \pm 1.4$ \\
\hline 140 & H18110 & $0.226 \pm 0.011$ & $2.26 \pm 0.05$ & $1.46 \pm 0.06$ & $32 \pm 6$ & $41.1 \pm 1.1$ & $35.2 \pm 7.1$ & $54 \pm 1.0$ & $648 \pm 17$ & $3.71 \pm 0.22$ & $64.1 \pm 1.5$ & 5 & $17.3 \pm 1.1$ \\
\hline 150 & H18111 & $0.256 \pm 0.010$ & $2.45 \pm 0.05$ & $1.61 \pm 0.06$ & $33 \pm 6$ & $45.9 \pm 1.2$ & $49.5 \pm 6.4$ & $55 \pm 1.0$ & $681 \pm 17$ & $3.75 \pm 0.22$ & $82.9 \pm 1.2$ & 9 & $22.1 \pm 1.4$ \\
\hline 160 & H18112 & $0.249 \pm 0.007$ & $2.38 \pm 0.04$ & $1.57 \pm 0.04$ & $25 \pm 4$ & $44.0 \pm 0.8$ & $44.6 \pm 4.4$ & $56 \pm 0.7$ & $666 \pm 12$ & $3.97 \pm 0.24$ & $75.1 \pm 2.0$ & 6 & $18.9 \pm 1.3$ \\
\hline 170 & H18113 & $0.259 \pm 0.008$ & $2.48 \pm 0.04$ & $1.65 \pm 0.04$ & $40 \pm 5$ & $43.3 \pm 0.8$ & $46.5 \pm 5.0$ & $59 \pm 0.8$ & $696 \pm 14$ & $3.87 \pm 0.22$ & $75.9 \pm 1.2$ & 9 & $19.6 \pm 1.2$ \\
\hline 180 & H18114 & & & & & & & & & & & & \\
\hline 200 & H18115 & $0.230 \pm 0.011$ & $2.24 \pm 0.05$ & $1.47 \pm 0.06$ & $29 \pm 7$ & $41.0 \pm 1.4$ & $38.3 \pm 7.3$ & $54 \pm 1.1$ & $633 \pm 18$ & $3.66 \pm 0.22$ & $83.4 \pm 3.1$ & 6 & $22.8 \pm 1.7$ \\
\hline 210 & H18116 & $0.275 \pm 0.011$ & $2.70 \pm 0.05$ & $1.77 \pm 0.06$ & $38 \pm 6$ & $47.5 \pm 1.0$ & $47.1 \pm 6.9$ & $64 \pm 1.0$ & $764 \pm 18$ & $4.10 \pm 0.24$ & $115.2 \pm 2.2$ & 12 & $28.1 \pm 1.8$ \\
\hline 220 & H18117 & $0.240 \pm 0.007$ & $2.38 \pm 0.04$ & $1.54 \pm 0.04$ & $25 \pm 4$ & $41.7 \pm 0.9$ & $43.5 \pm 4.8$ & $54 \pm 0.7$ & $676 \pm 13$ & $3.95 \pm 0.23$ & $98.2 \pm 1.3$ & 6 & $24.9 \pm 1.6$ \\
\hline 230 & H18118 & $0.256 \pm 0.010$ & $2.39 \pm 0.05$ & $1.61 \pm 0.06$ & $38 \pm 6$ & $40.6 \pm 0.9$ & $50.2 \pm 6.4$ & $56 \pm 0.9$ & $661 \pm 16$ & $3.80 \pm 0.22$ & $86.9 \pm 4.2$ & 3 & $22.9 \pm 1.8$ \\
\hline 240 & H18119 & $0.270 \pm 0.011$ & $2.65 \pm 0.05$ & $1.75 \pm 0.06$ & $36 \pm 6$ & $43.2 \pm 1.0$ & $48.9 \pm 7.1$ & $62 \pm 1.1$ & $751 \pm 18$ & $3.94 \pm 0.22$ & $99.4 \pm 0.9$ & 5 & $25.2 \pm 1.5$ \\
\hline 250 & H18120 & & & & & & & & & & & & \\
\hline 260 & $\mathrm{H} 18121$ & $0.263 \pm 0.014$ & $2.50 \pm 0.07$ & $1.67 \pm 0.08$ & $34 \pm 9$ & $43.8 \pm 1.4$ & $45.4 \pm 9.5$ & $62 \pm 1.4$ & $700 \pm 22$ & $3.83 \pm 0.23$ & $118.0 \pm 3.5$ & 6 & $30.8 \pm 2.2$ \\
\hline 270 & H18122 & $0.273 \pm 0.013$ & $2.69 \pm 0.06$ & $1.76 \pm 0.08$ & $38 \pm 8$ & $46.0 \pm 1.3$ & $46.9 \pm 8.7$ & $64 \pm 1.2$ & $767 \pm 21$ & $4.26 \pm 0.25$ & $116.6 \pm 2.8$ & 6 & $27.4 \pm 1.8$ \\
\hline 280 & H18123 & $0.254 \pm 0.011$ & $2.47 \pm 0.06$ & $1.62 \pm 0.06$ & $33 \pm 7$ & $43.6 \pm 1.4$ & $47.0 \pm 7.5$ & $57 \pm 1.1$ & $697 \pm 19$ & $3.94 \pm 0.23$ & $113.2 \pm 2.8$ & 12 & $28.7 \pm 1.9$ \\
\hline 290 & H18124 & $0.255 \pm 0.013$ & $2.50 \pm 0.06$ & $1.64 \pm 0.07$ & $28 \pm 7$ & $42.8 \pm 1.2$ & $46.5 \pm 8.3$ & $58 \pm 1.2$ & $708 \pm 20$ & $3.73 \pm 0.22$ & $123.0 \pm 2.3$ & 5 & $33.0 \pm 2.1$ \\
\hline 300 & H18125 & $0.264 \pm 0.011$ & $2.43 \pm 0.05$ & $1.65 \pm 0.06$ & $28 \pm 6$ & $41.2 \pm 1.3$ & $56.2 \pm 7.0$ & $55 \pm 1.0$ & $662 \pm 18$ & $3.76 \pm 0.22$ & $133.7 \pm 2.4$ & 9 & $35.5 \pm 2.3$ \\
\hline 310 & H18126 & $0.244 \pm 0.012$ & $2.47 \pm 0.06$ & $1.60 \pm 0.07$ & $35 \pm 7$ & $41.2 \pm 1.2$ & $39.7 \pm 8.1$ & $59 \pm 1.2$ & $713 \pm 19$ & $3.88 \pm 0.22$ & $118.2 \pm 3.3$ & 6 & $30.5 \pm 2.0$ \\
\hline 320 & H18127 & $0.242 \pm 0.012$ & $2.41 \pm 0.06$ & $1.57 \pm 0.07$ & $43 \pm 7$ & $41.6 \pm 1.4$ & $40.1 \pm 7.9$ & $57 \pm 1.1$ & $691 \pm 20$ & $3.72 \pm 0.22$ & $125.1 \pm 2.2$ & 6 & $33.7 \pm 2.2$ \\
\hline 330 & H18128 & $0.251 \pm 0.013$ & $2.50 \pm 0.07$ & $1.63 \pm 0.08$ & $31 \pm 8$ & $41.0 \pm 1.6$ & $46.5 \pm 8.8$ & $57 \pm 1.3$ & $713 \pm 22$ & $3.74 \pm 0.22$ & $125.7 \pm 2.1$ & 6 & $33.6 \pm 2.2$ \\
\hline
\end{tabular}




\begin{tabular}{|c|c|c|c|c|c|c|c|c|c|c|c|c|c|}
\hline 340 & H18129 & $0.276 \pm 0.011$ & $2.58 \pm 0.05$ & $1.74 \pm 0.06$ & $44 \pm 7$ & $44.5 \pm 1.1$ & $51.1 \pm 7.1$ & $63 \pm 1.1$ & $713 \pm 18$ & $3.67 \pm 0.21$ & $139.7 \pm 5.4$ & 6 & $38.0 \pm 2.8$ \\
\hline 350 & H18130 & $0.237 \pm 0.014$ & $2.52 \pm 0.07$ & $1.56 \pm 0.08$ & $29 \pm 8$ & $47.7 \pm 1.7$ & $34.1 \pm 8.9$ & $58 \pm 1.3$ & $740 \pm 23$ & $3.67 \pm 0.21$ & $148.3 \pm 5.4$ & 6 & $40.4 \pm 2.9$ \\
\hline 360 & H18131 & & & & & & & & & & & & \\
\hline 370 & H18132 & $0.256 \pm 0.010$ & $2.51 \pm 0.05$ & $1.65 \pm 0.06$ & $29 \pm 6$ & $43.2 \pm 1.0$ & $42.5 \pm 6.4$ & $61 \pm 1.0$ & $713 \pm 17$ & $3.88 \pm 0.22$ & $144.8 \pm 3.0$ & 6 & $37.3 \pm 2.4$ \\
\hline 380 & H18133 & $0.245 \pm 0.014$ & $2.38 \pm 0.07$ & $1.57 \pm 0.08$ & $32 \pm 8$ & $39.1 \pm 1.6$ & $46.8 \pm 8.8$ & $55 \pm 1.3$ & $670 \pm 22$ & $3.88 \pm 0.22$ & $122.2 \pm 8.5$ & 6 & $31.5 \pm 2.9$ \\
\hline 390 & H18134 & $0.257 \pm 0.015$ & $2.56 \pm 0.07$ & $1.67 \pm 0.08$ & $39 \pm 9$ & $42.8 \pm 1.4$ & $43.2 \pm 9.8$ & $61 \pm 1.4$ & $733 \pm 23$ & $3.10 \pm 0.18$ & $151.0 \pm 2.2$ & 6 & $48.7 \pm 3.0$ \\
\hline 400 & H18135 & $0.252 \pm 0.007$ & $2.53 \pm 0.04$ & $1.64 \pm 0.04$ & $36 \pm 4$ & $43.0 \pm 0.8$ & $42.1 \pm 4.4$ & $60 \pm 0.7$ & $725 \pm 12$ & $3.10 \pm 0.18$ & $160.5 \pm 2.7$ & 6 & $51.7 \pm 3.3$ \\
\hline 410 & H18136 & $0.266 \pm 0.015$ & $2.58 \pm 0.07$ & $1.70 \pm 0.09$ & $39 \pm 9$ & $43.9 \pm 1.9$ & $47.9 \pm 10$ & $61 \pm 1.5$ & $726 \pm 24$ & $3.10 \pm 0.18$ & $153.4 \pm 6.1$ & 6 & $49.5 \pm 3.6$ \\
\hline 420 & H18137 & $0.254 \pm 0.009$ & $2.53 \pm 0.04$ & $1.65 \pm 0.05$ & $36 \pm 5$ & $42.4 \pm 0.8$ & $42.1 \pm 5.6$ & $61 \pm 0.9$ & $724 \pm 14$ & $3.75 \pm 0.22$ & $145.4 \pm 8.4$ & 6 & $38.7 \pm 3.3$ \\
\hline 430 & H18138 & $0.255 \pm 0.012$ & $2.53 \pm 0.06$ & $1.65 \pm 0.07$ & $35 \pm 7$ & $42.3 \pm 1.4$ & $43.3 \pm 7.7$ & $60 \pm 1.1$ & $722 \pm 20$ & $3.75 \pm 0.22$ & $167.9 \pm 5.0$ & 6 & $44.7 \pm 3.0$ \\
\hline 440 & H18139 & $0.222 \pm 0.006$ & $2.20 \pm 0.06$ & $1.44 \pm 0.04$ & $27 \pm 16$ & $38.2 \pm 1.2$ & & $58 \pm 1.3$ & $633 \pm 22$ & $3.75 \pm 0.22$ & $164.3 \pm 2.6$ & 6 & $43.8 \pm 2.8$ \\
\hline 450 & H18140 & $0.255 \pm 0.011$ & $2.36 \pm 0.05$ & $1.60 \pm 0.06$ & $44 \pm 6$ & $40.7 \pm 1.0$ & $48.8 \pm 7.0$ & $57 \pm 1.0$ & $649 \pm 17$ & $3.30 \pm 0.19$ & $139.0 \pm 3.4$ & 6 & $42.1 \pm 2.7$ \\
\hline 460 & H18141 & $0.245 \pm 0.007$ & $2.37 \pm 0.05$ & $1.56 \pm 0.04$ & $50 \pm 18$ & $44.5 \pm 1.4$ & & $61 \pm 1.5$ & $670 \pm 20$ & $3.30 \pm 0.19$ & $115.7 \pm 13.0$ & 3 & $35.1 \pm 4.5$ \\
\hline 470 & H18142 & $0.254 \pm 0.012$ & $2.48 \pm 0.06$ & $1.64 \pm 0.07$ & $33 \pm 7$ & $40.7 \pm 1.4$ & $45.0 \pm 7.6$ & $59 \pm 1.1$ & $705 \pm 19$ & $3.30 \pm 0.19$ & $151.4 \pm 2.5$ & 3 & $45.9 \pm 2.9$ \\
\hline 480 & H18143 & $0.222 \pm 0.006$ & $2.36 \pm 0.05$ & $1.50 \pm 0.04$ & $37 \pm 14$ & $37.5 \pm 1.1$ & & $58 \pm 1.2$ & $702 \pm 20$ & $3.79 \pm 0.22$ & $125.9 \pm 8.9$ & 6 & $33.2 \pm 3.1$ \\
\hline 490 & H18144 & $0.261 \pm 0.009$ & $2.52 \pm 0.05$ & $1.67 \pm 0.05$ & $34 \pm 6$ & $42.7 \pm 0.9$ & $47.3 \pm 6.2$ & $60 \pm 0.9$ & $709 \pm 16$ & $3.79 \pm 0.22$ & $133.6 \pm 3.1$ & 6 & $35.2 \pm 2.3$ \\
\hline 500 & H18145 & & & & & & & & & & & & \\
\hline 510 & H18146 & $0.234 \pm 0.014$ & $2.24 \pm 0.07$ & $1.49 \pm 0.08$ & $33 \pm 8$ & $37.9 \pm 1.6$ & $42.6 \pm 8.9$ & $54 \pm 1.3$ & $627 \pm 21$ & $3.48 \pm 0.20$ & $134.5 \pm 1.6$ & 3 & $38.7 \pm 2.4$ \\
\hline 520 & H18147 & & & & & & & & & & & & \\
\hline 540 & H18148 & $0.214 \pm 0.016$ & $2.27 \pm 0.07$ & $1.44 \pm 0.09$ & $23 \pm 9$ & $37.1 \pm 1.5$ & $28.2 \pm 10$ & $56 \pm 1.4$ & $673 \pm 23$ & $3.47 \pm 0.20$ & $142.2 \pm 2.0$ & 3 & $41.0 \pm 2.6$ \\
\hline 560 & H18149 & $0.212 \pm 0.006$ & $2.14 \pm 0.06$ & $1.40 \pm 0.04$ & $53 \pm 21$ & $35.0 \pm 1.6$ & & $56 \pm 1.7$ & $621 \pm 22$ & $3.66 \pm 0.21$ & $150.3 \pm 5.9$ & 3 & $41.0 \pm 3.0$ \\
\hline
\end{tabular}

Note: $D_{e}$, dose rate and age results for missing samples H18102, H18114, H18120, H18131, H18145 and H18147 are not yet available. 


\section{SUPPLEMENTARY FILES}

Supplementary R script file: An annotated R script documents the age-depth calculations using the method of Zeeden et al. (2018), as well as the smoothing of results.

Table S1. Equivalent dose measurements ( $D_{\mathrm{e}}$, recycling ratio and recuperation), dose recovery tests (Dr) and luminescence ages for the Titel loess core. $n$ represents the number of aliquots.

\begin{tabular}{|c|c|c|c|c|c|c|c|c|}
\hline $\begin{array}{l}\text { Sample } \\
\text { code }\end{array}$ & $\begin{array}{l}\text { Depth } \\
(\mathrm{cm})\end{array}$ & $D_{\mathrm{e}}(\mathrm{Gy})$ & $\begin{array}{c}\text { Recycling } \\
\text { ratio }\end{array}$ & $\begin{array}{c}\text { Recuperation } \\
\text { (\% natural) }\end{array}$ & $\begin{array}{c}n \\
D_{e} \\
\end{array}$ & Dr & $\begin{array}{c}n \\
\text { Dr } \\
\end{array}$ & $\begin{array}{c}\text { OSL age } \\
(\mathrm{ka})\end{array}$ \\
\hline 168110 & 9.5 & $1.4 \pm 0.2$ & $1.060 \pm 0.047$ & $0.25 \pm 0.20$ & 10 & & & $0.4 \pm 0.1$ \\
\hline 168111 & 28.5 & & & & & $1.091 \pm 0.038$ & 6 & \\
\hline 168112 & 47.5 & $19.5 \pm 1.3$ & $0.953 \pm 0.048$ & $0.27 \pm 0.31$ & 26 & & & $7.4 \pm 0.7$ \\
\hline 168113 & 66.5 & $37.3 \pm 2.0$ & $1.002 \pm 0.034$ & $-0.22 \pm 0.41$ & 26 & $1.069 \pm 0.051$ & 6 & $15.6 \pm 1.2$ \\
\hline 168114 & 109 & $36.8 \pm 1.9$ & $0.960 \pm 0.034$ & $0.20 \pm 0.28$ & 26 & $1.009 \pm 0.026$ & 6 & $13.6 \pm 1.0$ \\
\hline 168115 & 127 & $44.0 \pm 2.6$ & $0.990 \pm 0.040$ & $0.27 \pm 0.28$ & 24 & $1.074 \pm 0.034$ & 6 & $18.8 \pm 1.6$ \\
\hline 168116 & 181 & $41.7 \pm 3.5$ & $1.037 \pm 0.071$ & $0.51 \pm 0.16$ & 24 & $1.044 \pm 0.046$ & 6 & $17.1 \pm 1.7$ \\
\hline 168117 & 209 & $47.8 \pm 3.2$ & $1.002 \pm 0.033$ & $0.02 \pm 0.06$ & 24 & & & $19.7 \pm 1.7$ \\
\hline 168118 & 227 & $62.6 \pm 3.1$ & $0.982 \pm 0.032$ & $0.34 \pm 0.09$ & 17 & & & $27.8 \pm 2.1$ \\
\hline 168119 & 245 & $65.6 \pm 4.4$ & $0.958 \pm 0.020$ & $-0.31 \pm 0.28$ & 24 & & & $25.8 \pm 2.3$ \\
\hline 168120 & 263 & $67.8 \pm 4.5$ & $0.978 \pm 0.071$ & $0.28 \pm 0.89$ & 24 & & & $31.3 \pm 2.9$ \\
\hline 168121 & 281 & $73.6 \pm 6.6$ & $0.944 \pm 0.032$ & $0.90 \pm 0.81$ & 18 & & & $24.6 \pm 2.6$ \\
\hline 168122 & 309 & $67.3 \pm 12.6$ & $0.963 \pm 0.017$ & $0.31 \pm 0.15$ & 6 & & & $29.8 \pm 5.8$ \\
\hline 168123 & 327 & $84.8 \pm 3.2$ & $0.988 \pm 0.044$ & $-0.16 \pm 0.48$ & 39 & & & $34.2 \pm 2.4$ \\
\hline 168124 & 345 & $111.8 \pm 9.8$ & $0.974 \pm 0.034$ & $-0.04 \pm 0.20$ & 26 & $1.035 \pm 0.076$ & 24 & $35.8 \pm 3.7$ \\
\hline 168125 & 363 & $86.6 \pm 7.0$ & $0.955 \pm 0.052$ & $1.18 \pm 0.56$ & 21 & & & $27.2 \pm 2.7$ \\
\hline 168126 & 381 & $93.9 \pm 6.5$ & $0.952 \pm 0.036$ & $-0.03 \pm 0.35$ & 24 & & & $28.1 \pm 2.5$ \\
\hline 168127 & 409 & $105.6 \pm 6.9$ & $1.038 \pm 0.048$ & $0.05 \pm 0.18$ & 20 & & & $35.9 \pm 3.1$ \\
\hline 168128 & 427 & $98.5 \pm 5.3$ & $0.951 \pm 0.028$ & $0.09 \pm 0.26$ & 30 & & & $30.8 \pm 2.3$ \\
\hline 168129 & 445 & & & & & & & \\
\hline 168130 & 463 & $98.7 \pm 8.0$ & $0.998 \pm 0.029$ & $-0.30 \pm 0.64$ & 26 & & & $38.9 \pm 3.9$ \\
\hline 168131 & 481 & $82.8 \pm 7.1$ & $0.943 \pm 0.034$ & $0.02 \pm 0.06$ & 23 & & & $32.3 \pm 3.5$ \\
\hline 168132 & 510 & & & & & & & \\
\hline
\end{tabular}




\begin{tabular}{|c|c|c|c|c|c|c|c|c|}
\hline 168133 & 529 & $108.3 \pm 10.9$ & $0.956 \pm 0.045$ & $-0.26 \pm 0.45$ & 30 & & & $33.4 \pm 3.9$ \\
\hline 168134 & 548 & $144.9 \pm 10.8$ & $0.938 \pm 0.024$ & $0.11 \pm 0.08$ & 27 & & & $49.9 \pm 6.0$ \\
\hline 168135 & 567 & $127.7 \pm 7.9$ & $0.917 \pm 0.026$ & $0.32 \pm 0.12$ & 26 & & & $41.9 \pm 3.5$ \\
\hline 168136 & 586 & $144.3 \pm 13.8$ & $0.983 \pm 0.032$ & $-0.15 \pm 0.18$ & 21 & & & $58.8 \pm 6.6$ \\
\hline 168137 & 615 & $136.4 \pm 11.4$ & $0.923 \pm 0.012$ & $0.25 \pm 0.09$ & 21 & & & $47.7 \pm 4.8$ \\
\hline 168138 & 633 & $124.0 \pm 11.6$ & $0.943 \pm 0.020$ & $-0.02 \pm 0.48$ & 20 & & & $51.9 \pm 5.7$ \\
\hline 168139 & 651 & $153.6 \pm 15.9$ & $0.913 \pm 0.033$ & $0.05 \pm 0.09$ & 14 & $1.023 \pm 0.048$ & 24 & $55.6 \pm 6.5$ \\
\hline 168140 & 669 & $149.6 \pm 17.7$ & $1.012 \pm 0.036$ & $-0.09 \pm 0.20$ & 9 & & & $55.5 \pm 7.3$ \\
\hline 168141 & 687 & $157.3 \pm 17.7$ & $1.032 \pm 0.019$ & $0.11 \pm 0.12$ & 9 & $1.109 \pm 0.045$ & 6 & $57.9 \pm 7.3$ \\
\hline 168142 & 715 & $167.8 \pm 9.4$ & $1.027 \pm 0.018$ & $0.00 \pm 0.18$ & 9 & & & $58.6 \pm 4.6$ \\
\hline 168143 & 733 & $95.6 \pm 10.9$ & $0.014 \pm-0.152$ & $-0.15 \pm 0.09$ & 11 & $1.145 \pm 0.097$ & 6 & $34.0 \pm 4.3$ \\
\hline 168144 & 751 & $97.9 \pm 7.6$ & $0.973 \pm 0.014$ & $0.22 \pm 0.12$ & 21 & & & $36.4 \pm 3.5$ \\
\hline 168145 & 769 & $125.6 \pm 11.4$ & $0.953 \pm 0.025$ & $0.07 \pm 0.09$ & 15 & & & $42.7 \pm 4.5$ \\
\hline 168146 & 787 & $82.5 \pm 8.6$ & $0.975 \pm 0.032$ & $-0.05 \pm 0.27$ & 15 & & & $28.5 \pm 3.3$ \\
\hline 168147 & 815 & $121.6 \pm 7.7$ & $0.951 \pm 0.019$ & $0.24 \pm 0.12$ & 17 & & & $44.8 \pm 3.9$ \\
\hline 168148 & 869 & $126.1 \pm 16.4$ & $0.953 \pm 0.029$ & $0.09 \pm 0.13$ & 16 & & & $44.0 \pm 6.3$ \\
\hline 168149 & 887 & $114.9 \pm 11.7$ & $0.947 \pm 0.020$ & $0.31 \pm 0.13$ & 18 & & & $51.3 \pm 6.1$ \\
\hline 168150 & 915 & $129.5 \pm 16.0$ & $0.964 \pm 0.056$ & $0.11 \pm 0.25$ & 13 & & & $47.6 \pm 8.4$ \\
\hline 168151 & 933 & $91.5 \pm 13.1$ & $1.019 \pm 0.034$ & $0.13 \pm 0.20$ & 17 & & & $31.7 \pm 4.9$ \\
\hline 168152 & 951 & $91.9 \pm 17.2$ & $0.981 \pm 0.029$ & $0.56 \pm 0.22$ & 12 & & & $30.1 \pm 5.9$ \\
\hline 168153 & 969 & $120.5 \pm 20.3$ & $0.943 \pm 0.015$ & $0.04 \pm 0.05$ & 13 & & & $38.5 \pm 6.8$ \\
\hline 168154 & 987 & $91.0 \pm 19.5$ & $0.970 \pm 0.041$ & $-0.15 \pm 0.17$ & 10 & & & $32.0 \pm 8.0$ \\
\hline 168155 & 1015 & $95.3 \pm 25.2$ & $0.863 \pm 0.026$ & $0.28 \pm 0.59$ & 9 & & & $31.9 \pm 8.6$ \\
\hline 168156 & 1033 & $154.3 \pm 25.8$ & $0.989 \pm 0.043$ & $0.14 \pm 0.18$ & 11 & & & $53.4 \pm 9.4$ \\
\hline 168157 & 1051 & $131.5 \pm 13.6$ & $0.968 \pm 0.034$ & $0.89 \pm 0.74$ & 11 & & & $45.1 \pm 7.8$ \\
\hline 168158 & 1069 & $134.8 \pm 12.9$ & $0.965 \pm 0.023$ & $-0.07 \pm 0.13$ & 11 & $1.016 \pm 0.029$ & 6 & $44.9 \pm 5.0$ \\
\hline 168159 & 1087 & $159.0 \pm 13.1$ & $0.972 \pm 0.026$ & $-0.16 \pm 0.17$ & 11 & $1.077 \pm 0.043$ & 6 & $54.8 \pm 5.5$ \\
\hline 168160 & 1115 & $50.0 \pm 7.9$ & $0.968 \pm 0.020$ & $0.24 \pm 0.17$ & 6 & & & $48.9 \pm 10.0$ \\
\hline
\end{tabular}

Note: $D_{\mathrm{e}}$, optical ages and test results (recycling ratio and recuperation) for missing samples (168111,168129 and 168132) are not available at this moment. 
Table S2. Equivalent dose measurements ( $D_{\mathrm{e}}$, recycling ratio and recuperation), dose recovery tests (Dr) and luminescence ages for the Lingtai loess section. $n$ represents the number of aliquots.

\begin{tabular}{|c|c|c|c|c|c|c|c|c|}
\hline $\begin{array}{l}\text { Sample } \\
\text { code }\end{array}$ & Depth (cm) & $D_{\mathrm{e}}(\mathrm{Gy})$ & $\begin{array}{l}\text { Recycling } \\
\text { ratio }\end{array}$ & $\begin{array}{c}\text { Recuperation } \\
\text { (\% natural) }\end{array}$ & $\begin{array}{c}n \\
D_{\mathrm{e}} \\
\end{array}$ & Dr & $\begin{array}{c}n \\
\mathrm{Dr}\end{array}$ & $\begin{array}{c}\text { OSL age } \\
(\mathrm{ka})\end{array}$ \\
\hline H18101 & 20 & $6.1 \pm 0.2$ & $0.945 \pm 0.051$ & $0.97 \pm 0.28$ & 6 & & & $1.6 \pm 0.3$ \\
\hline H18102 & 60 & & & & & & & \\
\hline H18103 & 70 & $54.8 \pm 4$ & $0.980 \pm 0.021$ & $0.77 \pm 0.01$ & 6 & & & $15.6 \pm 1.5$ \\
\hline H18104 & 80 & $75.6 \pm 1.8$ & $0.997 \pm 0.007$ & $0.58 \pm 0.04$ & 9 & & & $21.6 \pm 1.4$ \\
\hline H18105 & 90 & $53.7 \pm 1.0$ & $0.973 \pm 0.013$ & $0.72 \pm 0.08$ & 6 & & & $15.4 \pm 1.0$ \\
\hline H18106 & 100 & $62.9 \pm 2.0$ & $0.960 \pm 0.006$ & $0.73 \pm 0.12$ & 6 & & & $17.4 \pm 1.2$ \\
\hline H18107 & 110 & $55.2 \pm 1.3$ & $0.964 \pm 0.027$ & $0.63 \pm 0.10$ & 4 & & & $15.0 \pm 1.0$ \\
\hline H18108 & 120 & $55.9 \pm 0.5$ & $0.963 \pm 0.024$ & $0.42 \pm 0.02$ & 6 & & & $15.0 \pm 1.0$ \\
\hline H18109 & 130 & $68.9 \pm 3.0$ & $0.943 \pm 0.019$ & $0.69 \pm 0.08$ & 6 & & & $18.1 \pm 1.4$ \\
\hline H18110 & 140 & $64.1 \pm 1.5$ & $1.013 \pm 0.018$ & $0.81 \pm 0.23$ & 5 & & & $17.3 \pm 1.1$ \\
\hline H18111 & 150 & $82.9 \pm 1.2$ & $0.979 \pm 0.020$ & $0.47 \pm 0.05$ & 9 & & & $22.1 \pm 1.4$ \\
\hline H18112 & 160 & $75.1 \pm 2.0$ & $0.970 \pm 0.015$ & $0.77 \pm 0.17$ & 6 & & & $18.9 \pm 1.3$ \\
\hline H18113 & 170 & $75.9 \pm 1.2$ & $0.993 \pm 0.012$ & $0.54 \pm 0.02$ & 9 & & & $19.6 \pm 1.2$ \\
\hline H18114 & 180 & & & & & & & \\
\hline H18115 & 200 & $83.4 \pm 3.1$ & $1.067 \pm 0.009$ & $0.57 \pm 0.11$ & 6 & & & $22.8 \pm 1.7$ \\
\hline H18116 & 210 & $115.2 \pm 2.2$ & $0.964 \pm 0.012$ & $0.67 \pm 0.04$ & 12 & & & $28.1 \pm 1.8$ \\
\hline H18117 & 220 & $98.2 \pm 1.3$ & $0.973 \pm 0.014$ & $0.54 \pm 0.04$ & 6 & & & $24.9 \pm 1.6$ \\
\hline H18118 & 230 & $86.9 \pm 4.2$ & $0.930 \pm 0.038$ & $0.69 \pm 0.20$ & 3 & & & $22.9 \pm 1.8$ \\
\hline H18119 & 240 & $99.4 \pm 0.9$ & $0.938 \pm 0.010$ & $0.77 \pm 0.03$ & 5 & & & $25.2 \pm 1.5$ \\
\hline H18120 & 250 & & & & & & & \\
\hline H18121 & 260 & $118.0 \pm 3.5$ & $0.943 \pm 0.003$ & $0.95 \pm 0.02$ & 6 & $0.984 \pm 0.026$ & 4 & $30.8 \pm 2.2$ \\
\hline H18122 & 270 & $116.6 \pm 2.8$ & $0.940 \pm 0.000$ & $1.00 \pm 0.06$ & 6 & $0.945 \pm 0.009$ & 4 & $27.4 \pm 1.8$ \\
\hline H18123 & 280 & $113.2 \pm 2.8$ & $0.943 \pm 0.007$ & $0.84 \pm 0.03$ & 12 & & & $28.7 \pm 1.9$ \\
\hline H18124 & 290 & $123.0 \pm 2.3$ & $0.930 \pm 0.017$ & $1.02 \pm 0.03$ & 5 & $1.007 \pm 0.021$ & 4 & $33.0 \pm 2.1$ \\
\hline H18125 & 300 & $133.7 \pm 2.4$ & $0.952 \pm 0.005$ & $0.92 \pm 0.04$ & 9 & $1.015 \pm 0.015$ & 4 & $35.5 \pm 2.3$ \\
\hline H18126 & 310 & $118.2 \pm 3.3$ & $0.977 \pm 0.009$ & $1.07 \pm 0.04$ & 6 & $1.011 \pm 0.012$ & 4 & $30.5 \pm 2.0$ \\
\hline
\end{tabular}




\begin{tabular}{|c|c|c|c|c|c|c|c|c|}
\hline H18127 & 320 & $125.1 \pm 2.2$ & $0.960 \pm 0.006$ & $0.99 \pm 0.03$ & 6 & $0.981 \pm 0.013$ & 4 & $33.7 \pm 2.2$ \\
\hline H18128 & 330 & $125.7 \pm 2.1$ & $0.960 \pm 0.026$ & $0.94 \pm 0.02$ & 6 & $0.998 \pm 0.003$ & 4 & $33.6 \pm 2.2$ \\
\hline H18129 & 340 & $139.7 \pm 5.4$ & $0.987 \pm 0.009$ & $0.75 \pm 0.03$ & 6 & $0.977 \pm 0.024$ & 4 & $38.0 \pm 2.8$ \\
\hline H18130 & 350 & $148.3 \pm 5.4$ & $0.987 \pm 0.009$ & $0.73 \pm 0.01$ & 6 & $0.772 \pm 0.258$ & 4 & $40.4 \pm 2.9$ \\
\hline H18131 & 360 & & & & & $1.063 \pm 0.011$ & 4 & \\
\hline H18132 & 370 & $144.8 \pm 3.0$ & $0.970 \pm 0.006$ & $0.98 \pm 0.02$ & 6 & $1.032 \pm 0.009$ & 4 & $37.3 \pm 2.4$ \\
\hline H18133 & 380 & $122.2 \pm 8.5$ & $0.955 \pm 0.024$ & $1.00 \pm 0.14$ & 6 & & & $31.5 \pm 2.9$ \\
\hline H18134 & 390 & $151.0 \pm 2.2$ & $0.983 \pm 0.007$ & $0.95 \pm 0.04$ & 6 & $1.000 \pm 0.010$ & 4 & $48.7 \pm 3.0$ \\
\hline H18135 & 400 & $160.5 \pm 2.7$ & $0.967 \pm 0.009$ & $0.92 \pm 0.02$ & 6 & $1.043 \pm 0.012$ & 4 & $51.7 \pm 3.3$ \\
\hline H18136 & 410 & $153.4 \pm 6.1$ & $0.987 \pm 0.003$ & $0.89 \pm 0.05$ & 6 & $1.030 \pm 0.013$ & 4 & $49.5 \pm 3.6$ \\
\hline H18137 & 420 & $145.4 \pm 8.4$ & $0.983 \pm 0.007$ & $0.73 \pm 0.02$ & 6 & $1.032 \pm 0.013$ & 4 & $38.7 \pm 3.3$ \\
\hline H18138 & 430 & $167.9 \pm 5.0$ & $0.967 \pm 0.007$ & $0.74 \pm 0.03$ & 6 & $1.058 \pm 0.014$ & 4 & $44.7 \pm 3.0$ \\
\hline H18139 & 440 & $164.3 \pm 2.6$ & $0.970 \pm 0.010$ & $0.72 \pm 0.02$ & 6 & $1.042 \pm 0.008$ & 4 & $43.8 \pm 2.8$ \\
\hline H18140 & 450 & $139.0 \pm 3.4$ & $0.987 \pm 0.003$ & $0.79 \pm 0.02$ & 6 & $1.057 \pm 0.011$ & 4 & $42.1 \pm 2.7$ \\
\hline H18141 & 460 & $115.7 \pm 13.0$ & $0.973 \pm 0.045$ & $0.95 \pm 0.02$ & 3 & & & $35.1 \pm 4.5$ \\
\hline H18142 & 470 & $151.4 \pm 2.5$ & $0.960 \pm 0.010$ & $0.71 \pm 0.02$ & 3 & & & $45.9 \pm 2.9$ \\
\hline H18143 & 480 & $125.9 \pm 8.9$ & $0.977 \pm 0.057$ & $1.99 \pm 0.38$ & 6 & & & $33.2 \pm 3.1$ \\
\hline H18144 & 490 & $133.6 \pm 3.1$ & $1.005 \pm 0.010$ & $1.00 \pm 0.08$ & 6 & & & $35.2 \pm 2.3$ \\
\hline H18145 & 500 & & & & & & & \\
\hline H18146 & 510 & $134.5 \pm 1.6$ & $0.967 \pm 0.012$ & $1.18 \pm 0.09$ & 3 & & & $38.7 \pm 2.4$ \\
\hline H18147 & 520 & & & & & & & \\
\hline H18148 & 540 & $142.2 \pm 2.0$ & $1.047 \pm 0.028$ & $0.78 \pm 0.40$ & 3 & & & $41.0 \pm 2.6$ \\
\hline H18149 & 560 & $150.3 \pm 5.9$ & $0.957 \pm 0.007$ & $1.11 \pm 0.05$ & 3 & & & $41.0 \pm 3.0$ \\
\hline
\end{tabular}

Note: $D_{\mathrm{e}}$, optical ages and test results (recycling ratio and recuperation) for missing samples (H18102, H18114, H18120, H18131, H18145 and H18147) are not yet available. 
Table S3. Grain-size distribution data for the Lingtai loess section.

\begin{tabular}{|c|c|c|c|c|c|c|c|c|}
\hline $\begin{array}{c}\text { Sampling } \\
\text { Average Depth }\end{array}$ & $\begin{array}{l}\text { Volumetric } \\
\text { Mean }\end{array}$ & $\begin{array}{l}\text { Volumetric } \\
\text { Median }\end{array}$ & $\begin{array}{c}\text { Fraction }<5.5 \\
\mu \mathrm{m}\end{array}$ & $\begin{array}{l}\text { Fraction Silt: } 5.5 \text { to } \\
63 \mu \mathrm{m}\end{array}$ & $\begin{array}{c}\text { Fraction } 5.5 \text { to } \\
16 \mu \mathrm{m}\end{array}$ & $\begin{array}{l}\text { Fraction } 16 \\
\text { to } 44 \mu \mathrm{m}\end{array}$ & $\begin{array}{c}\text { Fraction } 44 \\
\text { to } 63 \mu \mathrm{m}\end{array}$ & $\begin{array}{c}\text { Fraction } 63 \\
\text { to } 160 \mu \mathrm{m}\end{array}$ \\
\hline \multicolumn{9}{|l|}{0.01} \\
\hline 0.06 & 21.63410989 & 14.80147954 & 27.94031089 & 67.58495032 & 24.32178016 & 33.79499767 & 9.468172487 & 4.456191099 \\
\hline 0.11 & 21.60013136 & 14.18616559 & 27.48244428 & 68.54957511 & 23.61908456 & 35.00327678 & 9.927213769 & 3.947172388 \\
\hline 0.16 & 20.88872806 & 14.87121342 & 28.49087577 & 67.75488782 & 23.89227536 & 34.27189909 & 9.590713371 & 3.739575972 \\
\hline 0.21 & 20.82028827 & 14.57393066 & 28.07905009 & 68.17502221 & 23.76726872 & 35.00998414 & 9.397769341 & 3.745499735 \\
\hline 0.26 & 22.27942054 & 14.02257905 & 26.9157902 & 68.19358574 & 23.86978675 & 34.52001329 & 9.803785704 & 4.877744348 \\
\hline 0.31 & 23.8858242 & 15.88182324 & 25.59747072 & 68.30634606 & 23.46566478 & 34.53257312 & 10.30810816 & 6.054260046 \\
\hline 0.36 & 20.81987805 & 12.41323798 & 28.76404664 & 67.50634735 & 23.7793645 & 34.19028237 & 9.53670048 & 3.722824718 \\
\hline 0.41 & 20.83361594 & 14.63406928 & 28.0067068 & 68.30613733 & 23.9611825 & 34.88488555 & 9.460069278 & 3.68673687 \\
\hline 0.46 & 22.36387527 & 16.0744465 & 26.54560131 & 68.97734568 & 22.86202448 & 35.74990751 & 10.36541369 & 4.467004852 \\
\hline 0.51 & 21.92690005 & 14.04325906 & 27.27804049 & 68.33086471 & 23.5363368 & 34.61195414 & 10.18257377 & 4.379481665 \\
\hline 0.56 & 22.39382418 & 15.56709419 & 24.20797661 & 71.516735 & 24.14140306 & 37.33534143 & 10.03999051 & 4.271851158 \\
\hline 0.61 & 21.57196245 & 14.59852472 & 26.41398466 & 69.19506458 & 25.5514773 & 33.76799326 & 9.87559403 & 4.388776705 \\
\hline 0.66 & 22.64550714 & 16.18420004 & 25.78139839 & 69.36664114 & 23.81728014 & 35.32942097 & 10.21994002 & 4.833316811 \\
\hline 0.71 & 21.06016228 & 14.85215728 & 27.34013405 & 68.69346409 & 25.1133791 & 34.05804559 & 9.522039395 & 3.95924919 \\
\hline
\end{tabular}




\begin{tabular}{|c|c|c|c|c|c|c|c|c|}
\hline 0.76 & 22.0523511 & 16.12266694 & 24.22352022 & 71.63611873 & 25.2187941 & 36.46027652 & 9.95704811 & 4.135105539 \\
\hline 0.81 & 21.80973769 & 13.7782925 & 25.08082054 & 70.83098196 & 25.26941688 & 35.92101604 & 9.640549039 & 4.080099796 \\
\hline 0.86 & 20.35692532 & 12.81756224 & 27.69395097 & 68.72850731 & 25.86674448 & 33.66586225 & 9.195900581 & 3.577012301 \\
\hline 0.91 & 23.07019257 & 15.22333798 & 23.79837257 & 71.38970127 & 23.98153224 & 36.53917288 & 10.86899615 & 4.810351622 \\
\hline 0.96 & 22.10573491 & 13.71008186 & 25.13477583 & 70.51161517 & 25.06643106 & 35.07220517 & 10.37297894 & 4.351674619 \\
\hline 1.01 & 21.60076104 & 13.7480211 & 25.18154085 & 70.92539627 & 25.10193948 & 35.88273339 & 9.940723408 & 3.890986646 \\
\hline 1.06 & 21.73174575 & 16.03959689 & 24.18676667 & 71.95752556 & 25.09768886 & 37.16780039 & 9.692036315 & 3.854461874 \\
\hline 1.11 & 22.66936264 & 15.99981133 & 23.03057146 & 72.7322562 & 24.21476865 & 37.8395166 & 10.67797096 & 4.236879952 \\
\hline 1.16 & 20.76968699 & 14.85109992 & 26.16928041 & 70.08234165 & 26.42453385 & 34.58139767 & 9.076410124 & 3.747369079 \\
\hline 1.21 & 21.69528536 & 16.10035956 & 23.85883585 & 72.39089423 & 25.5315757 & 37.19602376 & 9.663294777 & 3.749343142 \\
\hline 1.26 & 20.07303379 & 13.43189668 & 27.91807345 & 68.69558756 & 27.15515893 & 32.87819618 & 8.662232441 & 3.375763781 \\
\hline 1.31 & 20.57931353 & 14.73733086 & 25.9902696 & 70.39621802 & 26.3840734 & 34.93015284 & 9.081991771 & 3.613405213 \\
\hline 1.36 & 20.78887728 & 14.00875482 & 24.19508266 & 72.52211804 & 26.69875325 & 37.17622327 & 8.64714152 & 3.281918291 \\
\hline 1.41 & 19.29452851 & 13.29700307 & 26.63919367 & 70.44216742 & 28.48650959 & 33.84320128 & 8.112456549 & 2.918638911 \\
\hline 1.46 & 18.77408592 & 11.79762074 & 28.15044487 & 69.01128929 & 28.83224733 & 32.27609724 & 7.902944727 & 2.838265834 \\
\hline 1.51 & 19.20944545 & 11.90159179 & 28.74276664 & 67.89635625 & 28.23229664 & 31.55304707 & 8.111012539 & 3.360068722 \\
\hline 1.56 & 20.46677878 & 12.45188032 & 25.84856245 & 70.58386317 & 27.17110119 & 34.78283462 & 8.629927358 & 3.566376565 \\
\hline 1.61 & 21.15054651 & 13.69697179 & 24.33711662 & 72.23352307 & 25.85289465 & 37.0438702 & 9.33675821 & 3.428896857 \\
\hline 1.66 & 21.28606849 & 16.29445262 & 23.96709659 & 72.6086918 & 25.81436184 & 37.44784925 & 9.346480713 & 3.423601416 \\
\hline
\end{tabular}




\begin{tabular}{|c|c|c|c|c|c|c|c|c|}
\hline 1.71 & 18.92052515 & 11.70036662 & 28.54945984 & 68.48724083 & 28.07209851 & 32.63374586 & 7.781396459 & 2.963059025 \\
\hline 1.76 & 20.68127618 & 16.3018929 & 23.94510199 & 73.21690817 & 25.84525795 & 38.46223241 & 8.909417809 & 2.837907656 \\
\hline 1.81 & 19.16014011 & 13.28026997 & 27.46180124 & 69.78874698 & 27.55577666 & 34.37839367 & 7.85457665 & 2.749227353 \\
\hline 1.86 & 18.78073267 & 11.38248465 & 28.02943409 & 69.29737213 & 28.05352037 & 33.67406925 & 7.569782518 & 2.672986159 \\
\hline 1.91 & 18.40904967 & 11.56937101 & 28.5470122 & 69.15409292 & 27.85839894 & 33.64765696 & 7.648037026 & 2.298894876 \\
\hline 1.96 & 19.95432582 & 14.87020439 & 26.60122995 & 70.57943151 & 26.07998464 & 35.69214497 & 8.807301905 & 2.819338538 \\
\hline 2.01 & 19.28252687 & 13.20278528 & 28.15193677 & 69.12155877 & 26.48221982 & 34.46491531 & 8.174423638 & 2.726323791 \\
\hline 2.06 & 18.16196236 & 11.87445527 & 29.69710528 & 68.22300852 & 27.1900306 & 33.38629663 & 7.64668129 & 2.079766024 \\
\hline 2.11 & 19.96485664 & 14.50742984 & 26.30461561 & 71.35154705 & 25.5967738 & 36.82447635 & 8.930296892 & 2.343510203 \\
\hline 2.16 & 18.22994733 & 13.11451046 & 28.04561104 & 71.01118831 & 26.48473253 & 36.02512123 & 8.501334557 & 0.943200644 \\
\hline 2.21 & 18.94921201 & 14.75108274 & 26.46945472 & 72.36315334 & 26.02945384 & 37.4059587 & 8.927740803 & 1.167391944 \\
\hline 2.26 & 19.13345454 & 12.99157472 & 27.80720256 & 69.91781875 & 26.37225301 & 35.50593846 & 8.039627284 & 2.274597532 \\
\hline 2.31 & 19.68995881 & 14.44853326 & 25.85418085 & 72.05595941 & 25.96550815 & 37.56558035 & 8.524870907 & 2.089859742 \\
\hline 2.36 & 18.79825902 & 12.52614548 & 26.71886072 & 72.01681421 & 26.48206791 & 36.81621028 & 8.718536021 & 1.264325067 \\
\hline 2.41 & 18.38590541 & 12.07719853 & 28.28688296 & 69.72956733 & 27.50280901 & 34.4517646 & 7.774993717 & 1.983549712 \\
\hline 2.46 & 18.80484518 & 13.30569972 & 27.81424539 & 70.21342296 & 27.17110612 & 35.18669197 & 7.85562487 & 1.972064935 \\
\hline 2.51 & 20.74350749 & 14.09344438 & 26.04010236 & 70.8034228 & 24.95199449 & 36.25439871 & 9.597029594 & 3.156291363 \\
\hline 2.56 & 18.65794828 & 13.38166839 & 27.98995191 & 69.64093875 & 27.18487574 & 34.69371822 & 7.762344788 & 2.369109347 \\
\hline 2.61 & 17.89930013 & 11.39548355 & 28.35003065 & 70.42299368 & 27.75384619 & 34.62112009 & 8.048027398 & 1.226975663 \\
\hline
\end{tabular}




\begin{tabular}{|c|c|c|c|c|c|c|c|c|}
\hline 2.66 & 20.31473734 & 14.28402008 & 25.47701344 & 71.58551271 & 25.97330287 & 36.74393782 & 8.868272018 & 2.937473853 \\
\hline 2.71 & 21.61266566 & 15.38758419 & 23.48339633 & 73.4192834 & 24.49006432 & 38.1831998 & 10.74601929 & 3.097320271 \\
\hline 2.76 & 20.27467334 & 14.16669868 & 25.45288489 & 71.86857997 & 25.74785827 & 36.87517105 & 9.245550658 & 2.678535138 \\
\hline 2.81 & 22.12506855 & 16.80801335 & 22.74636521 & 73.96331827 & 24.0395545 & 38.64399388 & 11.27976989 & 3.290316512 \\
\hline 2.86 & 19.79359235 & 14.76619876 & 26.04442852 & 71.415865 & 26.46800128 & 36.10923367 & 8.838630058 & 2.53970648 \\
\hline 2.91 & 19.25043893 & 13.19611148 & 27.8509518 & 69.53615036 & 26.84706662 & 34.75396688 & 7.935116859 & 2.611550094 \\
\hline 2.96 & 20.23852504 & 14.41469371 & 25.85459955 & 71.35427771 & 25.84510584 & 36.35102442 & 9.158147447 & 2.791122738 \\
\hline 3.01 & 20.15885809 & 14.61066254 & 25.94862239 & 71.2003648 & 26.19555023 & 36.13112747 & 8.873687105 & 2.850832171 \\
\hline 3.06 & 18.97101402 & 13.4147735 & 27.73608762 & 69.82232478 & 27.5019312 & 34.21988409 & 8.100509488 & 2.44146517 \\
\hline 3.11 & 17.7345872 & 12.11086147 & 29.79638827 & 68.29284291 & 27.87217048 & 33.23805772 & 7.182614704 & 1.91076882 \\
\hline 3.16 & 18.20188252 & 11.46956461 & 29.01991156 & 69.13464183 & 27.00362871 & 34.50942819 & 7.621584927 & 1.845446616 \\
\hline 3.21 & 18.01396915 & 11.86046855 & 28.99716148 & 69.12935672 & 28.13101378 & 33.46717731 & 7.531165634 & 1.873481801 \\
\hline 3.26 & 17.60666298 & 12.21290305 & 29.59737774 & 68.64907784 & 28.46284704 & 32.9956456 & 7.1905852 & 1.753544426 \\
\hline 3.31 & 21.60780415 & 16.28751102 & 24.78956079 & 71.3519529 & 24.99015889 & 36.25431529 & 10.10747872 & 3.858308707 \\
\hline 3.36 & 19.72172151 & 13.1310104 & 26.42372968 & 70.67061896 & 26.68390515 & 36.03468395 & 7.952029856 & 2.905547527 \\
\hline 3.41 & 18.909883 & 12.82695111 & 26.67222217 & 71.42696239 & 27.27384927 & 35.92986412 & 8.223248994 & 1.900815443 \\
\hline 3.46 & 19.03890196 & 12.91008046 & 27.69942729 & 70.10689752 & 26.27464656 & 35.5294164 & 8.302834557 & 2.193675187 \\
\hline 3.51 & 19.61094931 & 14.05746227 & 26.88905018 & 70.68624617 & 25.83444503 & 36.08991594 & 8.761885201 & 2.424703655 \\
\hline 3.56 & 17.62038615 & 12.04181372 & 29.5541807 & 68.88445714 & 27.9925528 & 33.64836244 & 7.243541903 & 1.56136216 \\
\hline
\end{tabular}




\begin{tabular}{|c|c|c|c|c|c|c|c|c|}
\hline 3.61 & 17.94185553 & 11.78734259 & 29.59115438 & 68.69126012 & 27.21502837 & 34.00940745 & 7.466824306 & 1.717528118 \\
\hline 3.66 & 21.52084324 & 15.62670564 & 23.81797409 & 73.16371775 & 24.63209058 & 38.1945045 & 10.33712267 & 3.018166891 \\
\hline 3.71 & 16.47499287 & 10.68574885 & 31.21952808 & 68.08300963 & 28.26423306 & 32.93045298 & 6.888323596 & 0.697462287 \\
\hline 3.76 & 18.53323275 & 13.5435969 & 28.83289571 & 69.39106555 & 26.48482477 & 34.73319108 & 8.173049705 & 1.775898423 \\
\hline 3.81 & 16.0200724 & 11.01221379 & 31.42607307 & 67.94324484 & 29.37319004 & 32.14768316 & 6.422371644 & 0.630682092 \\
\hline 3.86 & 17.64527174 & 11.59181666 & 29.12140695 & 69.70995265 & 27.28303825 & 34.89074101 & 7.536173396 & 1.168640405 \\
\hline 3.91 & 19.2647647 & 12.57179322 & 26.92840318 & 71.09606319 & 26.31909877 & 36.17999064 & 8.596973776 & 1.975518796 \\
\hline 3.96 & 19.07207019 & 13.3111707 & 28.55172773 & 69.2330181 & 26.12028816 & 34.68579665 & 8.426933288 & 2.214365485 \\
\hline 4.01 & 18.36848057 & 13.45441833 & 28.56834657 & 69.44852178 & 26.64573204 & 35.05316846 & 7.749621279 & 1.983131652 \\
\hline 4.06 & 19.6763735 & 14.82941382 & 26.80318068 & 70.9115034 & 25.78781624 & 36.42807849 & 8.695608678 & 2.284882875 \\
\hline 4.11 & 19.60304381 & 14.48554275 & 26.41855224 & 71.64882058 & 25.43677253 & 37.44457988 & 8.767468161 & 1.932627178 \\
\hline 4.16 & 18.34441798 & 13.01269978 & 27.57749751 & 71.33933553 & 26.69346917 & 36.24599288 & 8.399873474 & 1.083166959 \\
\hline 4.21 & 20.74309635 & 13.80126945 & 24.83473156 & 72.46023467 & 25.57390551 & 37.19630953 & 9.690019633 & 2.704550975 \\
\hline 4.26 & 19.47447107 & 14.63485216 & 26.49474708 & 71.78733243 & 25.66540779 & 37.08799147 & 9.033933179 & 1.717920484 \\
\hline 4.31 & 20.06485155 & 14.34186696 & 25.70980176 & 71.79393572 & 25.86205764 & 36.84134239 & 9.090535694 & 2.496262513 \\
\hline 4.36 & 21.09995677 & 13.82421202 & 24.70389473 & 71.93194843 & 25.75057289 & 36.76790463 & 9.413470909 & 3.363989431 \\
\hline 4.41 & 22.11921663 & 15.68170592 & 24.0427321 & 72.16120168 & 24.54238735 & 37.10888937 & 10.50992496 & 3.794638964 \\
\hline 4.46 & 19.53520591 & 12.81642234 & 26.68490331 & 70.81887036 & 27.13628958 & 35.23554058 & 8.447040199 & 2.495653248 \\
\hline 4.51 & 20.00106803 & 12.83517477 & 27.15230681 & 69.79300404 & 26.59349365 & 34.25096205 & 8.948548336 & 3.053568156 \\
\hline
\end{tabular}




\begin{tabular}{|c|c|c|c|c|c|c|c|c|}
\hline 4.56 & 20.94035292 & 13.6848755 & 24.78757487 & 72.09336257 & 25.37290425 & 37.08623726 & 9.634221059 & 3.119049326 \\
\hline 4.61 & 20.06686844 & 14.73589466 & 25.5432401 & 71.72031096 & 26.94226282 & 35.94378784 & 8.834260301 & 2.7360034 \\
\hline 4.66 & 18.31246994 & 11.95182627 & 28.38251898 & 69.36754548 & 29.09803381 & 32.72064524 & 7.548866426 & 2.249393316 \\
\hline 4.71 & 20.48106479 & 14.46730746 & 25.49212844 & 71.38854622 & 26.34772088 & 35.95537938 & 9.085445966 & 3.119037494 \\
\hline 4.76 & 18.1753352 & 11.84751722 & 28.54878718 & 69.3819354 & 28.63019231 & 33.16322384 & 7.588519251 & 2.069277423 \\
\hline 4.81 & 21.1728807 & 14.60290247 & 24.67860769 & 71.99875005 & 25.4563005 & 37.05806235 & 9.484387203 & 3.321712834 \\
\hline 4.86 & 20.13287613 & 14.56291165 & 25.58612731 & 71.57818392 & 26.49464084 & 36.35093709 & 8.732606 & 2.835532836 \\
\hline 4.91 & 19.8902781 & 12.52829497 & 25.95952481 & 71.02620587 & 27.29577474 & 35.33528315 & 8.395147971 & 3.014198178 \\
\hline 4.96 & 20.72331269 & 14.29909715 & 25.39417152 & 71.2048892 & 26.07367744 & 36.03155003 & 9.099661723 & 3.400655686 \\
\hline 5.01 & 19.0835486 & 13.5275306 & 27.36871424 & 69.92281056 & 28.18967446 & 33.70921111 & 8.023924982 & 2.708373882 \\
\hline 5.06 & 20.46380651 & 14.76379714 & 25.63200358 & 70.91529846 & 26.89249495 & 35.4189186 & 8.603884912 & 3.451816741 \\
\hline 5.11 & 19.2875386 & 13.06915476 & 26.66126411 & 70.57371533 & 27.91872717 & 34.67239845 & 7.982589709 & 2.765020556 \\
\hline 5.16 & 19.31561172 & 13.34479074 & 27.11970724 & 69.98633994 & 28.02114916 & 33.82776711 & 8.137423673 & 2.893933359 \\
\hline 5.21 & 21.38743845 & 13.71402236 & 24.67801214 & 71.46931112 & 25.54252982 & 36.40269785 & 9.524083454 & 3.852540882 \\
\hline 5.26 & 20.32840429 & 12.59938582 & 26.3937898 & 69.92599026 & 26.95192552 & 34.96363286 & 8.010431883 & 3.679348714 \\
\hline 5.31 & 19.71414676 & 13.11179464 & 27.14894462 & 69.57589629 & 27.34038359 & 33.93773417 & 8.297778532 & 3.275086783 \\
\hline 5.36 & 20.08467131 & 14.70107481 & 25.75596577 & 71.27816917 & 26.62006723 & 36.08212886 & 8.57597308 & 2.965865059 \\
\hline 5.41 & 21.16498572 & 13.87119671 & 24.91130776 & 71.42355935 & 25.63938992 & 36.33438263 & 9.449786799 & 3.665120322 \\
\hline 5.46 & 19.88461837 & 12.56517781 & 26.27833473 & 70.76632651 & 27.02611451 & 35.25975506 & 8.480456944 & 2.954825096 \\
\hline
\end{tabular}




\begin{tabular}{|c|c|c|c|c|c|c|c|c|}
\hline 5.51 & 19.85487549 & 12.56202679 & 26.20830691 & 70.82435585 & 27.08013281 & 35.42598826 & 8.318234787 & 2.966913473 \\
\hline 5.56 & 21.3380484 & 16.1298062 & 23.82177214 & 72.30887438 & 25.61838292 & 37.87144822 & 8.819043241 & 3.869353483 \\
\hline 5.61 & 21.67399606 & 15.77625433 & 24.0781665 & 72.32077765 & 24.67188794 & 37.57020159 & 10.07868812 & 3.600887906 \\
\hline 5.66 & 21.25802354 & 13.81403862 & 24.9759254 & 71.49142591 & 25.4580285 & 36.64366658 & 9.389730835 & 3.531499337 \\
\hline 5.71 & 20.36532947 & 14.30779965 & 25.47722135 & 71.6546233 & 26.03559379 & 36.59485258 & 9.024176928 & 2.867603484 \\
\hline 5.76 & 22.73733511 & 17.70770961 & 22.75043283 & 73.17468682 & 23.81150051 & 38.32707737 & 11.03610895 & 4.074830597 \\
\hline 5.81 & 21.98918996 & 15.68194002 & 23.97510778 & 72.18062849 & 24.60719746 & 37.28101495 & 10.29241608 & 3.843939039 \\
\hline 5.86 & 20.80025501 & 13.78405115 & 24.99545888 & 71.94284707 & 25.37597046 & 37.29256089 & 9.274315726 & 3.061553022 \\
\hline 5.91 & 22.17473002 & 15.56672821 & 23.70172904 & 72.32689784 & 24.65242008 & 37.39604736 & 10.2784304 & 3.970496515 \\
\hline 5.96 & 22.76002553 & 17.61259138 & 22.52351261 & 73.34003765 & 23.84520555 & 38.7444963 & 10.7503358 & 4.136404943 \\
\hline 6.01 & 19.89276111 & 12.54649738 & 26.43677795 & 70.61729843 & 26.81746733 & 35.46433518 & 8.335495915 & 2.945356487 \\
\hline 6.06 & 20.85979767 & 13.68701426 & 24.20285508 & 73.02510763 & 25.96702525 & 37.65749918 & 9.400583192 & 2.768409708 \\
\hline 6.11 & 20.09995085 & 14.28725386 & 25.31201562 & 71.91953908 & 26.15766957 & 37.15175661 & 8.610112902 & 2.768445303 \\
\hline 6.16 & 19.64803005 & 12.71181386 & 26.31674791 & 70.81471654 & 27.32943501 & 35.29113452 & 8.194147009 & 2.868535555 \\
\hline 6.21 & 21.24356677 & 14.55961137 & 24.40441275 & 72.3969977 & 25.64035001 & 36.99430876 & 9.762338932 & 3.19725025 \\
\hline 6.26 & 21.63029707 & 15.92701236 & 24.13579811 & 72.34665138 & 24.91736299 & 37.50322696 & 9.926061423 & 3.516571938 \\
\hline 6.31 & 23.07791303 & 17.06118898 & 21.53518259 & 74.27873717 & 23.72705884 & 39.64827568 & 10.90340264 & 4.185782751 \\
\hline 6.36 & 23.80826225 & 16.54321695 & 21.25782682 & 74.21661232 & 23.13414142 & 39.66352998 & 11.41894092 & 4.524232888 \\
\hline 6.41 & 22.43959106 & 15.99466646 & 23.02889774 & 73.06596655 & 24.14696472 & 38.42816258 & 10.49083925 & 3.904165126 \\
\hline
\end{tabular}




\begin{tabular}{|c|c|c|c|c|c|c|c|c|}
\hline 6.46 & 23.38196597 & 17.08418131 & 21.84864461 & 73.82731356 & 23.50974582 & 39.29118758 & 11.02638016 & 4.322366514 \\
\hline 6.51 & 19.92685627 & 12.88952001 & 27.06639204 & 69.75595377 & 26.82285142 & 34.32436468 & 8.608737677 & 3.177192481 \\
\hline 6.56 & 23.28193605 & 16.87735351 & 21.33150488 & 74.4543102 & 23.47769583 & 40.28801813 & 10.68859624 & 4.213360344 \\
\hline 6.61 & 18.71454528 & 13.28866553 & 27.36178431 & 70.44468987 & 27.69036696 & 35.23780385 & 7.516519066 & 2.193525816 \\
\hline 6.66 & 18.02416393 & 11.84056088 & 28.70841337 & 69.13731156 & 28.65846301 & 33.63502911 & 6.843819434 & 2.154032624 \\
\hline 6.71 & 18.42774537 & 12.57394928 & 26.44716683 & 72.72949048 & 26.97479133 & 37.47413324 & 8.280565908 & 0.82334269 \\
\hline 6.76 & 18.10628641 & 13.31442211 & 27.28477721 & 71.22968026 & 28.03166942 & 35.92547187 & 7.272538977 & 1.485542531 \\
\hline 6.81 & 20.93317555 & 15.55977222 & 23.30927447 & 74.37648731 & 24.90134761 & 39.75864847 & 9.716491229 & 2.314110051 \\
\hline 6.86 & 15.99816749 & 11.0543442 & 31.25023051 & 67.88786209 & 29.98754387 & 31.77328886 & 6.127029358 & 0.861907408 \\
\hline 6.91 & 17.58282018 & 11.4156122 & 29.16050273 & 68.78430298 & 26.75022075 & 34.50743018 & 7.526652052 & 2.055194286 \\
\hline 6.96 & 22.37506529 & 17.62486358 & 22.29994481 & 74.07104616 & 23.97290205 & 39.4213211 & 10.67682301 & 3.629009028 \\
\hline 7.01 & 15.86880284 & 10.87770224 & 30.57338109 & 68.90701541 & 30.36893388 & 32.51074984 & 6.027331688 & 0.519603498 \\
\hline 7.06 & 17.03516887 & 11.60839299 & 28.68144255 & 70.58093505 & 28.26048212 & 35.58310792 & 6.737345012 & 0.737622402 \\
\hline 7.11 & 17.56116284 & 13.54294755 & 28.97038592 & 70.18478157 & 26.62139303 & 36.17121287 & 7.392175671 & 0.844832512 \\
\hline 7.16 & 17.67995266 & 11.78664992 & 29.93711689 & 68.53707819 & 26.88329357 & 34.54477729 & 7.10900733 & 1.525804926 \\
\hline 7.21 & 16.4821351 & 10.37298685 & 30.58014016 & 68.70042003 & 28.4295365 & 33.61363407 & 6.657249454 & 0.719439812 \\
\hline 7.26 & 22.38376734 & 15.95569461 & 23.67147079 & 72.65738365 & 23.44949404 & 38.43127975 & 10.77660986 & 3.669871946 \\
\hline 7.31 & 22.33049083 & 16.00573187 & 23.3895219 & 72.49756054 & 23.78865872 & 37.98912164 & 10.71978018 & 4.112917561 \\
\hline 7.36 & 19.24608712 & 13.25284708 & 28.78928084 & 68.23326755 & 25.86197083 & 34.07183114 & 8.299465585 & 2.977348443 \\
\hline
\end{tabular}




\begin{tabular}{|c|c|c|c|c|c|c|c|c|}
\hline 7.41 & 16.52958241 & 10.73369114 & 31.57178072 & 67.6079618 & 28.00656398 & 32.46887663 & 7.132521189 & 0.820257481 \\
\hline 7.46 & 19.43756029 & 13.29688527 & 27.14547934 & 70.44393479 & 25.87338628 & 35.83100585 & 8.739542662 & 2.410585873 \\
\hline 7.51 & 16.0548756 & 11.10859479 & 31.73917756 & 67.33034343 & 29.26589213 & 32.07219571 & 5.992255599 & 0.930479009 \\
\hline 7.56 & 16.13115033 & 11.04820567 & 32.29069479 & 66.97929705 & 28.17696709 & 32.0984336 & 6.703896358 & 0.730008165 \\
\hline 7.61 & 15.46780339 & 9.731830894 & 33.49707294 & 65.91427949 & 28.76006993 & 31.03203953 & 6.122170028 & 0.588647573 \\
\hline 7.66 & 20.96786299 & 16.13205174 & 25.65161676 & 71.50110327 & 23.8232975 & 37.24574772 & 10.43205805 & 2.847279968 \\
\hline 7.71 & 20.51031157 & 14.64980985 & 26.27733528 & 71.13912391 & 23.94930108 & 37.35985828 & 9.829964553 & 2.583540802 \\
\hline 7.76 & 16.18607644 & 10.91248249 & 31.95974649 & 67.25405372 & 28.25430753 & 32.364399 & 6.635347191 & 0.786199792 \\
\hline 7.81 & 18.26720639 & 12.78844461 & 28.9577399 & 69.25674809 & 26.59339491 & 34.92140772 & 7.741945454 & 1.785512012 \\
\hline 7.86 & 14.11584756 & 9.218921932 & 36.24130823 & 63.3845673 & 30.13981961 & 28.19911168 & 5.045636009 & 0.374124475 \\
\hline 7.91 & 15.84865696 & 10.62467741 & 32.3961741 & 66.85172456 & 29.04169049 & 31.44784989 & 6.362184183 & 0.752101332 \\
\hline 7.96 & 17.65612269 & 11.76509881 & 29.96124567 & 68.50470177 & 26.92545619 & 34.37413292 & 7.205112663 & 1.533995443 \\
\hline 8.01 & 16.86956022 & 10.76255773 & 32.16095484 & 66.5282662 & 27.1143921 & 32.25594408 & 7.157930023 & 1.310778962 \\
\hline 8.06 & 19.72694927 & 14.58484865 & 26.65327027 & 70.93347966 & 25.43732882 & 36.52381729 & 8.972333546 & 2.413250078 \\
\hline 8.11 & 23.92620755 & 19.45705371 & 22.05382403 & 73.32040278 & 21.64714329 & 39.34374926 & 12.32951023 & 4.625615166 \\
\hline 8.16 & 20.51574935 & 14.7250178 & 25.2223481 & 72.12449736 & 25.17408938 & 37.6793157 & 9.271092286 & 2.653128937 \\
\hline 8.21 & 20.18455325 & 14.24732283 & 26.78815975 & 70.70065277 & 24.48946406 & 36.2079927 & 10.00319601 & 2.511187485 \\
\hline 8.26 & 21.18247108 & 14.64227051 & 26.10219588 & 70.44611069 & 24.10706997 & 36.12460564 & 10.21443508 & 3.451564309 \\
\hline 8.31 & 15.12256332 & 7.832343209 & 36.82093444 & 61.94223815 & 28.80219432 & 27.02900377 & 6.111040059 & 1.236752693 \\
\hline
\end{tabular}




\begin{tabular}{|c|c|c|c|c|c|c|c|c|}
\hline 8.36 & 25.47626715 & 18.63295818 & 21.45554655 & 72.19719379 & 21.1953388 & 37.88753993 & 13.11431506 & 6.346912062 \\
\hline 8.41 & 20.63392582 & 14.03905395 & 25.81925795 & 71.18413093 & 25.07674954 & 36.38957693 & 9.717804459 & 2.996611123 \\
\hline 8.46 & 23.96153763 & 16.64035877 & 22.30142346 & 72.75565768 & 22.39659498 & 38.19535436 & 12.16370833 & 4.94224116 \\
\hline 8.51 & 24.33321832 & 19.51665217 & 22.03189122 & 72.9088669 & 21.86851556 & 38.49576742 & 12.54458393 & 5.05849301 \\
\hline 8.56 & 20.60189458 & 14.80904387 & 27.94658018 & 68.63347639 & 24.37306076 & 34.09487864 & 10.16553698 & 3.419943435 \\
\hline 8.61 & 20.54473732 & 14.2215462 & 26.18585032 & 70.56985041 & 25.11767592 & 35.97655086 & 9.475623622 & 3.244299275 \\
\hline 8.66 & 26.23921581 & 20.87697927 & 20.21496252 & 73.64098164 & 20.1793723 & 39.18740478 & 14.27420456 & 6.143593389 \\
\hline 8.71 & 27.14513669 & 20.67949299 & 20.29169297 & 72.07689993 & 20.00168972 & 37.42218006 & 14.65303016 & 7.630655812 \\
\hline 8.76 & 20.30423284 & 14.5421724 & 27.58323397 & 69.68704298 & 24.22902745 & 35.63366278 & 9.824352745 & 2.729643862 \\
\hline 8.81 & 18.84187646 & 13.2921177 & 28.60143026 & 69.21318521 & 26.26438729 & 34.11856353 & 8.8302344 & 2.185384522 \\
\hline 8.86 & 22.60257464 & 15.73584404 & 25.75582574 & 69.24450755 & 23.02501011 & 35.20912849 & 11.01036895 & 4.99966671 \\
\hline 8.91 & 20.0532079 & 14.56500728 & 26.29781626 & 70.94233314 & 25.75546812 & 35.61869117 & 9.56817385 & 2.759850595 \\
\hline 8.96 & 21.04221233 & 13.83212264 & 26.29240987 & 70.33889893 & 24.16821562 & 36.49115435 & 9.679528964 & 3.367754565 \\
\hline 9.01 & 21.04889179 & 14.52917961 & 27.18401355 & 68.9915085 & 24.6233066 & 34.03050957 & 10.33769233 & 3.824343024 \\
\hline 9.06 & 21.69405536 & 15.83783769 & 24.5929347 & 71.73199145 & 24.29335531 & 36.78374131 & 10.65489484 & 3.675073847 \\
\hline 9.11 & 23.97304646 & 19.64897092 & 21.48572459 & 73.92490974 & 22.37039784 & 39.43784467 & 12.11666724 & 4.588884305 \\
\hline 9.16 & 23.82364576 & 17.48886918 & 23.27864551 & 71.68619635 & 23.09936448 & 36.22422576 & 12.36260612 & 5.031763078 \\
\hline 9.21 & 22.63340542 & 17.72402662 & 23.45202316 & 72.57509879 & 23.15475996 & 37.9392186 & 11.48112023 & 3.972878044 \\
\hline 9.26 & 23.42174542 & 17.42480058 & 23.18638352 & 71.9291484 & 22.95597714 & 37.17007966 & 11.8030916 & 4.88446808 \\
\hline
\end{tabular}




\begin{tabular}{|c|c|c|c|c|c|c|c|c|}
\hline 9.31 & 24.60852861 & 16.6390706 & 22.88790839 & 71.46734071 & 22.33069639 & 35.95327854 & 13.18336578 & 5.644381367 \\
\hline 9.36 & 25.69978127 & 18.27137727 & 20.52623334 & 73.70132128 & 21.41858521 & 38.47060029 & 13.81213578 & 5.771135895 \\
\hline 9.41 & 25.48330962 & 18.95857237 & 21.62262973 & 72.44197584 & 21.49194805 & 37.57299738 & 13.37703041 & 5.92537333 \\
\hline 9.46 & 21.90236732 & 14.20697342 & 25.76002548 & 69.76162196 & 25.4015882 & 33.15228941 & 11.20774435 & 4.478169259 \\
\hline 9.51 & 25.28120596 & 19.05128387 & 22.008878 & 71.92862665 & 21.64047972 & 36.64653103 & 13.6416159 & 6.062116101 \\
\hline 9.56 & 25.79850297 & 18.35555476 & 20.80097888 & 72.99906743 & 21.31672139 & 38.2731398 & 13.40920624 & 6.199152706 \\
\hline 9.61 & 27.71349308 & 23.66124385 & 18.95331871 & 73.82042208 & 19.60106383 & 39.12980036 & 15.0895579 & 7.220907942 \\
\hline 9.66 & 24.44983551 & 16.51411883 & 22.15418829 & 72.36029076 & 22.49473171 & 37.12139979 & 12.74415927 & 5.485301987 \\
\hline 9.71 & 26.09644604 & 18.46105755 & 20.86026649 & 72.43121912 & 21.52388188 & 37.47915756 & 13.42817968 & 6.706203011 \\
\hline 9.76 & 25.55062328 & 18.54665765 & 20.80499474 & 73.1217699 & 21.5673314 & 38.31696169 & 13.23747681 & 6.072425425 \\
\hline 9.81 & 24.70810386 & 19.53035134 & 21.89583029 & 72.44103184 & 22.26503239 & 37.24252168 & 12.93347778 & 5.663081692 \\
\hline 9.86 & 24.94857184 & 18.91999745 & 21.00781112 & 73.55709122 & 21.8767014 & 38.80488648 & 12.87550334 & 5.434579413 \\
\hline 9.91 & 23.80832705 & 16.98360942 & 22.92484796 & 72.1385442 & 22.50510103 & 37.72800579 & 11.90543738 & 4.936204562 \\
\hline 9.96 & 23.43286529 & 17.71495823 & 23.35989216 & 71.70068232 & 23.41994039 & 36.6284571 & 11.65228483 & 4.938831255 \\
\hline 10.01 & 25.00205012 & 19.42458342 & 22.09153476 & 72.05067303 & 21.94018175 & 37.14426166 & 12.96622962 & 5.856223801 \\
\hline 10.06 & 23.04040796 & 17.66117187 & 23.24773892 & 72.48223186 & 23.3461134 & 37.75853088 & 11.37758758 & 4.269189256 \\
\hline 10.11 & 24.63573306 & 18.23884929 & 19.89507618 & 75.58551811 & 21.54452977 & 41.25141829 & 12.78957005 & 4.519405704 \\
\hline 10.16 & 22.46051737 & 15.30544865 & 24.51045725 & 71.37692975 & 23.44210135 & 36.67910653 & 11.25572187 & 4.112492813 \\
\hline 10.21 & 23.30811595 & 15.00910024 & 24.35129226 & 70.64529842 & 23.14193257 & 35.7410673 & 11.76229854 & 5.002630145 \\
\hline
\end{tabular}




\begin{tabular}{|c|c|c|c|c|c|c|c|c|}
\hline 10.26 & 23.00845201 & 17.40712978 & 22.90665408 & 72.99545373 & 23.20507522 & 38.22456608 & 11.56581243 & 4.097771272 \\
\hline 10.31 & 23.74556103 & 16.68617334 & 22.40829624 & 73.13535523 & 22.57504408 & 38.43351062 & 12.12680053 & 4.455727212 \\
\hline 10.36 & 22.56152007 & 17.8553645 & 23.443557 & 72.82901756 & 23.52707947 & 37.99107187 & 11.31086622 & 3.727271475 \\
\hline 10.41 & 23.97874132 & 19.39632647 & 21.3977802 & 74.29037817 & 22.20033112 & 39.74966954 & 12.34037751 & 4.311585887 \\
\hline 10.46 & 22.56027227 & 17.39230016 & 21.67500837 & 74.85003288 & 24.11358647 & 39.86497701 & 10.8714694 & 3.474958747 \\
\hline 10.51 & 22.84293981 & 17.1420559 & 21.5731829 & 74.95061229 & 23.70632222 & 40.58895437 & 10.6553357 & 3.474947047 \\
\hline 10.56 & 20.14963559 & 14.74941938 & 26.99721536 & 70.29037817 & 25.32442378 & 35.55280616 & 9.413148234 & 2.712212948 \\
\hline 10.61 & 19.47580921 & 12.83819587 & 27.58165765 & 69.93964712 & 26.1488224 & 34.61885687 & 9.171967846 & 2.478695229 \\
\hline 10.66 & 21.94954258 & 16.9192533 & 22.09283197 & 74.89297251 & 24.70449628 & 39.9751103 & 10.21336593 & 3.013924959 \\
\hline 10.71 & 19.90015017 & 12.9965361 & 27.69410982 & 69.32200089 & 26.31309562 & 34.06438174 & 8.944523528 & 2.983889293 \\
\hline 10.76 & 20.34436406 & 14.43837414 & 26.199866871 & 70.7983492 & 25.49828097 & 36.09483434 & 9.205233885 & 3.001533457 \\
\hline 10.81 & 18.94183244 & 13.55552905 & 28.12860506 & 69.32771225 & 27.26087746 & 33.55199196 & 8.514842833 & 2.543682686 \\
\hline 10.86 & 19.13103473 & 12.71941455 & 26.80600202 & 71.52311121 & 26.775566668 & 35.26328521 & 9.484259321 & 1.670886766 \\
\hline 10.91 & 20.72510138 & 14.26164119 & 25.8199626 & 70.73928362 & 25.53809481 & 35.96669868 & 9.234490131 & 3.440753784 \\
\hline 10.96 & 18.56784683 & 12.45370432 & 28.57148629 & 69.89991598 & 26.83646387 & 33.75416267 & 9.309289443 & 1.528597724 \\
\hline 11.01 & 19.45172976 & 13.10498982 & 27.85563907 & 69.4092326 & 26.45369983 & 33.95142576 & 9.004107014 & 2.735128323 \\
\hline 11.06 & 19.5923992 & 13.24080599 & 28.24683106 & 68.80629925 & 26.31019743 & 33.72993774 & 8.766164079 & 2.946621411 \\
\hline 11.11 & 20.01367659 & 14.86284932 & 26.17435318 & 70.9599456 & 26.53745003 & 35.34788533 & 9.074610239 & 2.865701222 \\
\hline 11.16 & 20.2077581 & 12.54693729 & 27.0234671 & 69.79542239 & 26.05714437 & 34.57255704 & 9.165720981 & 3.180968605 \\
\hline
\end{tabular}




\begin{tabular}{|c|c|c|c|c|c|c|c|c|}
\hline 11.21 & 19.79763419 & 12.84347641 & 27.17710949 & 69.86378491 & 26.62527151 & 34.25171124 & 8.986802157 & 2.9591056 \\
\hline 11.26 & 20.24771338 & 14.86088351 & 26.78154595 & 70.0373101 & 25.83117308 & 34.95201137 & 9.254125645 & 3.18114395 \\
\hline 11.31 & 19.55711833 & 13.40964885 & 28.5290121 & 68.42137307 & 26.37118412 & 33.10029084 & 8.949898113 & 3.049582981 \\
\hline 11.36 & 21.36111746 & 15.88797232 & 23.10517116 & 73.66781495 & 25.80071167 & 38.17018199 & 9.696921293 & 3.22689133 \\
\hline 11.41 & 20.17110972 & 12.54663132 & 27.86544528 & 69.01542835 & 25.0840374 & 34.20824349 & 9.723147462 & 3.119126372 \\
\hline 11.46 & 20.30781681 & 12.61792651 & 27.75487053 & 68.85704656 & 25.36549092 & 34.00005674 & 9.491498905 & 3.387975636 \\
\hline 11.51 & 20.65950927 & 14.43812312 & 25.90460338 & 70.82138475 & 25.82674739 & 35.39104169 & 9.603595669 & 3.273925904 \\
\hline 11.56 & 20.90153909 & 14.11651127 & 25.86499304 & 70.69450769 & 25.17456195 & 35.75617825 & 9.76376749 & 3.44049927 \\
\hline 11.61 & 20.76932447 & 14.65365086 & 27.00913058 & 69.26387156 & 25.10377498 & 34.47190005 & 9.688196522 & 3.726111999 \\
\hline 11.66 & 20.91715129 & 14.08686609 & 25.75392066 & 70.89589781 & 25.22386836 & 35.51413265 & 10.1578968 & 3.350181534 \\
\hline 11.71 & 23.7101337 & 19.0577577 & 20.22452167 & 76.01981103 & 22.42051957 & 41.83607297 & 11.7632185 & 3.755667296 \\
\hline 11.76 & 23.20882094 & 16.99178116 & 21.62400781 & 74.16009784 & 23.47519191 & 39.55787378 & 11.12703215 & 4.215878974 \\
\hline 11.81 & 22.91982273 & 17.80119004 & 23.0370922 & 72.56009903 & 23.74296455 & 37.76250221 & 11.05463227 & 4.402630935 \\
\hline 11.86 & 22.591104 & 15.96895371 & 23.13993269 & 72.69051706 & 24.00700489 & 37.75867695 & 10.92483522 & 4.16955025 \\
\hline 11.91 & 23.22096681 & 17.07084769 & 21.98457567 & 73.77808015 & 23.39970903 & 38.92350172 & 11.45486941 & 4.237344179 \\
\hline 11.96 & 22.69852049 & 15.13072605 & 23.97273742 & 71.54877296 & 23.62454374 & 36.76282071 & 11.16140851 & 4.478489618 \\
\hline 12.01 & 24.83774602 & 18.20794012 & 18.82843747 & 76.45966118 & 22.02471997 & 42.28076374 & 12.15417747 & 4.711671278 \\
\hline 12.06 & 22.06700165 & 13.94877588 & 26.54611636 & 68.84813407 & 24.09438119 & 34.09174358 & 10.6620093 & 4.604415984 \\
\hline 12.11 & 23.9123932 & 17.36914207 & 24.01775309 & 70.47028348 & 22.28863817 & 36.02579732 & 12.15584799 & 5.511210422 \\
\hline
\end{tabular}


Table S4. Loess Mass Accumulation Rate (MAR $\mathrm{g} \mathrm{m}^{-2} \mathrm{a}^{-1}$ ) calculated for Titel and Lingtai based on modelling output.

\begin{tabular}{|c|c|c|c|c|c|c|c|}
\hline \multicolumn{4}{|l|}{ Titel } & \multicolumn{4}{|c|}{ Lingtai } \\
\hline \multicolumn{2}{|c|}{ Bacon } & \multicolumn{2}{|c|}{ Inverse (Smoothed) } & \multicolumn{2}{|c|}{ Bacon } & \multicolumn{2}{|c|}{ Inverse (Smoothed) } \\
\hline Age & MAR & Age & MAR & Age & MAR & Age & MAR \\
\hline 0.5 & 90.7 & 3.9 & 127.9 & 5.5 & 114.5 & 7.8 & 64.7 \\
\hline 1.4 & 86.7 & 6.2 & 12.7 & 6.2 & 110.6 & 8.8 & 52.0 \\
\hline 2.2 & 84.9 & 8.5 & -1.2 & 6.9 & 115.6 & 9.9 & 55.7 \\
\hline 3.1 & 86.1 & 10.8 & 191.8 & 7.5 & 112.8 & 10.9 & 64.1 \\
\hline 4.0 & 84.7 & 13.1 & 492.3 & 8.2 & 111.7 & 11.9 & 86.1 \\
\hline 4.9 & 86.9 & 15.4 & 647.6 & 8.9 & 112.5 & 12.9 & 136.3 \\
\hline 5.7 & 88.0 & 17.8 & 520.3 & 9.5 & 114.5 & 13.9 & 204.0 \\
\hline 6.6 & 95.6 & 20.1 & 249.1 & 10.2 & 113.5 & 14.9 & 249.8 \\
\hline 7.4 & 114.3 & 22.4 & 88.0 & 10.8 & 113.0 & 16.0 & 244.6 \\
\hline 8.0 & 114.6 & 24.7 & 121.6 & 11.5 & 117.2 & 17.0 & 206.9 \\
\hline 8.7 & 115.0 & 27.0 & 210.2 & 12.1 & 132.2 & 18.0 & 187.6 \\
\hline 9.3 & 135.0 & 29.3 & 206.9 & 12.7 & 136.6 & 19.0 & 214.3 \\
\hline 9.9 & 154.6 & 31.6 & 137.1 & 13.3 & 157.2 & 20.0 & 258.1 \\
\hline 10.4 & 156.0 & 33.9 & 122.3 & 13.7 & 168.5 & 21.0 & 265.0 \\
\hline 10.9 & 155.2 & & & 14.2 & 173.6 & 22.1 & 218.5 \\
\hline
\end{tabular}




\begin{tabular}{ll}
11.3 & 155.5 \\
11.8 & 155.8 \\
12.3 & 156.1 \\
12.8 & 152.7 \\
13.3 & 153.2 \\
13.8 & 155.5 \\
14.2 & 154.8 \\
14.7 & 156.3 \\
15.2 & 163.0 \\
15.7 & 189.3 \\
16.1 & 186.6 \\
16.5 & 187.5 \\
16.9 & 186.5 \\
17.3 & 186.3 \\
17.7 & 190.0 \\
18.1 & 191.8 \\
18.5 & 186.4 \\
18.9 & 184.8 \\
19.3 & 188.2 \\
\hline & \\
\hline
\end{tabular}

\begin{tabular}{|c|c|c|c|}
\hline 14.6 & 179.0 & 23.1 & 161.4 \\
\hline 15.0 & 190.0 & 24.1 & 148.5 \\
\hline 15.4 & 194.7 & 25.1 & 185.1 \\
\hline 15.8 & 196.4 & 26.1 & 221.1 \\
\hline 16.2 & 188.9 & 27.1 & 207.7 \\
\hline 16.6 & 181.2 & 28.2 & 151.2 \\
\hline 17.0 & 178.4 & 29.2 & 104.3 \\
\hline 17.4 & 179.9 & 30.2 & 107.2 \\
\hline 17.8 & 180.5 & 31.2 & 147.1 \\
\hline 18.3 & 183.8 & 32.2 & 176.2 \\
\hline 18.7 & 175.3 & 33.2 & 164.2 \\
\hline 19.1 & 179.9 & 34.3 & 125.3 \\
\hline 19.5 & 192.2 & 35.3 & 97.1 \\
\hline 19.9 & 184.4 & 36.3 & 100.6 \\
\hline 20.3 & 180.7 & 37.3 & 126.6 \\
\hline 20.7 & 182.1 & 38.3 & 152.8 \\
\hline 21.1 & 171.5 & & \\
\hline 21.6 & 175.2 & & \\
\hline 22.0 & 166.7 & & \\
\hline
\end{tabular}




\begin{tabular}{|c|c|c|c|}
\hline 19.7 & 175.2 & 22.4 & 165.0 \\
\hline 20.1 & 163.2 & 22.9 & 171.7 \\
\hline 20.5 & 161.6 & 23.3 & 164.5 \\
\hline 21.0 & 163.2 & 23.8 & 169.3 \\
\hline 21.5 & 165.5 & 24.2 & 175.2 \\
\hline 21.9 & 161.6 & 24.7 & 185.3 \\
\hline 22.4 & 143.8 & 25.1 & 176.3 \\
\hline 22.9 & 133.2 & 25.5 & 180.7 \\
\hline 23.5 & 134.6 & 25.9 & 171.4 \\
\hline 24.0 & 140.0 & 26.3 & 169.7 \\
\hline 24.6 & 158.2 & 26.8 & 169.3 \\
\hline 25.0 & 154.6 & 27.2 & 160.4 \\
\hline 25.5 & 160.6 & 27.7 & 166.1 \\
\hline 26.0 & 157.7 & 28.1 & 162.9 \\
\hline 26.5 & 157.2 & 28.6 & 165.9 \\
\hline 26.9 & 155.9 & 29.1 & 174.7 \\
\hline 27.4 & 156.8 & 29.5 & 171.4 \\
\hline 27.9 & 165.7 & 29.9 & 163.7 \\
\hline 28.4 & 170.2 & 30.4 & 157.1 \\
\hline 28.8 & 167.9 & 30.9 & 147.1 \\
\hline
\end{tabular}




$\begin{array}{llll}29.2 & 172.1 & 31.4 & 150.5 \\ 30.0 & 153.9 & 31.9 & 160.0 \\ 30.2 & 150.8 & 32.3 & 165.7 \\ 30.7 & 152.8 & 32.8 & 178.1 \\ 31.2 & 149.5 & 33.2 & 171.1 \\ 31.7 & 150.3 & 33.7 & 153.9 \\ 32.2 & 149.7 & 34.1 & 152.3 \\ 32.7 & 145.3 & 34.6 & 152.3 \\ 33.2 & 148.6 & 35.1 & 150.4 \\ 33.7 & 149.9 & 35.6 & 140.4 \\ 34.2 & 150.3 & 36.1 & 143.2 \\ 34.7 & 147.2 & 36.7 & 152.0 \\ 35.2 & 151.3 & 37.2 & 151.4 \\ 35.7 & 144.8 & 37.6 & 164.0 \\ & & 38.1 & 162.4 \\ & & 38.6 & 173.3 \\ & & 39.0 & 168.1 \\ & & 39.4 & 161.2 \\ & & 40.0 & 154.9\end{array}$




$\begin{array}{ll}40.4 & 139.1 \\ 40.9 & 142.8 \\ 41.5 & 153.4 \\ 41.9 & 160.6 \\ 42.4 & 175.5 \\ 42.8 & 173.5 \\ 43.3 & 190.6 \\ 43.7 & 185.5 \\ 44.1 & 171.2 \\ 44.5 & 175.0 \\ 45.0 & 173.4 \\ 45.4 & 179.6 \\ 45.8 & 164.7 \\ 46.2 & 146.0\end{array}$

